\title{
RATES OF REACTION AND PROCESS DESIGN DATA FOR THE HYDROCARB PROCESS
}

\author{
by \\ BNL -47946 \\ Meyer Steinberg and Atsushi Kobayashi \\ DE93 001438 \\ Brookhaven National Laboratory \\ Upton, NY 11973 \\ and \\ Yuanki Tung \\ Hydrocarb Corporation \\ 232 West 40th Street \\ New York, NY 10018
}

Interagency Agreement No. DW89934598

EPA Project Officer: Robert H. Borgwardt Air and Energy Engineering Research Laboratory

Research Triangle Park, NC 27711

Prepared For:

U.S. Environmental Protection Agency

Office of Research and Development

Washington, DC 20460 


\begin{abstract}
In support of studies for developing the coprocessing of fossil fuels with biomass by the Hydrocarb Process, experimental and process design data are reported. The experimental work includes the hydropryolysis of biomass and the thermal decomposition of methane in a tubular reactor. The rates of reaction and conversion were obtained at temperature and pressure conditions pertaining to a Hydrocarb Process design. A Process Simulation Computer Model was used to design the process and obtain complete energy and mass balances. Multiple feedstocks including biomass with natural gas and biomass with coal were evaluated. Additional feedstocks including green waste, sewage sludge and digester gas were also evaluated for a pilot plant unit.
\end{abstract}




\section{CONTENTS}

Page

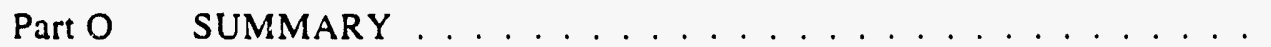

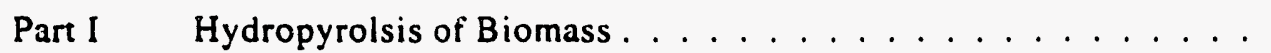

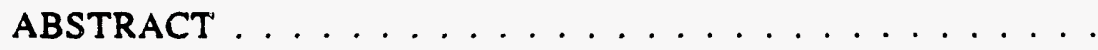

INTRODUCTION .

Experimental Description

Biomass Preparation

Experimental Procedure

Experimental Result and Discussion

Conclusion .

References

Part II

Thermal Decomposition of Methane

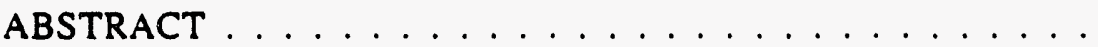

INTRODUCTION

Chemical Equilibrium

Experimental Description

Experimental Result and Discussion

Conclusion .

References .

Part III

Design Analysis of the Hydrocarb Process with Alternate and Multiple Feedstocks.

ABSTRACT

INTRODUCTION

Basic Data and Definition

Results and Discussion

Single Solid Feedstock

Multiple Feedstock with Sludge and Digester Gas

Pressure and Temperature Effects

Conclusion

References

\section{APPENDIX}

III-I Computer Printout with Wood and CH4 as Feedstocks.

III-25 to III-30

III-2

Computer Printout with Wood, Sludge. $\mathrm{CH} 4$ and Digester Gas as Feedstocks.

III-31 to III-38

Quality Control Evaluation Report
$0-1$

I-1 to $1-23$

I-2

I-3

I-4

I -4

$[-4$

I-6

[-1]

I -12

II- 1 to II-20

II-2

II -3

II-4

II-5

II-6

II- 10

II-II

III- 1 to III-37

III-2

III-3

III -5

III-8

III-8

III-10

III-12

III-14

III-15

A-1 to A-2 


\section{TABLES}

Number

Biomass (Popular Sawdust) Composition. . . . . . . . . . . .

Initial Condition for the Experimental runs . . . . . . . . .

Initial Rates of the Biomass Conversion . . . . . . . . . .

I-6 Experimental Data for Hydrogasification in the Rapid Heating up of the Biomass at $800^{\circ} \mathrm{C}$ and at $32.0 \mathrm{~atm}$ of Initial Hydrogen Pressure . .

I-7 Experimental Data for Hydrogasification in the Rapid Heating up of the Biomass at $800^{\circ} \mathrm{C}$ and at 52.4 atm of Initial Hydrogen Pressure . .

II-1 Experimental Data of Methane Decomposition. . . . . . . . . . .

II-2 Calculation Data of Methane Decomposition. . . . . . . . . .

II -14

\section{II-3}

Rate Constants at 56.1 atm . . . . . . . . . . .

III-1 Basic Data for the Feedstocks Used in the Study . . . . . . . . . . . .

III-2 Results of Hydrocarb Process with Single Solid feedsock . . . . . . .

III-3 Results of Hydrocarb Process with Multiple feedsock . . . . . . . . .

III-4 Results of Pressure and Temperature on Process Efficiency and Product Distribution. 


\section{FIGURES}

I-I Schematic Flow Sheet of Tubular Reactor Equipment

I-16

I-2 Reactor Temperature, Generated Gases vs. Lapse of Time at 52.4

I-3 Pressure Change in the Reactor vs. Reactor Temperature

I-18

I-4 Weight Losing Curve of Biomass (Poplar Sawdust) with Temperature using PTGA (Pressurized Thermogravimetric Analyzer) at Heat-up Rate of $50 \mathrm{C} / \mathrm{min}$. and $28.2 \mathrm{~atm}$.

I-5 Weight Losing Curve of Biomass (Fair Woods) with Temperature using PTGA (Pressurized Thermogravimetric Analyzer) at Heat-up Rate of 50 $\mathrm{C} / \mathrm{min}$. and 28.2 atm. . . . . . . . . . . . . . . . . . .

I-6 The Change in Number of Moles in the Reactor with time at $800^{\circ} \mathrm{C}$ and $32.0 \mathrm{~atm}$ of Initial Hydrogen Pressure. . . . . . . . . . . . . . .

I-7 The Rate of Molar Change with Time at $800^{\circ} \mathrm{C}$ and $32.0 \mathrm{~atm}$ of Initial Hydrogen Pressure. . . . . . . . . . . . . . . . .

I-8 The Change in Number of Moles in the Reactor with Time at $800^{\circ} \mathrm{C}$ and $52.4 \mathrm{~atm}$ of Initial Hydrogen Pressure. . . . . . . . . . . . . . .

I-9 The Rate of Molar Change with Time at $800^{\circ} \mathrm{C}$ and $52.4 \mathrm{~atm}$ of Initial Hydrogen Pressure. . . . . . . . . . . . . . . . . .

II-1 Schematic Flow Sheet of Tabular Reactor for Methane Decompnsition . . . . . . . . . . . . . . .

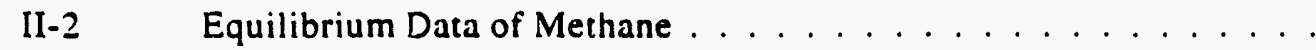

II-3 Methane Concentrations vs. Residence Time .

II-16

II-4 Tubular Reactor Model and Derivation of Rate Equation . . . . . . .

II $-5 \quad K_{1} \times t$ vs Residence Time at $56.1 \mathrm{~atm} \ldots \ldots \ldots$

II-6 Rate Constant of Methane Decomposition vs. Recipical Temperature.

II -7 $\quad K_{1} \times t$ vs. Residence Time at $900^{\circ} \mathrm{C}$

III-I Brief Illustration of Cycle 1 and Cycle 2 .

III-2 Strategy of Computer for a Single Solid Feedstock.

III-21

III-3 Data Summary with Wood and $\mathrm{CH} 4$ as Feedstocks .

III-22

III-4 Plot of Methanol Production of Thermal Efficiency vs. Sludge Feed Rate.

III-5 Data Summary with Wood, Sludge, $\mathrm{CH} 4$, and Digester Gas as Feedstocks. 


\section{ACKNOWLEDGEMENT}

The authors wish to acknowledge the assistance of the L' $S$ Easinent. fo

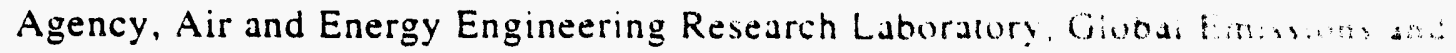

Division in providing guidance and support. Robert Borgwardt provided ntas s assistance as Project Officer and Richard Stern and Frank Pincioura have prob ded $1: 4$ : port and recognition of the merits of this work.

\section{METRIC CONVERSION FACTORS}

Readers more familiar with the metric system my use the following ts:ors to wne: se wh metric units used in this report:

\begin{tabular}{|c|c|c|}
\hline Nonmentric & Times & Yields Meiric \\
\hline atm & 1013 & $k P_{s}$ \\
\hline bar & 100 & $\mathrm{PPJ}_{\mathrm{J}}$ \\
\hline $\mathrm{Btu} / \mathrm{ft}^{3}$ & 37.233 & $\lim 3$ \\
\hline Btu/gal. & 278.5 & Hater \\
\hline $\mathrm{Btu} / \mathrm{lb}$ & 2324 & $1 / k_{g}$ \\
\hline $\mathrm{ft}$ & 0.3048 & $m$ \\
\hline $\mathrm{ft}^{3}$ & 0.02832 & $m^{\prime}$ \\
\hline gal. & 3.785 & liter \\
\hline Ib & 0.4536 & $k$ \\
\hline ton & 907.2 & $k_{B}$ \\
\hline Btu/lb mol & 0.555 & silgming \\
\hline kcal & 103 & $\therefore \|^{\prime \prime}$ \\
\hline Btu & 1.06 & is \\
\hline psi & 6.89 & APs \\
\hline
\end{tabular}

\footnotetext{
ABBREVIATIONS

HPR - Hydropyrolysis reactor

HGR - Hydrogasifier reactor: HPR and HGR are equivalem

MPR - Methane pyrolysis reactor

BTX - Benzene, toluene and xylene

HCSP - Hydrocarb process simulation program

FHP - Flash hydropyrolysis

MTG - Methanol to gasoline process

MSW - Municipal solid waste

PDU - Process demonstration unit

GW - Green Waste
} 


\section{Part O}

\section{SLMMARY}

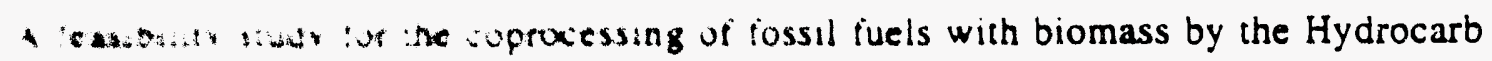

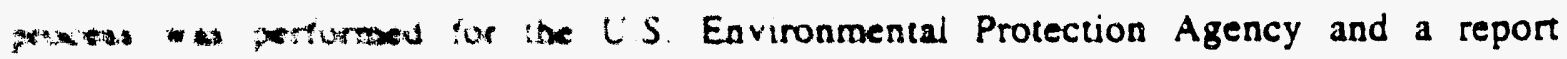

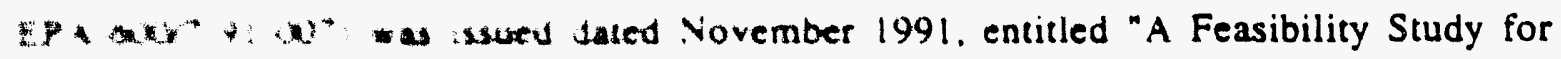

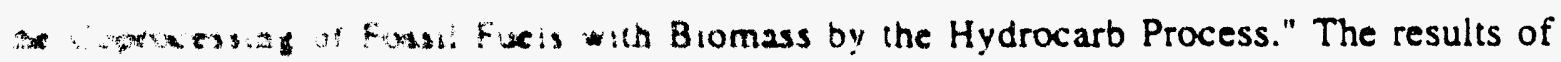

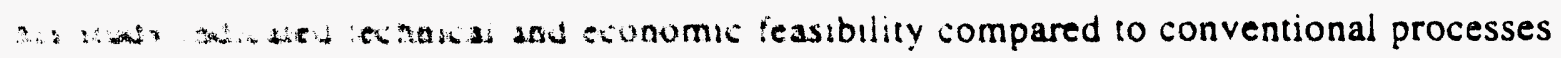

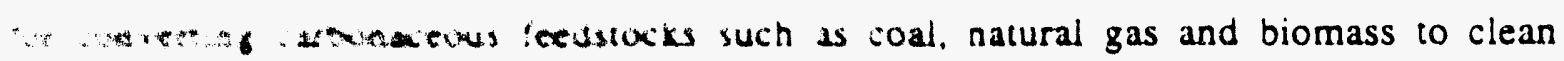

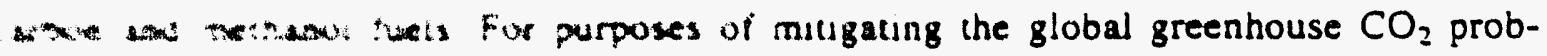

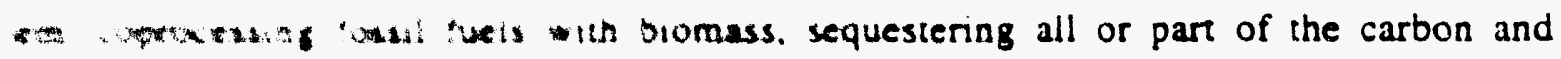
methanot as a power or transportation fuel, presents the option of

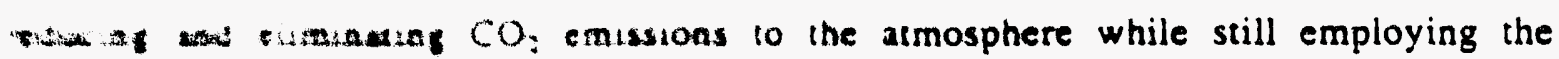

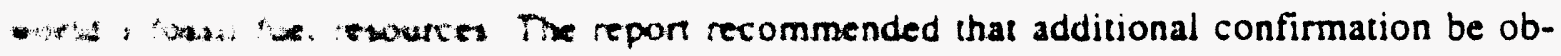
- ane stops in the Hydrocarb process. which includes the

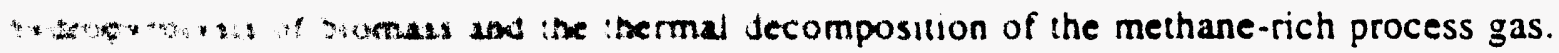

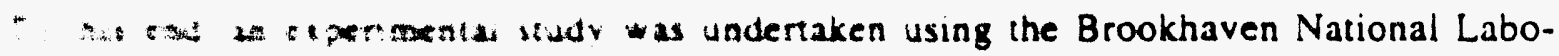

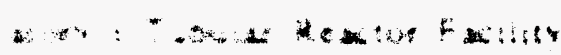

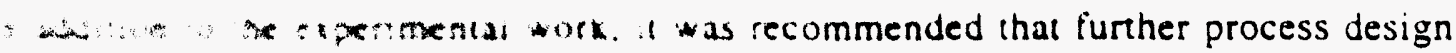

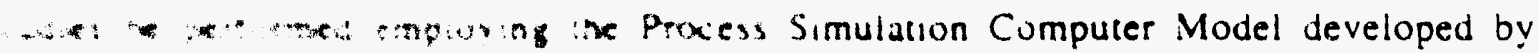

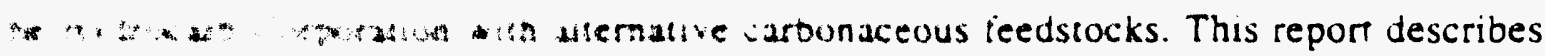

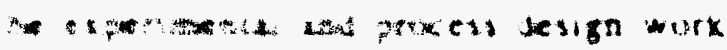

* * + t. sto nree sections Pan I deals with the hydropyrolysis of bio-

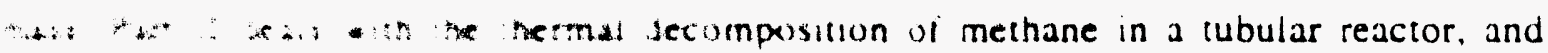

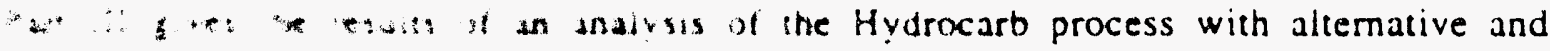

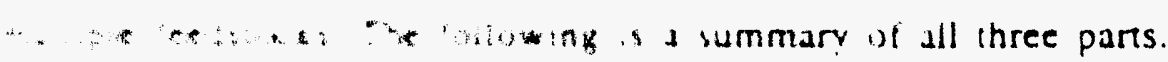

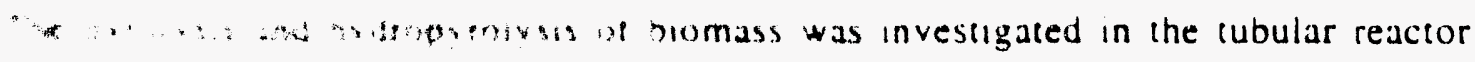
$\therefore$ a 
reactor having dimensions $25.4 \mathrm{~mm}$ inside diameter and $2.44 \mathrm{~m}$ long heated to temperatures of $800^{\circ} \mathrm{C}$ and pressures between 30 and 50 atm. At low heat-up rate, the reaction proceeds in two steps. First pyrolysis takes place at temperatures of 300 to $400^{\circ} \mathrm{C}$ and then hydropyrolysis takes place at $700^{\circ} \mathrm{C}$ and above. This is also confirmed by pressurized thermogravimetric analysis (PTGA). Under conditions of rapid heat-up at higher temperatures and higher hydrogen pressure, gasification and hydrogasification of biomass is especially effective in producing carbon monoxide and methane. An overall conversion of 88 to $90 \mathrm{wt} \%$ of biomass was obtained. This is in agreement with previous work on flash pyrolysis and hydropyrolysis of biomass under rapid heat-up and short reaction residence time conditions. Initial rates of biomass conversion indicate that the rate increases significantly with increase in hydrogen pressure. At $800^{\circ} \mathrm{C}$ and $51.3 \mathrm{~atm}$ the initial rate of biomass conversion to gases is found to be $92 \%$ per min.

The reaction rate of methane decomposition using a tubular reactor having a $25.4 \mathrm{~mm}$ inside diameter with an $2.44 \mathrm{~m}$ long heated zone using the same tubular reactor facility was investigated in the temperature range of 700 to $900^{\circ} \mathrm{C}$ with pressures ranging from 28.2 to 56.1 atm. The rate is represented by a conventional model, $\frac{-\mathrm{dC}_{\mathrm{CH}_{4}}}{\mathrm{dt}}=\mathrm{k} \mathrm{C}_{\mathrm{CH} 4}$, where $\mathrm{C}$ is the molar concentration and $\mathrm{k}$ is the rate constant. When initial $\mathrm{H}_{2}$ concentration is zero, the activation energy for methane decomposition is $31.3 \mathrm{kcal} / \mathrm{mol}$, as determined by an Arrhenius Plot. This value is lower than for previously published results for methane decomposition and appears to indicate that the high-surface-area submicron carbon particles found adhering to the inside of the reactor tend to catalyze the methane decomposition. The rate constant has been found to be approximately constant at $900^{\circ} \mathrm{C}$ in the pressure range investigated. The rate of methane decomposition increases with methane partial pressure to the first-order. The conclusion is reached that the rate of methane decomposition is favored by higher temperatures and pressures while the thermochemical equilibrium of methane decomposition is favored by lower pressures. 
The designed performance of the Hydrocarb process with alternative and multiple feedstocks was investigated. The alternative feedstocks studied for the Hydrocarb process included biomass (wood), Alaska Beluga (sub-bituminous) coal Kentucky (bituminous) coal, North Dakota (lignite) coal and Wyodak (sub-bituminous) coal. A Process Simulation Computer Model was used to design the process, and obtain complete energy and mass balances. Boundary conditions of pressure, temperature and mass balances for the cyclical process were determined. The study also included using sludge and digester gas from sewage plants as additional feedstocks. It was found that these feedstocks have to be coprocessed with either biomass or coal to obtain a workable mass balance. The maximum allowable feed ratios of sludge to biomass or sludge to coal were determined. The effect of pressure and temperature for the biomass and sludge feedstock cases were also developed. 
Part I

HYDROPYROLYSIS OF BIOMASS

ATSUSHI KOBAYASHI AND MEYER STEINBERG

BROOKHAVEN NATIONAL LABORATORY

Upton, Long Island, NY, 11973

IINTERAGENCY AGREEMENT NO. EPAVIAGDW89934598-01-2

U.S.ENVIRONMENTAL PROTECTION AGENCY

AIR AND ENERGY RESEARCH LABORATORY

RESEARCH TRIANGLE PARK, NC, 27711 


\title{
Hydropyrolysis of Biomass
}

by

\author{
Atsushi Kobayashi and Meyer Steinberg \\ Brookhaven National Laboratory \\ Upton, New York, 11973
}

\begin{abstract}
The pyrolysis and hydropyrolysis of biomass was investigated. Experimental runs using the biomass (Poplar wood sawdust) were performed using a tubular reactor of dimensions $25.4 \mathrm{~mm}$ inside diameter and $2.44 \mathrm{~m}$ long heated at a temperature of $800 \mathrm{C}$ and pressures between 30 and $50 \mathrm{~atm}$. At low heat-up rate the reaction procedes in two steps. First pyrolysis takes place at temperatures of 300 to $400 \mathrm{C}$ and subsequent hydropyrolysis takes place at 700 $C$ and above. This was confirmed by pressurized thermogravimetric analysis (PTGA). Under conditions of rapid heat-up at higher temperatures and higher hydrogen pressure gasification and hydrogasification of biomass is especially effective in producing carbon monoxide and methane. An overall conversion of 88 to 90 wt\% of biomass was obtained. This value is in agreement with the previous work of flash pyrolysis and hydropyrolysis of biomass for rapid heat-up and short residence time. Initial rates of biomass conversion indicate that the rate increases significantly with increase in hydrogen pressure. At $800 \mathrm{C}$ and 52.4 atm the initial rate of biomass conversion to gases is $0.921 / \mathrm{min}$.
\end{abstract}




\section{INTRODUCTION}

The Hydrocarb Process involves two main reactions; (1)hydrogasification of the carbonaceous feedstock to produce methane-rich gas, and (2)the thermal decomposition of methane to produce hydrogen-rich gas, which is recycled to the hydrogasification section, and finally produces clean carbon black as product. ${ }^{(1-1)}$ A third step combines the CO formed from the hydrogasification section with hydrogen and produces methanol as co-product. The hydrogasification step is important in this process because the composition and the rate of formation of the methane-rich gas can determine the performance of the methane decomposition and methanol reactors as well as the overall performance of the cyclical Hydrocarb Process.

This work was performed in order to investigate both the rate and degree of conversion for the pyrolysis and hydropylolysis of biomass using a tubular reactor at a temperature of 800 $\mathrm{C}$ and at pressures of 30 to $50 \mathrm{~atm}$ in a hydrogen atmosphere. Data at higher loading densities of biomass compared to previous experiments were also investigated. Previous experiments were performed under flash hydropyrolysis conditions in dilute phase at low $\mathrm{CH}_{4}, \mathrm{CO}$, and $\mathrm{CO}_{2}$ in the gaseous phase. ${ }^{(1-2.1-3)}$ 


\section{EXPERIMENTAL DESCRIPTION}

\section{BIOMASS PREPARATION}

The biomass, essentially Poplar wood sawdust, is ground and sieved to less than 150 micron diameter. This particle size was chosen in order that the external heat and gaseous hydrogen in the reactor could penetrate through the biomass particles easily and the biomass could be smoothly fed into the tubular reactor from the feeder attached to the top of the reactor. The ground biomass is first dried in an oven, in which the temperature is kept constant at about $100 \mathrm{C}$ until the moisture content of the biomass is reduced to less than $3 \mathrm{wt} \%$ so that the effect of water on the rate of the hydropyrolysis reaction is minimized. The dried biomass component was analyzed by standard analytical procedure and the elemental analysis is shown in Table I-1.

TABLE I-1. BIOMASS (POPLAR SAWDUST) COMPOSITION

\begin{tabular}{|c|c|}
\hline Component & Weight Percentage \\
\hline C & 51.32 \\
H & 6.16 \\
N & 1.18 \\
S & 0.13 \\
O & 34.57 \\
Ash & 6.64 \\
& $100 w$ wo (total) \\
\hline
\end{tabular}

A very fine silica flour (Cab-O-Sil) was mixed with the ground biomass to prevent agglomeration and allow smooth flow of the sawdust from the feeder into the reactor. This process also prevented plugging inside the reactor. The weight content of silica flour was fixed at about $20 \mathrm{wt} \%$ as determined from past experience. ${ }^{(1-2,1-3)}$

\section{EXPERIMENTAL PROCEDURE}

Figure I- 1 shows the schematic flow sheet of the experimental equipment which consists of a biomass feeder, a tubular reactor, a carbon trap, and a gas-chromatograph. Experiments were performed under two different modes; (1) In the first mode of operation, the biomass was 
loaded into the reactor on top of a $50.8 \mathrm{~mm}$ height of packing consisting of $3.18 \mathrm{~mm}$ alumina balls which rests on a perforated disk made of stainless steel positioned at the bottom of the reactor. After a helium purge, hydrogen was introduced into the system up to 52.4 atm and heated up from room temperature $800 \mathrm{C}$ by the external electrical clamshell heaters. The pressure in the reactor was monitored by a pressure gauge and the concentrations of the effluent carbon containing gases, $\mathrm{CH}_{4}, \mathrm{C}_{2} \mathrm{H}_{4}, \mathrm{C}_{2} \mathrm{H}_{6}, \mathrm{CO}$, and $\mathrm{CO}_{2}$, were analyzed with the thermal conductivity detector in the on-line gas-chromatograph; (2) In the second mode of operation, the reactor temperature was raised to $800 \mathrm{C}$ and the reactor was pressurized with hydrogen over the range 32.0 to $52.4 \mathrm{~atm}$, and the biomass was fed into the reactor at a rate bet ween 10 and 20 grams/min. The pressure in the reactor was monitored and the effluent gases were analyzed in the same manner, , mentioned method.

The reactor was a $25.4 \mathrm{~mm}$ diameter Inconel 617 tube with $6.35 \mathrm{~mm}$ wall thickness. The total tube height was $3.35 \mathrm{~m}$ of which $2.44 \mathrm{~m}$ is heated externally with electrical clamshell heaters. As described earlier, it had a disk of stainless steel positioned $0.61 \mathrm{~m}$ up from the bottom of the heated zone to act as a hold-up platform for the biomass, and $3.18 \mathrm{~mm}$ alumina balls about $50.8 \mathrm{~mm}$ in height is also set on the disk to assist in holding the biomass sawdust. The sawdust bed height ranges from 1.52 to $1.83 \mathrm{~m}$ in the heated zone. 


\section{EXPERIMENTAL RESULT AND DISCUSSION}

Data Table I-1 and Figure I-2 show the results of the experimental Run No. 1154 for the conditions of biomass and hydrogen preloaded into the reactor, system purge and heated up from room temperature to $800 \mathrm{C}$ at an initial pressure of $52.4 \mathrm{~atm}$. The temperature and the concentrations of the gases generated are plotted as a function of the run time and are shown in Figure I-2. At first, $\mathrm{CO}$ and $\mathrm{CO}_{2}$ gases are generated before $\mathrm{CH}_{4}$ is formed. The volume of $\mathrm{CO}_{2}$ generated is much larger than $\mathrm{CO}$ at the beginning of the run. These gases begin to form around $470 \mathrm{C} . \mathrm{CH}_{4}$ also begins to generate slowly around $470 \mathrm{C}$ and it rapidly increases above $700 \mathrm{C}$. This phenomena appears to indicate that pyrolysis of biomass starts around $470 \mathrm{C}$ and hydropyrolysis starts about $700 \mathrm{C}$.

A pressure calibration run is shown in Figure I-3 which indicates the pressure change in the reactor with the temperature for the above mentioned conditions. The dotted line in the figure indicates the calibration line with hydrogen pressure as the reactor is heated up in the same manner as in the run when the biomass was present. This is compared with the pressure change for the Run No. 1154 when the biomass was present as shown by the solid line. At approximately $300 \mathrm{C}$, the pressure increases sharply compared with the calibration line. The difference between solid line and dotted line indicates that a reaction has occurred in the biomass itself or between the heated biomass and the gaseous hydrogen. As indicated by the composition of the gases generated, $\mathrm{CO}, \mathrm{CO}_{2}, \mathrm{CH}_{4}$, and others, as shown in Figure I-2, the pyrolysis of the biomass begins around $300 \mathrm{C}$. Above $400 \mathrm{C}$, there appears to be almost no change in pressure shown in Figure I-3. However taking into account the data shown in Figure I-2, certainiy some gases are generated in that temperature range. A zero pressure change in this re would mean that there is a balance between the gases generated and the hydrogen consumed by hydropyrolysis. Taking this effect into account, pyrolysis and hydropyrolysis of the biomass can be totally represented by following two steps; 


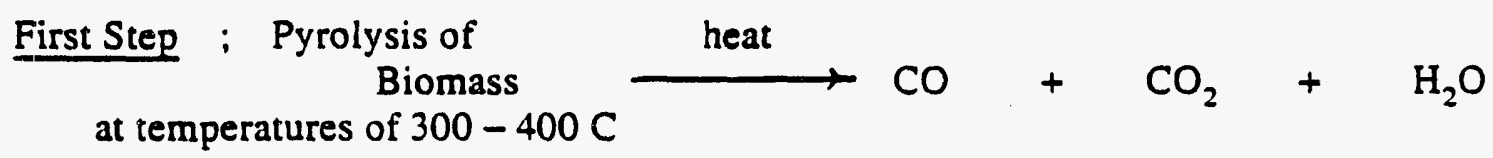

Second Step ; Hydropyrolysis of

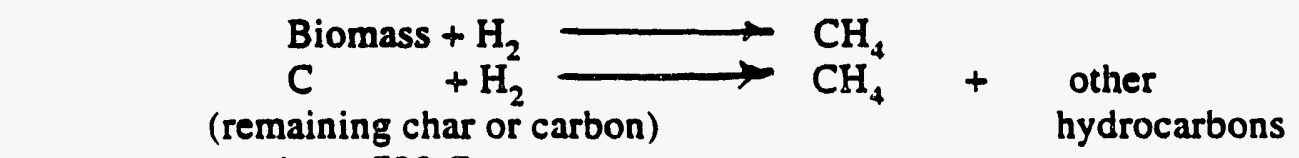

at temperature above $700 \mathrm{C}$

In the first step, at the lower temperatures of 300 through $400 \mathrm{C}$ pyrolysis of the biomass occurs in the early stage of the reaction to produce mainly $\mathrm{CO}$ and $\mathrm{CO}_{2}$. In the subsequent step, at higher temperatures above $700 \mathrm{C}$ and at elevated hydrogen pressure, $\mathrm{CH}_{4}$ and some higher hydrocarbons are generated by hydropyrolysis.

In connection with this work $R$. Khan ${ }^{(1-4)}$ performed two pressurized thermogravimetric analyses (PTGA) for us on Poplar and Fir wood. The PTGA data are shown in Figures I-4 and I-5 at 28.2 atm in helitm (solid line) and hydrogen (dotted line) atmospheres. The hydrogen line for weight loss in Figure $[-4$ for Poplar wood shows 3 steps. The first weight loss of about $10 \mathrm{wt} \%$ takes place at the temperature of 150 to $300 \mathrm{C}$, which is probably due to water vaporization from the biomass. A large second weight loss of about $55 \mathrm{wt} \%$ starts at approximately $300 \mathrm{C}$ and continues to about $450 \mathrm{C}$. Up to $450 \mathrm{C}$, both the helium and hydrogen curves are very similar. Thus in the low temperature regime, the pyrolysis reaction in the biomass occurs independent of the atmosphere present. On the other hand, beyond this temperature region, the hydrogen atomosphere data line decreases more than the helium data line which stops losing weight at about $600 \mathrm{C}$. The third weight loss of 10 to $15 \mathrm{wt} \%$ is probably due to the reaction of hydrogen with the remaining carbon to produce $\mathrm{CH}_{4}$ and other hydrocarbons. Similar results are shown in Figure I-5 for Fir wood. These PTGA results are in accord with our tubular reactor expeimental results. 
Data Tables I-2 and I-3 show the results of measurements that were obtained for conditions when the biomass is gradually fed into the reactor by the feeder. The reactor was heated up to $800 \mathrm{C}$ before the start of the expeimental run, and the system is filled with hydrogen to pressures of 32.0 and $52.4 \mathrm{~atm}$ respectively. Data Table I-3 showing the results of Run No. 1152 gives the measurements obtained at $800 \mathrm{C}$ and 52.4 atm initial pressure of hydrogen, whereas Data Table I-2 of Run No. 1144 was obtained at $800 \mathrm{C}$ and an initial pressure of 32.0 atm. Table I-2 shows the initial conditions of the experiments for the two runs reffered to in Data Tables I-2 and I-3, respectively.

TABLE I-2. INITIAL CONDITION FOR THE EXPERIMENTAL RUNS

\begin{tabular}{|c|c|c|c|c|}
\hline Exp. No. & Temperature & $\begin{array}{c}\text { Initial } \\
\text { Pressure } \\
\text { atm }\end{array}$ & $\begin{array}{c}\text { Biomass* } \\
\text { Feed Rate } \\
\text { grams/min. }\end{array}$ & $\begin{array}{c}\text { Biomass* } \\
\text { Quantity } \\
\text { grams }\end{array}$ \\
\hline $\begin{array}{c}\text { Data Table I-2 } \\
\text { Run No. 1144 } \\
\begin{array}{c}\text { Data Table I-3 } \\
\text { Run No. 1152 }\end{array}\end{array}$ & 800 & 32.0 & 16.9 & 184 \\
\hline
\end{tabular}

*The biomass used in both runs includes 20 wt\% Silica

The biomass feeding times are $11 \mathrm{~min}$. for Data Table $1-2$ and $12 \mathrm{~min}$. for Data Table I-3. The total conversion of biomass to generated gases in these two runs are $88.5 w t \%$ and $89.6 w t \%$ respectively, based on the remaining char in the reactor at the end of the runs. These results confirm the earlier dilute phase, short residence time flash hydropyrolysis ${ }^{(1-2.1-3)}$ where over $90 \%$ conversions were obtained at 800 to $1000 \mathrm{C}$ and 35.0 atm pressure.

The change in the number of moles of gas in the reactor during the run has been calculated from the pressure change and is graphically given in Figure I-6 and I-8. The calculated data include the net molar change of both the generated gases, $\mathrm{CO}, \mathrm{CO}_{2}$, and $\mathrm{CH}_{4}$ and the hydrogen gas consumed. These calculated data do not accurately indicate the change of the total moles in the gas phase, because water $\left(\mathrm{H}_{2} \mathrm{O}\right)$ formed in the gases was not measured. However the 
data gives some indication of the rate of the reaction. The slope of the change in numbers of moles in the reactor shown in Figure I-6, increases with time more slowly than that shown in Figure [-8. The reaction appears to continue for $30 \mathrm{~min}$. of residence time, which is almost 20 min. after all of the biomass was fed into the reactor. On the other hand, under the condition of 52.4 atm of initial hydrogen atmosphere in Figure I-8, it appears to stop at around $15 \mathrm{~min}$, only 3 min. after completion of feeding the biomass. These results indicate that the hydrogasification is favored by higher hydrogen pressure.

Table I-3 below shows the initial rate of molar change. These data were calculated by taking into account the initial molar change data in each run and dividing by the feed rate of the biomass.

TABLE I-3. INITIAL RATE OF MOLAR CHANGE IN THE HYDROPYROLYSYS OF WOOD

\begin{tabular}{|c|c|}
\hline Exp. No. & $\begin{array}{l}\text { Molar Change Rate } \\
\text { mol/mir ram-biomass }\end{array}$ \\
\hline $\begin{array}{l}\text { Data Table I-2 } \\
\qquad 800 \mathrm{C} 32.0 \mathrm{~atm}\end{array}$ & 0.012 \\
\hline $\begin{array}{l}\text { Data Table I-3 } \\
800 \text { C } 52.4 \mathrm{~atm}\end{array}$ & 0.036 \\
\hline
\end{tabular}

The initial rate of molar numbers change of Data Table I-3 is 3 times as large as that of Data Table I-2, even though the biomass used was smaller than in Data Table I-2. This result also implies that the total pressure of gaseous hydrogen strongly affects the rate of the reaction of biomass.

The gaseous concentrations shown in Data Table I-3 are also higher than those of Data Table I-2; $\mathrm{CH}_{4}$ concentrations in Data Table I-3 are in the range between 25 and 30 vol\%, whereas those in Data Table I-2 are 16 to 20 vol\%. As indicated previously, the amount of biomass fed into the reactor in Data Table I-3 is smaller than in Data Table I-2. These results indicate that the higher pressure is more effective in promoting gasification and hydrogasification of biomass. 
In both Data Tables I- 2 and I-3, the average ratio of the gases generated, $\mathrm{CO}, \mathrm{CO}_{2}$, and $\mathrm{CH}_{4}$ are approximately $3: 1: 3$. Taking this ratio, and unreacted carbon of 10 to $15 \mathrm{wt} \%$, into account and performing $\mathrm{C}, \mathrm{H}$ and $\mathrm{O}$ mass balances, the following stoichiometric overall equation for hydropyrolysis of biomass at $800 \mathrm{C}$ is derived.

$$
\mathrm{CH}_{1.44} \mathrm{O}_{0.5} \frac{\text { hydrogen }}{\text { heat }}-0.3 \mathrm{CO}+0.1 \mathrm{CO}_{2}+0.3 \mathrm{CH}_{4}+0.3 \mathrm{C}+0.12 \mathrm{H}_{2}
$$

This equation indicates that hydrogen is generated from the biomass. However, hydrogen is nesessary to enhance the formation of $\mathrm{CH}_{4}$. Taking the sum of the molar number, 0.82 $\mathrm{mo} / \mathrm{mol}$-biomass, of gas generated in this equation and the initial rate of molar change cited earlier into account, the initial rate of biomass conversion to gases is determined in Table I-4.

TABLE I-4. INITIAL RATE OF THE BIOMASS CONVERSION

\begin{tabular}{|c|c|}
\hline Exp. No. & $\begin{array}{l}\text { Initial Rate of Biornass } \\
\text { to Gas ( } 1 / \text { min.) }\end{array}$ \\
\hline $\begin{array}{l}\text { Data Table I-2 } \\
800 \mathrm{C} 32.0 \mathrm{~atm}\end{array}$ & 0.31 \\
\hline $\begin{array}{l}\text { Data Table } 1-3 \\
800 \text { C } 52.4 \mathrm{~atm}\end{array}$ & 0.92 \\
\hline
\end{tabular}

According to the result of the initial rate from Data Table I-3 at $800 \mathrm{C}$ and $52.4 \mathrm{~atm}$, approximately 92 wt\% of the biomass appears to be converted to gases in one minute. For the conditions of Data Table I-2 at $800 \mathrm{C}$ and $32.0 \mathrm{~atm}$, a $31 \%$ per min. conversion rate is obtained. The fact that an increase in pressure by a factor of 2 results in an increase in rate by a factor of 3 , indicates the very strong effect of pressure on the rate.

It should be noted that a number of additional runs were made during the course of this work, but the data could not be accurately presented because of operational leaks of gases from the system during the runs. 


\section{CONCLUSION}

The following conclusions are derived from this work.

(1) Biomass hydropyrolysis conversion of 88 through 90 wt\% can be vbtained at remperature up to $800 \mathrm{C}$ and initial hydrogen pressure of 32.0 and $52.4 \mathrm{~atm}$ respectively.

(2) The initial rate of biomass conversion of $0.311 / \mathrm{min}$. is obtained at an initial pressure of $32.0 \mathrm{~atm}$ and $800 \mathrm{C}$, and a higher value of $0.92 \mathrm{l} / \mathrm{min}$. is obtained at the higher pressure of 52.4 atm and $800 \mathrm{C}$. Hydrogen pressure has a significant enhancing effect un the rate of conversion of biomass to gases.

(3) Higher temperatures, above $700 \mathrm{C}$, and rapid heat-up rate enhance the conversion of busmass to $\mathrm{CH}_{\downarrow}$ and $\mathrm{CO}$.

(4) At low heat-up rate the reaction appears to proceed in two steps: pyrolysis at 300 10 $400 \mathrm{C}$ followed by hydropyrolysis at temperatures up to $700 \mathrm{C}$ or higher. 


\section{REFERENCES}

W se:ne: 5 Gronse and $Y$ Tung: "A Feasibility Study for the Corprocessing of Fas. Fe:s in Biomass by the Hydrocarb Process," EPA-600/7-91-007 (NTIS

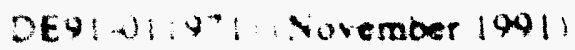

1: H Stenoe: and P Fallon. "Flash Pyrolysis and Hydropyrolysis of Biomass," BNL W:o3 Browkmaven Vational Laboratory, Upton. NY. (October 1981)

: 1 S Sundram $M$ Steinberg, and $P$ T. Fallon: "Characterization of the Products and Enpariswn of ine Produc: Yields from the Flash Pyrolysis of Fir Wood in Hydrogen and He..un "Symporium paper of Energy from Biomass and Wastes 8th, pp $: 349.14: 94: 45$

Q Kuen Prise Communicalion (August 19.1991) 
TABLE I-5. EXPERIMENTAL DATA FOR THE HYDROGASIFICATION

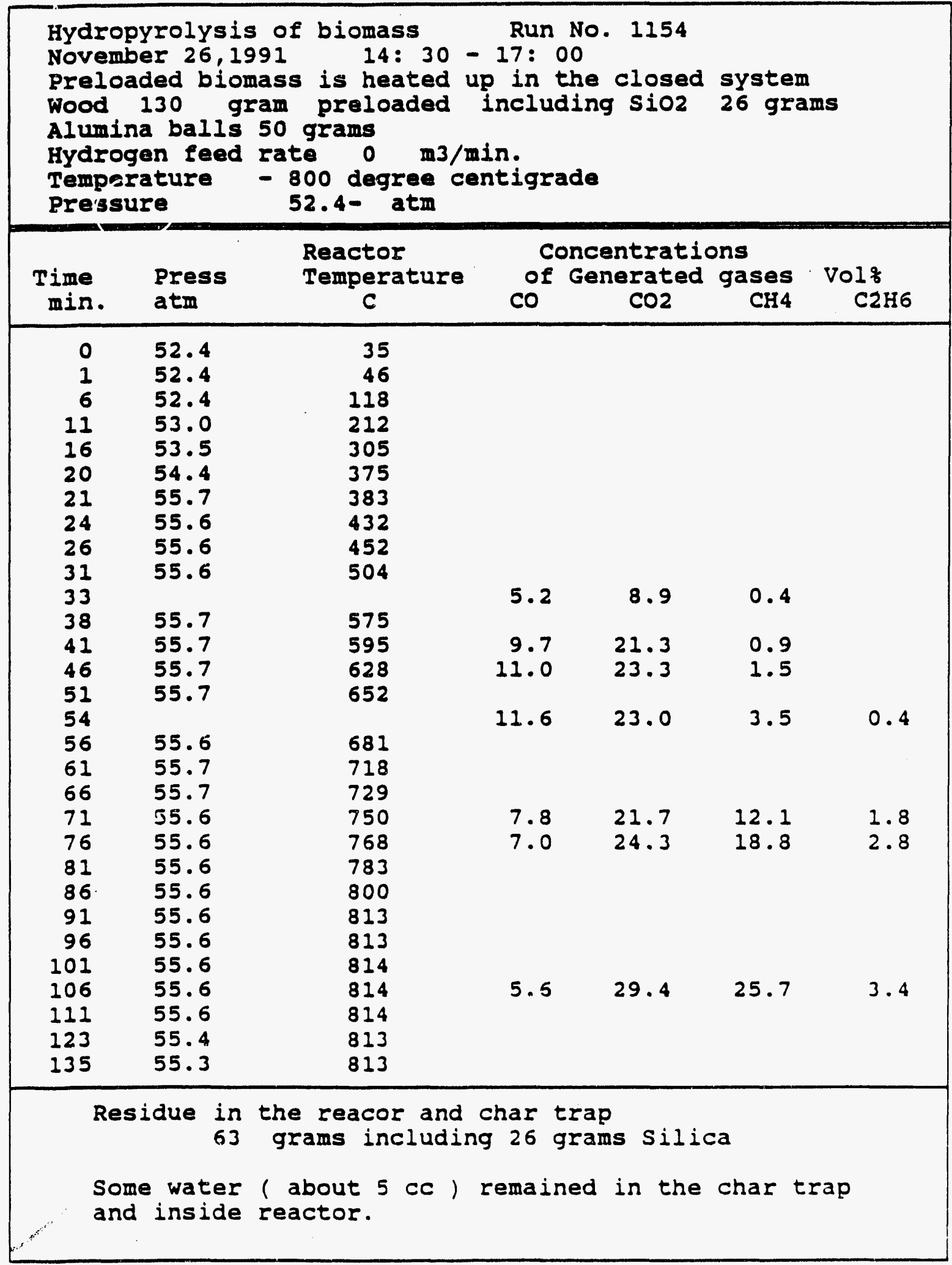


TABLE I-6. EXPERIMENTAL DATA FOR THE HYDROGASIFICATION IN THE RAPID HEATING UP OF THE BIOMASS.

AT 800 C AND AT 32.0 atm OF INITIAL HYDROGEN PRESSURE

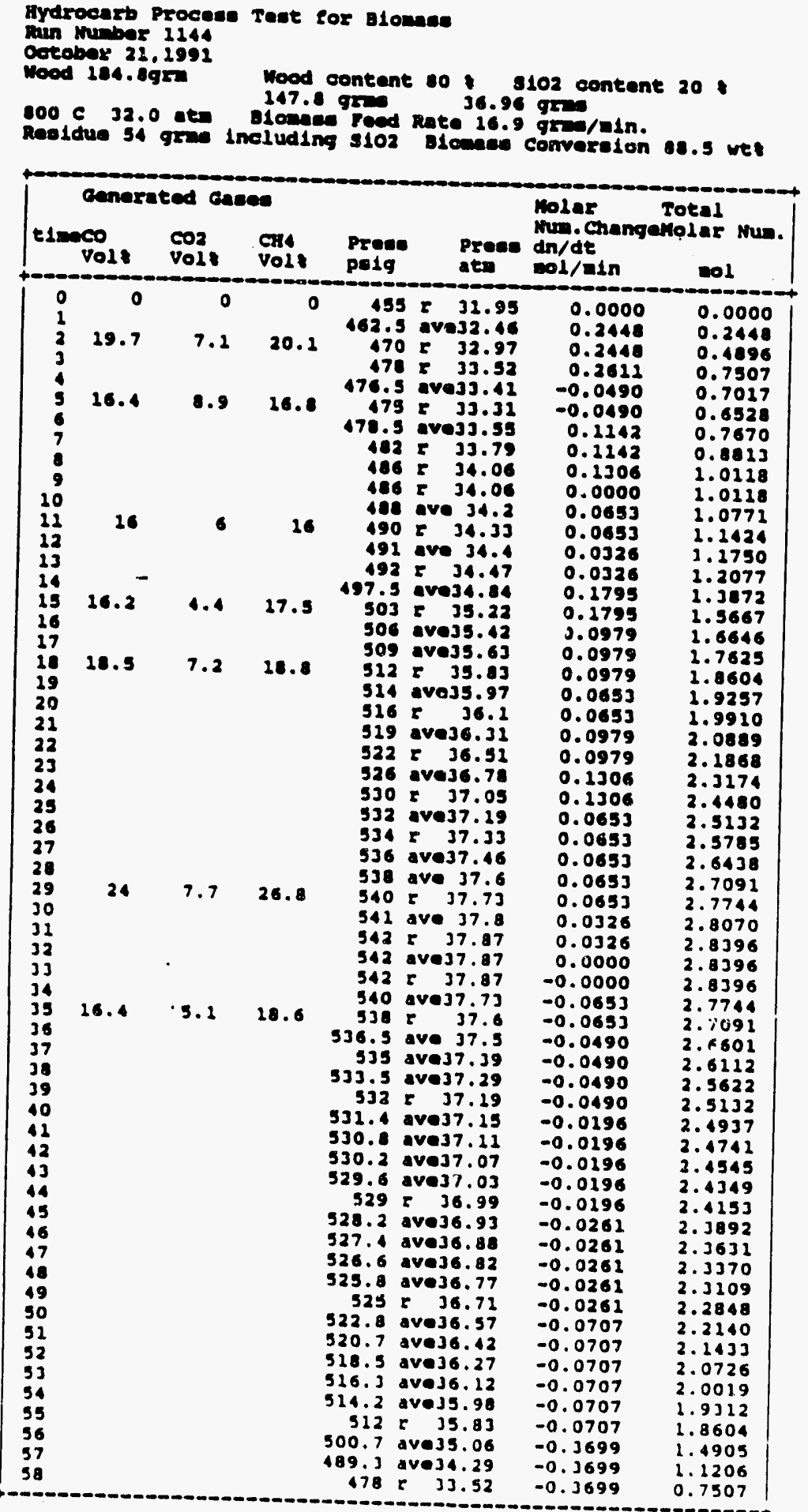

$1-14$ 
TABLE I-7. EXPERIMENTAL DATA FOR THE HYDROGASIFICATION IN THE RAPID HEATING UP OF THE BIOMASS.

AT 800 C AND AT 52.4 atm OF INITIAL HYDROGEN PRESSURE

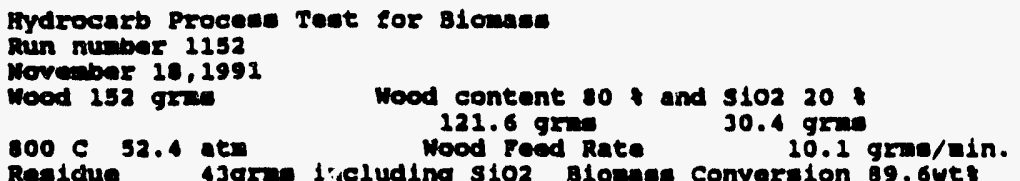

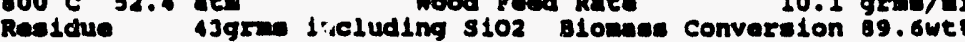

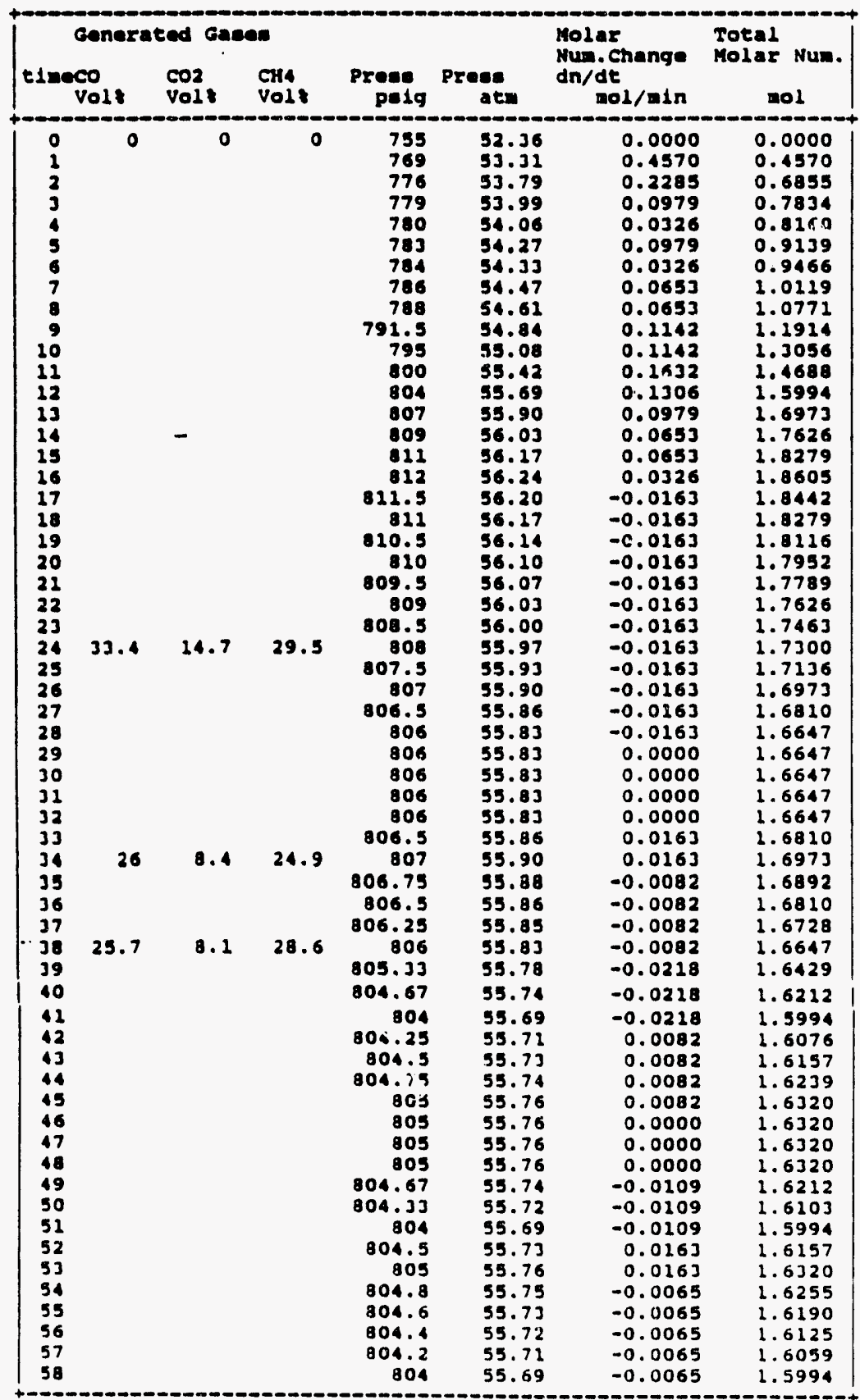




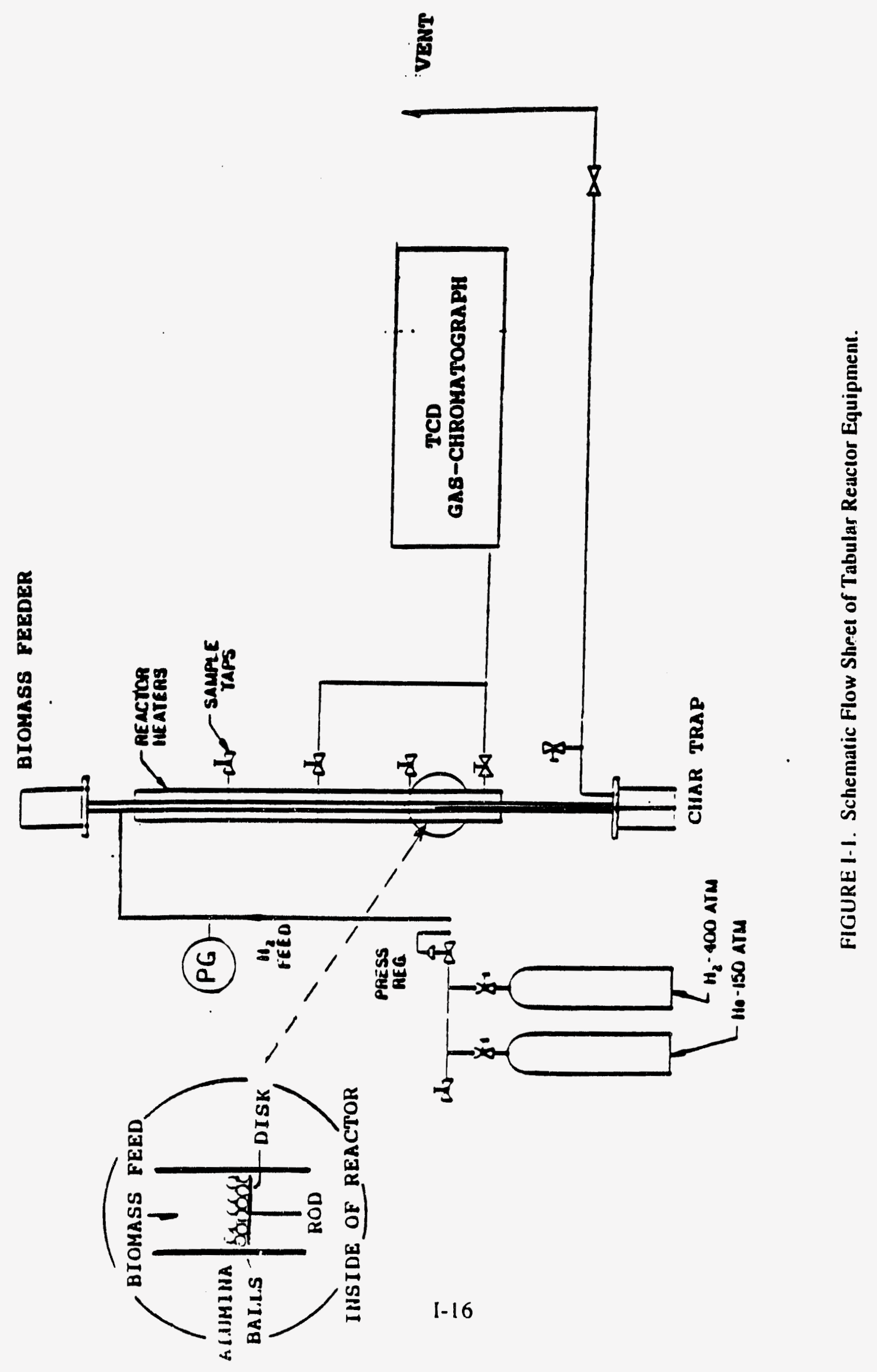




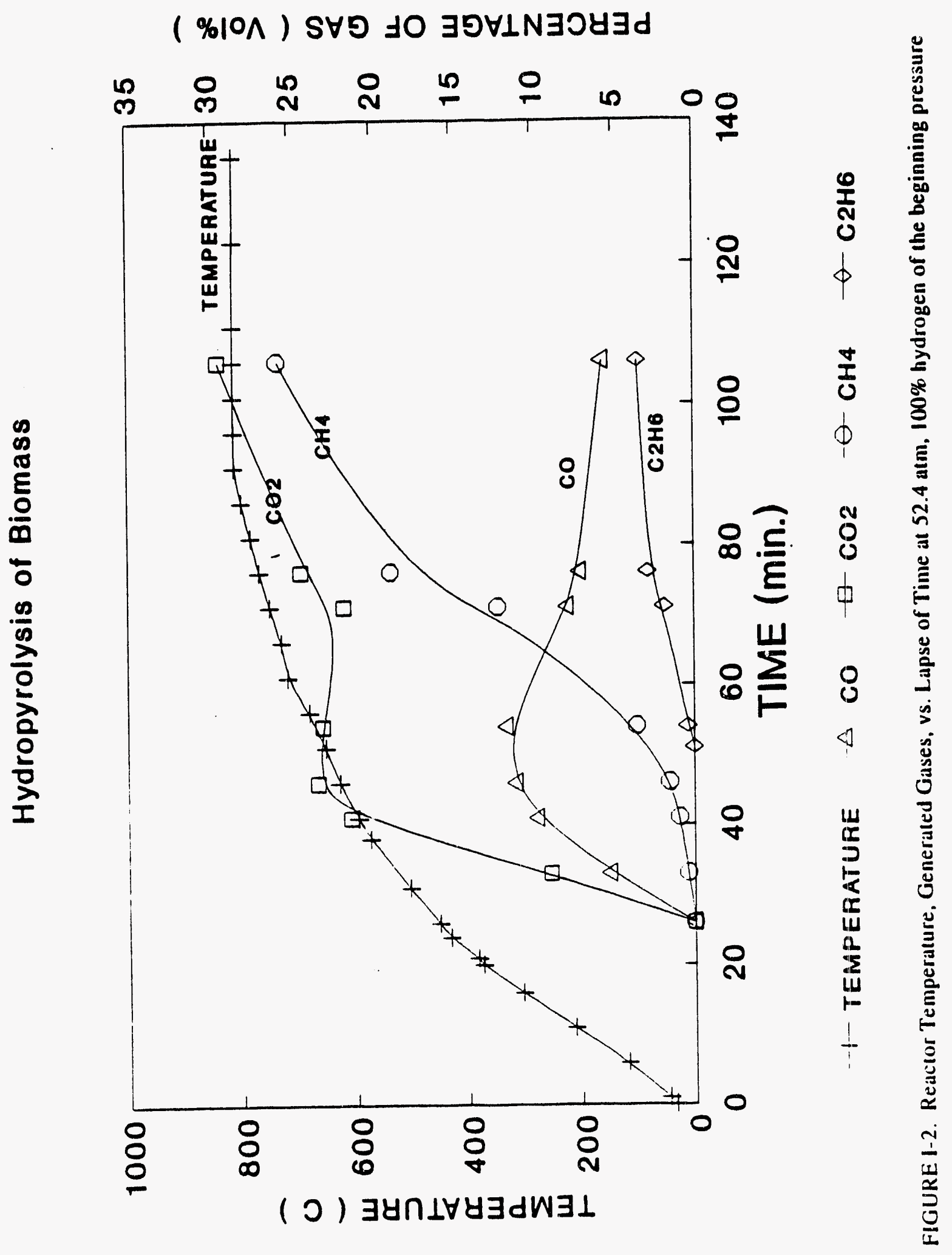

$1-17$ 


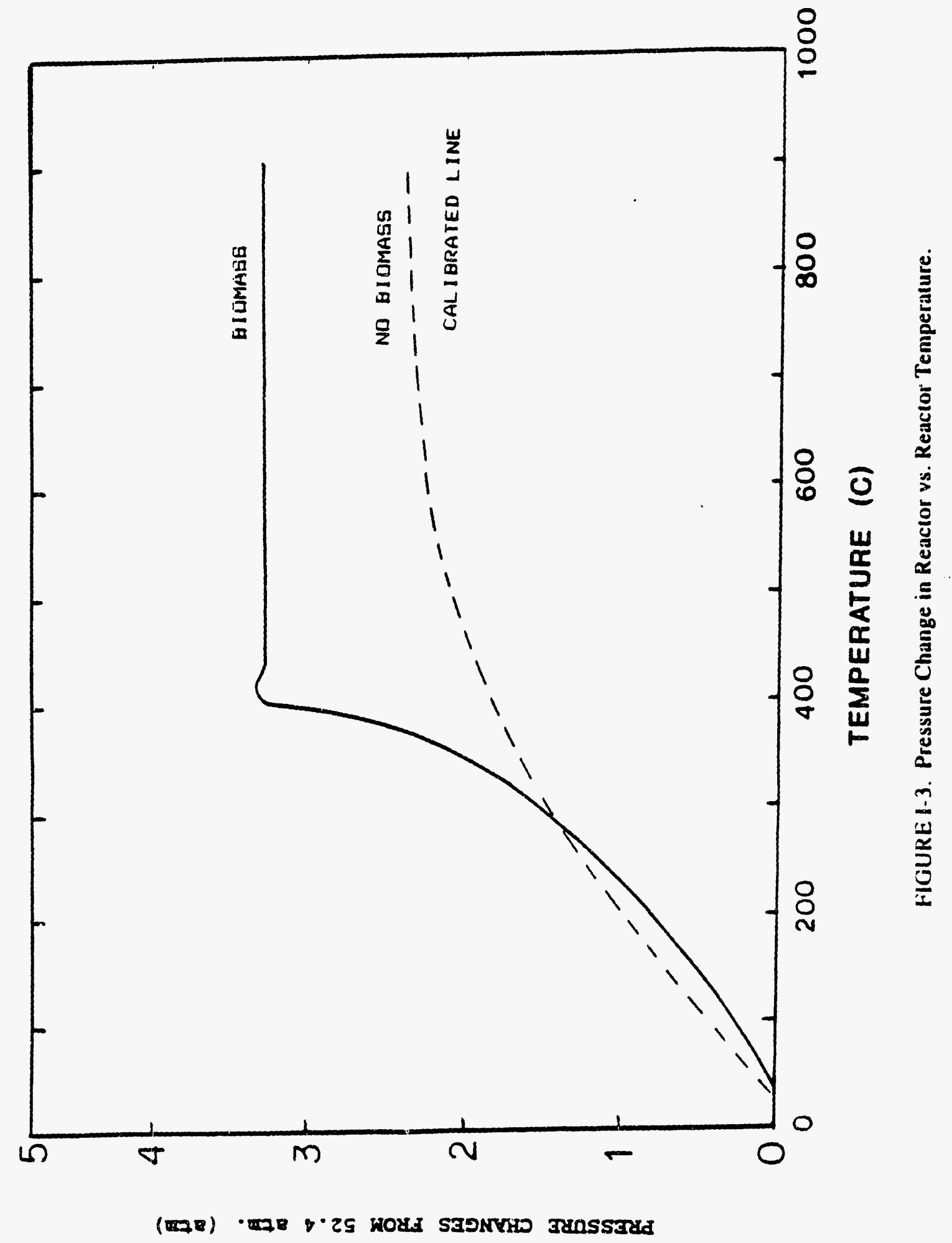

$[-18$ 


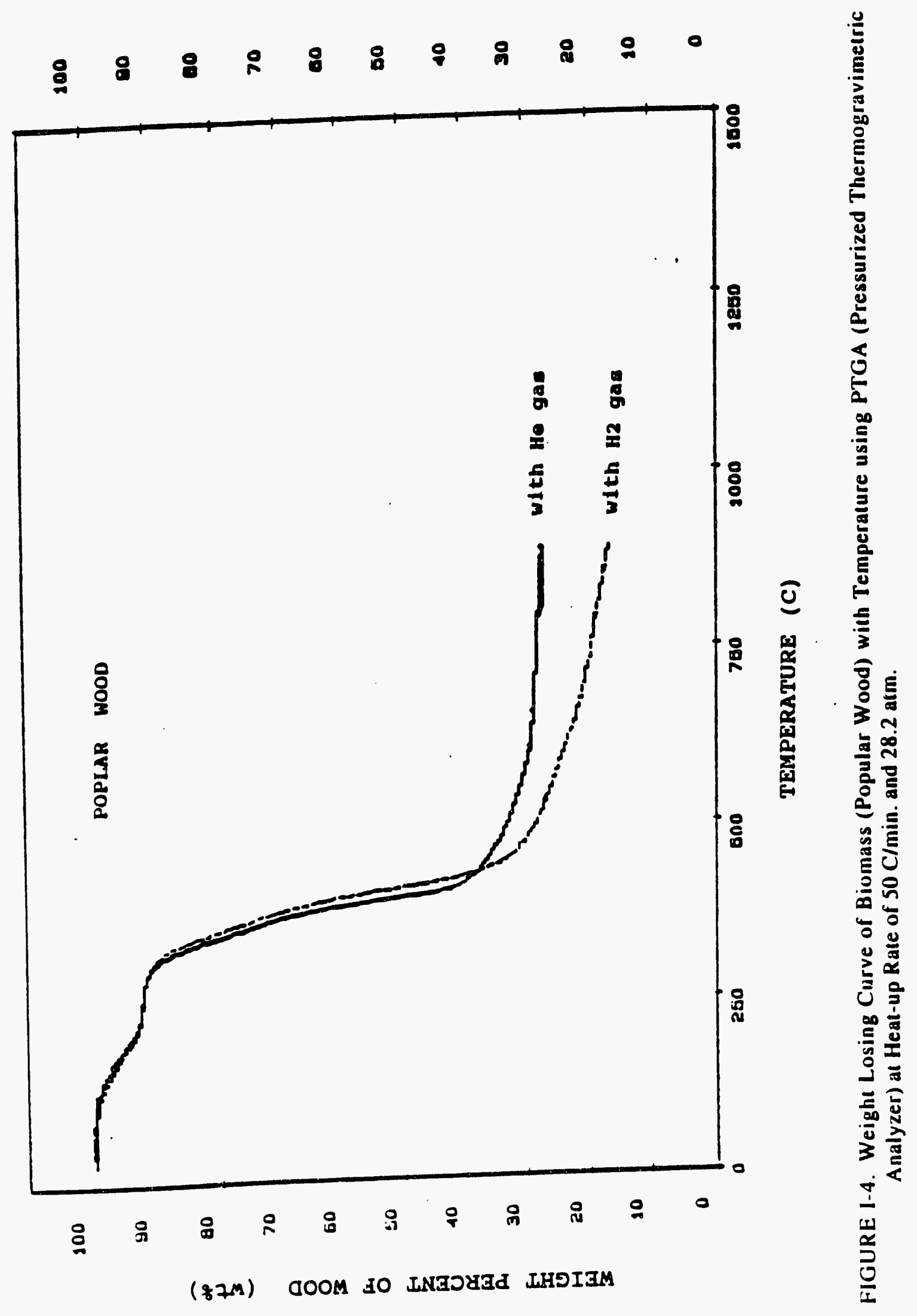

[-19 


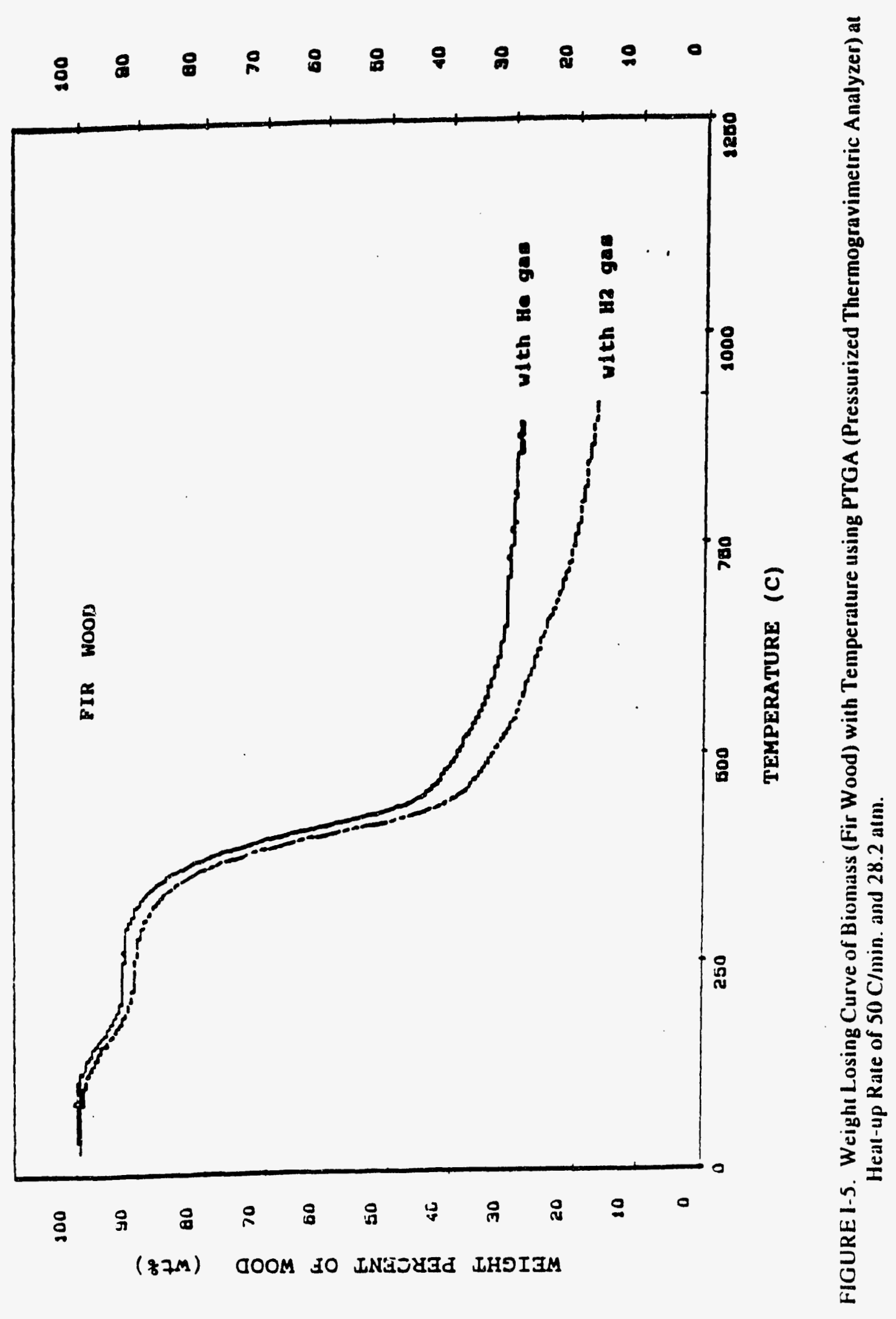


Hydropylorysis of Biomass

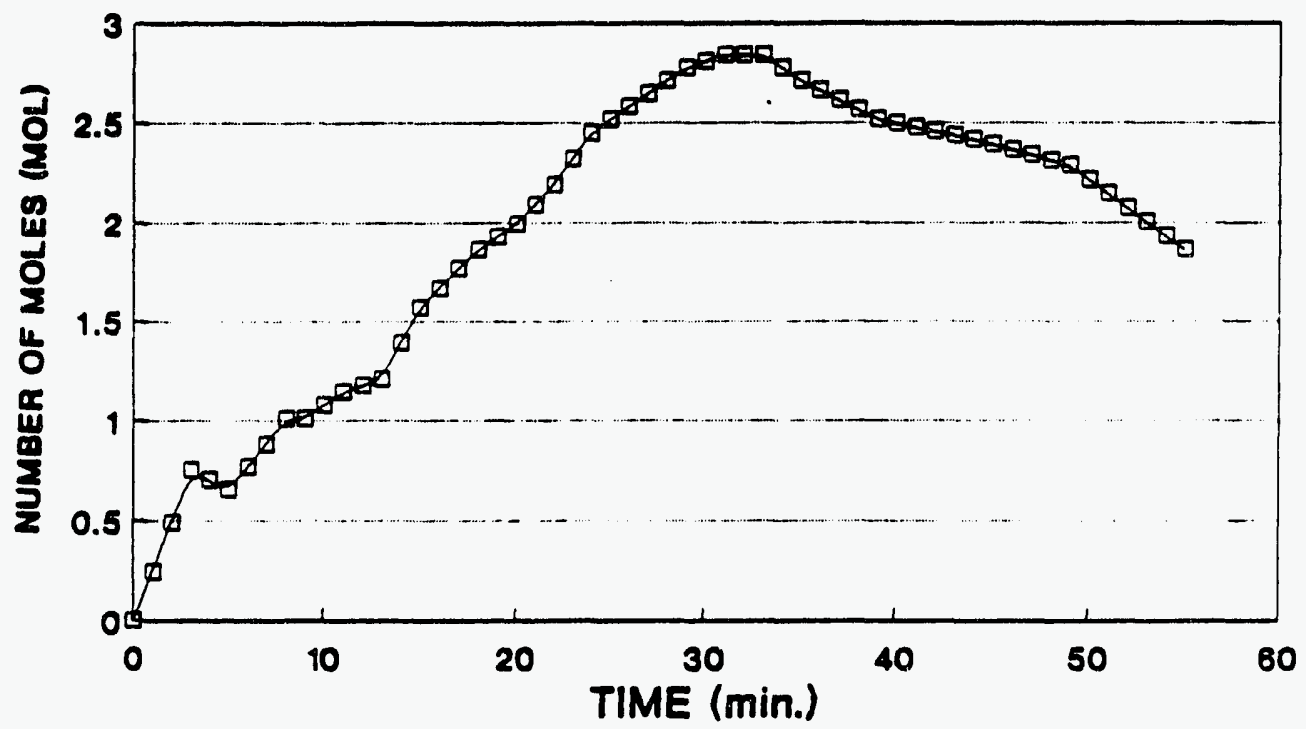

Figure I-6. The Change in Number of Moles in the Reactor with Time at $800 \mathrm{C}$ and 32.0 atm of Initial Hydrogen Pressure.

Run No. 1144 - Data Table I-2

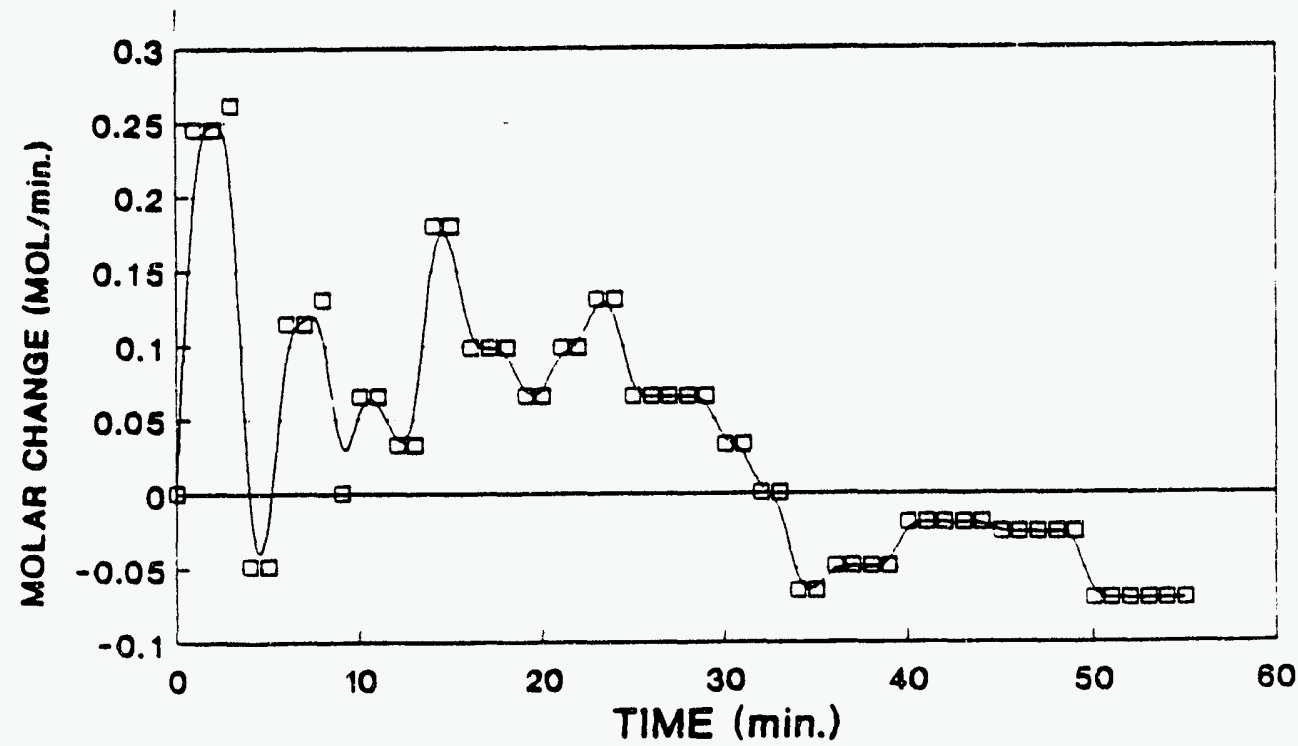

Figure I-7. The Rate of Molar Change with Time at $800 \mathrm{C}$ and $32.0 \mathrm{~atm}$ of Initial Hydrogen Pressure.

Run No. 1144 - Data Table I-2 
Hydropylorysis of Biomass

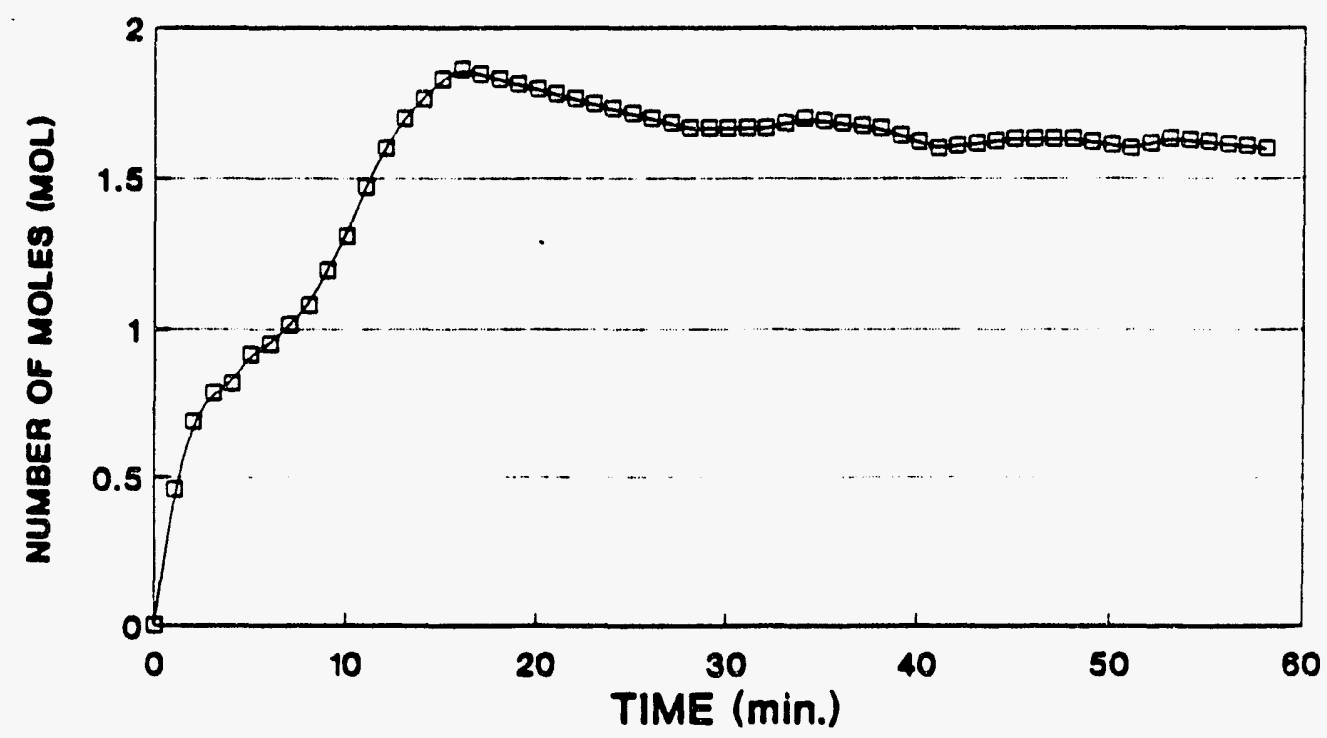

Figure I-8. The Change in Number of Moles in the Reactor with Time at $800 \mathrm{C}$ and 52.4 atm of Initial Hydrogen Pressure.

Run No. 1152 - Data Table 1-7

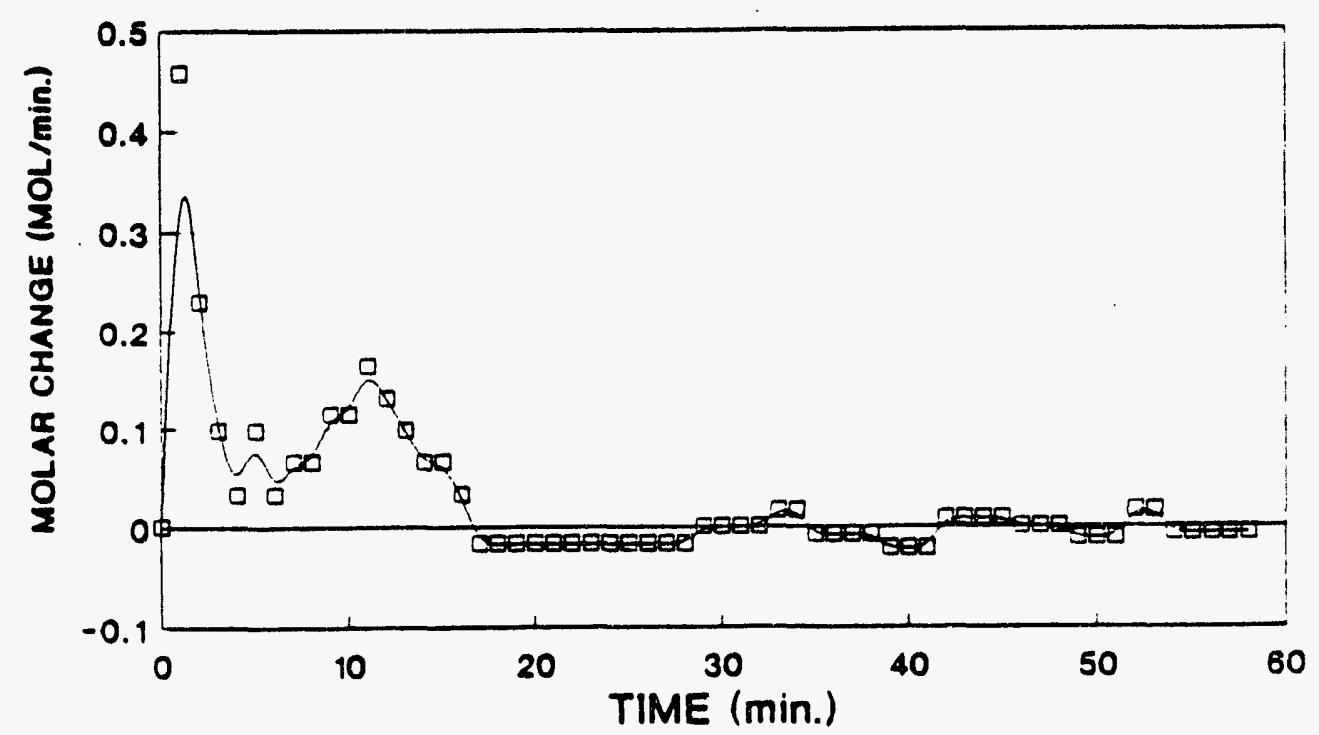

Figure I-9. The Rate of Molar Change with Time at $800 \mathrm{C}$ and $52.4 \mathrm{~atm}$ of Initial Hydrogen Pressure.

Run No. 1152 - Data Table 1-7 


\section{Part II}

\section{THE THERMAL DECOMPOSITION OF METHANE IN A TUBULAR REACTOR}

ATSUSHI KOBAYASHI AND MEYER STEINBERG

BROOKHAVEN NATIONAL LABORATORY

Upton, Long Island, NY, 11973

IINTERAGENCY AGREEMENT NO. EPA/IAGDW89934598-01 -2

U.S ENVIRONMENTAL PROTECTION AGENCY AIR AND ENERGY RESEARCH LABORATORY

RESEARCH TRIANGLE PARK, NC, 27711 


\title{
The Thermal Decomposition of Methane \\ in a Pressurized Tubular Reactor
}

by

\author{
Atsushi Kobayashi and Meyer Steinberg \\ Brookhaven National Laboratory \\ Upton, New York, 11973
}

\begin{abstract}
The reaction rate of methane decomposition using a tubular reactor having a $25.4 \mathrm{~mm}$ inside diameter with a $2.44 \mathrm{~m}$ long heated zone was investigated in the temperature range of 700 to $900 \mathrm{C}$ with pressures ranging from 28.2 to $56.1 \mathrm{~atm}$. Representing the rate by a conventional model, $-\mathrm{dC}_{\mathrm{CH} 4} / \mathrm{dt}=\mathrm{k} 1 \mathrm{C}_{\mathrm{CH} 4}-\mathrm{k} 2 \mathrm{C}_{\mathrm{H} 2}^{2}$, the rate constant $\mathrm{k} 1$ for methane decomposition was determined. The activation energy, $31.3 \mathrm{kcal} / \mathrm{mol}$, calculated by an Arrhenius Plot was lower than for previously published results for methane decomposition. This result indicates that submicron particles found in the reactor adhere to the inside of the reactor and these submicron high surface area carbon particles tend to catalyze the methane decomposition. The rate constant has been found to be approximately constant at $900 \mathrm{C}$ with pressure range cited above. The rate of methane decomposition is first-order with respect to methane partial pressure. The rate of the methane decomposition is favored by higher temperatures and pressures while the thermochemical equilibrium of methane decomposition is favored by lower pressures.
\end{abstract}




\section{INTRODUCTION}

The Hydrocarb Process ${ }^{(11-1)}$ consists of the two main reactions; (1) hydrogasification of the carboneous feedstock to produce a methane-rich gas and (2) the thermal decomposition of methane to produce carbon black and a hydrogen-rich gas. The section on methane decomposition is especially important in order to maintain high efficiency in the process. A key element in the process is that the hydrogen-rich gas produced in the methane decomposition reactor is recycled to the hydrogasification reactor as the reactant gas. Furthermore, the product carbon black is produced in the methane decomposition section.

This work was performed in order to investigate the phenomena of methane decomposition and to obtain data on the kinetics of the reaction for the purpose of designing the methane decomposition reactor. 


\section{CHEMICAL EQUILIBRIUM}

Since the methane decomposition is endothermic, the methane concentration decreases - ith incessing :emperature. Due to the increase of volume during methane decomposition, the decomposilion of methane is favored by decreasing pressure.

$$
\mathrm{CH}_{4}=\mathrm{C}+2 \mathrm{H}_{2}-17.9 \mathrm{kcal} / \mathrm{mol}
$$

Figure $11-1$ shows the equilibnum data of the methane at temperature from 600 to $1200 \mathrm{C}$ snd st pressures of 25.30 . 40 . and $50 \mathrm{~atm}$. These data are calculated from the following Gibbs Free Energy and equilibrium constant.

$$
\begin{aligned}
& R T \ln K_{1}=-d G \\
& K_{1}=X_{\mathrm{H}_{2}}^{2} / X_{\mathrm{CH} 4}
\end{aligned}
$$

where $X$ is the mol iraction of each gaseous component, and

$$
K_{p}=\left(P_{H 2}\right)^{2} / P_{C H 4}
$$

where $p p$ is the partial pressure of each component 


\section{EXPERIMENTAL DESCRIPTION}

Figure II-2 shows the schematic flow sheet of the experimental equipment which mainly consists of a tubular reactor, a carbon trap, a gas-chromatograph and gas meter. Methane enters the system through a remotely controlled regulator located next to the methane cylinders which keeps the pressure approximately constant at selected pressure of 28.2, 41.8 or $56.1 \mathrm{~atm}$ in the system. Methane then flows through a preheater and enters the reactor which consists of a $25.4 \mathrm{~mm}$ inside diameter by $6.35 \mathrm{~mm}$ wall Inconel 617 tube. The total length of the reactor tube is $3.35 \mathrm{~m}$ of which the first $2.44 \mathrm{~m}$ is externally heated and selectively maintained at constant experimental temperatures of 700,800 and $900 \mathrm{C}$ by clamshell electric heaters. Methane is decomposed into carbon and hydrogen in the heated reactor and the effluent gas flows through the carbon trap connected at the bottom of the reactor, where the carbon generated by the reaction is separated. Gas is sampled before and after the reactor and onalyzed by an on-line gas-chromatograph which measures the concentrations of $\mathrm{CH}_{4} \mathrm{CO}$, and $\mathrm{CO}_{2}$ in the gas by a thermal conductivity detector. The flow rate of exit gas is controlled in the range between 10 and 150 liters/min. by a flow valve located after the reactor. The exit gas flows through the gas meter where the flow rate is measured and the gas is finally vented to the atmosphere. 


\section{EXPERIMENTAL RESULT AND DISCUSSION}

Table II-1 shows the results of the data for the experimental runs to measure the conversion of methane into hydrogen and carbon at 700,800, and $900 \mathrm{C}$ and at 56.1, 41.8 and 28.2 atm. Figure II-3 shows the relationship between the methane concentrations in exit gas and residence time in the reactor under these conditions. The residence time of the methane gas in the reactor is given by the inlet gas velocity. The concentration of the methane decreases with increasing temperature and residence time. At both 700 and $800 \mathrm{C}$ and at 56.1 atm the concentration of methane decreases less with residence time than that at $900 \mathrm{C}$ and $56.1 \mathrm{~atm}$. Under the latter conditions, the concentration of methane decreases dramatically with residence time and appears to be approaching equilibrium conditions. The concentration of methane at a residence time of 103 seconds was 48.1 vol\%, and in this case the equilibrium concentration of the methane is 39.6 vol\%.

The equilibrium data at the lower temperatures of 700 and $800 \mathrm{C}$ and at 56.1 atm are 54.3 and 69.3 vol\% respectively and higher than that at $900 \mathrm{C}$. Taking these conditions into account and considering the curves of methane decomposition in Figure II-3, the rate of methane decomposition in the lower temperature range seems to be much smaller than that at the higher temperature of $900 \mathrm{C}$.

Generally the equation for the rate of decomposition of methane is derived as follows:

$$
\mathrm{CH}_{4} \underset{\mathrm{k} 2}{\stackrel{\mathrm{k} !}{\rightleftharpoons}} \mathrm{C}+2 \mathrm{H}_{2}
$$

where $k 1$ is the rate constant of methane decomposition. and $k 2$ is the rate constant of methane formation.

The rate equation for this reversible reaction can be written as follows:

$$
\begin{aligned}
{ }^{-r_{\mathrm{CH} 4}} & =-d C_{\mathrm{CH} 4} / d t=k 1 C_{\mathrm{CH} 4}-k 2 C_{\mathrm{H} 2}^{2} \\
& =k l C_{\mathrm{CH} 4}\left(1-1 / k \mathrm{e} \times \mathrm{C}_{\mathrm{H}_{2}:} / \mathrm{C}_{\mathrm{CH} 4}\right)
\end{aligned}
$$

where $\mathrm{C}_{\mathrm{CH} 4}, \mathrm{C}_{\mathrm{H} 2}$ are the molar concentrations of $\mathrm{CH}_{4}$ and $\mathrm{H} 2$ respectively. 
The above differential equation for methane decomposition in the tubular reactor is solved for the condition of $\mathrm{C}_{\mathrm{H} 20}=0$ (initial concentration of hydrogen is 0 ), for inlet methane concentration $\mathrm{C}_{\mathrm{CH} 40}$, exit methane concentration $\mathrm{C}_{\mathrm{CH}_{4}}$ and equilibrium concentration of methane $\mathrm{C}_{\mathrm{CH} 4 \mathrm{E}}$. Figure II-4 shows a model of the tubular reactor and the derivation of the following rate equation.

$$
k 1 \times t=\frac{\mathrm{Ch}_{\mathrm{CH} 40}-\mathrm{C}_{\mathrm{CH} 4 \mathrm{E}}}{\mathrm{C}_{\mathrm{CH} 40}+\mathrm{C}_{\mathrm{CH} 4 \mathrm{E}}} \ln \frac{\mathrm{C}_{\mathrm{CH} 40}^{2}-\mathrm{C}_{\mathrm{CH} 4} \times \mathrm{C}_{\mathrm{CH} 4 \mathrm{E}}}{\mathrm{C}_{\mathrm{CH} 40} \times\left(\mathrm{C}_{\mathrm{CH} 4}-\mathrm{C}_{\mathrm{CH} 4 \mathrm{E}}\right)}
$$

where $t$ is the residence time

Table II-2 shows the calculated data of inlet, outlet and equilibrium concentrations of methane, inlet flow rate, and $k l \times t$ values. Figure II-5 shows the relationship between $k \perp \times t$ value versus residence time at 700,800 , and $900 \mathrm{C}$ and at $56.1 \mathrm{~atm}$. Each slope in the Figure 5 indicates a rate constant $k l$ of the methane decomposition at each temperature. Table II-3 represents the $k 1$ value at these conditions.

TABLE II-3. RATE CONSTANTS AT 56.1 ATM

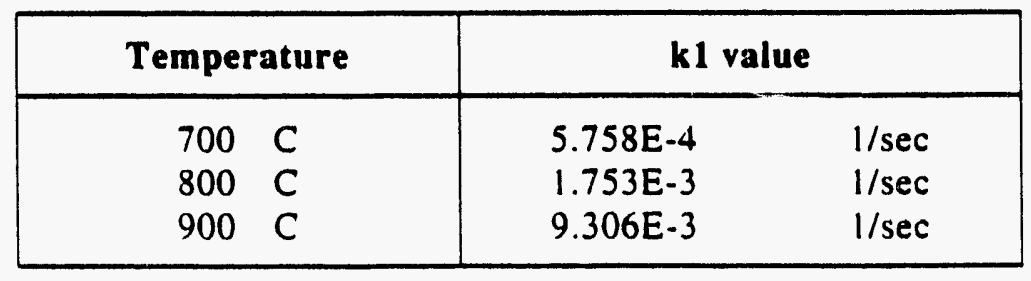

In Figure II-6, the rate constants, $\mathrm{kl}$, for methane decomposition are plotted versus recipical temperature. From this Arrhenius plot an activation energy for methane decomposition and the rate constant $\mathrm{kl}$ are calculated as follows;

$$
\begin{gathered}
E=31.3 \mathrm{kcal} / \mathrm{mol} \\
k 1=5.4 \times 10^{3} \exp (-E / R T) \quad 1 / \mathrm{sec}
\end{gathered}
$$

The activation energy appears to indicate a diffusion controlled process which usually has values up to about $30 \mathrm{kcal} / \mathrm{mol}$ as opposed to a chemical reaction controlled process which has much higher activation energies ranging above $50 \mathrm{kcal} / \mathrm{mol}$. From the limited methane 
decomposition data in the literatures, (II-2,3,4,5,and 6) the homogeneous activation energy for methane decomposition is determined to be $65 \mathrm{kcal} / \mathrm{mol}$. The data gathered in these experiments appear to be influenced by a heterogeneous effect of surfaces. During our experiments some of the carbon formed from methane decomposition adhered to the walls of the Inconel high alloy steel of the tubular reactor. In fact, at the end of several extended runs, it was found that the carbon plugged the tube to the extent that it restricted the gas flow. Thus, the fine submicron carbon particles could tend to catalyze the thermal decomposition of the methane. References 7 and 8 clearly indicate that different materials increase the rate of the mathane decomposition in the order of iron oxide, alumina, graphite, and quartz. In the tubular reactor the small submicron particle size of the carbon presents a very large surface area on which methane can decompose and thus a lower activation energy for decomposition results.

The influence of the total pressure in this system on the rate constant of the methane decomposition was investigated because the Hydrocarb Process is being operated under pressure and it is important to determine the influence of the total pressure on the reaction rate. Figure II -7 shows the relationship between the $k \perp \times t$ value and residence time at $28.2,41.8$, and $56.1 \mathrm{~atm}$ at $900 \mathrm{C}$. The slopes in Figure II-7 represent the rate constants $\mathrm{k} /$ at their respective conditions. These values are calculated and listed in Table II-4.

TABLE II-4. RATE CONSTANTS AT $900 \mathrm{C}$

\begin{tabular}{|l|ll|}
\hline Pressure & \multicolumn{2}{|c|}{ k1 value } \\
\hline $28.2 \mathrm{~atm}$ & $1.066 \mathrm{E}-2$ & $1 / \mathrm{sec}$ \\
$41.8 \mathrm{~atm}$ & $1.380 \mathrm{E}-2$ & $1 / \mathrm{sec}$ \\
$56.1 \mathrm{~atm}$ & $9.036 \mathrm{E}-3$ & $1 / \mathrm{sec}$ \\
\hline
\end{tabular}

average rate constant $1.126 \mathrm{E}-2 \quad 1 / \mathrm{sec}$

Although there is not enough data to establish a relationship with pressure, the rate constant appears to be really indipenddent of pressure. The variation in the rate constant with pressure is probably within the deviation in the experimental measurements for this type of equipment. 
Some other studies to obtain the rate data of carbon formation from methane on silicate substrate indicate that the rate increased in first-order with pressure up to $15 \mathrm{~atm}^{\text {(II-2) }}$ The rate equation (6) modelled in this paper indicates that since the methane molar concentration is first-order in pressure, the result that the rate constant is constant and independent of pressure is in accord with other published results; and the rate of the methane decomposition indeed increases with partial methane pressure approximately in first-order. The thermochemical equilibrium for methane decomposition is favored by lower pressures, but as our results indicate, the rate is favored by higher pressure. 


\section{CONCLUSION}

The influence of the temperature and total pressure on the rate of the methane decomposition has been determined by using a tubular reactor assembly. The following results and conclusions were obtained.

(1) A model for methane decomposition was developed, which resulted in the following rate equation;

$$
\begin{aligned}
{ }^{-r_{\mathrm{CH} 4}} & =-\mathrm{dC}_{\mathrm{CH} 4} / \mathrm{dt}=\mathrm{k} 1 \mathrm{C}_{\mathrm{CH} 4}-\mathrm{k} 2 \mathrm{C}_{\mathrm{H}^{2}} \\
& =\mathrm{k} 1 \mathrm{C}_{\mathrm{CH} 4}\left(1-1 / \mathrm{ke} \times \mathrm{C}_{\mathrm{H} 2}^{2} / \mathrm{C}_{\mathrm{CH} 4}\right)
\end{aligned}
$$

$\mathrm{kl}$ value was calculated as follows;

$$
\mathrm{k} 1 \times \mathrm{t}=\frac{\mathrm{C}_{\mathrm{CH} 40}-\mathrm{C}_{\mathrm{CH} 4 \mathrm{E}}}{\mathrm{C}_{\mathrm{CH} 40}+\mathrm{CH} 4 \mathrm{E}} \ln \frac{\mathrm{C}_{\mathrm{CH} 40}^{2}-\mathrm{C}_{\mathrm{CH} 4} \times \mathrm{C}_{\mathrm{CH} 4 \mathrm{E}}}{\mathrm{C}_{\mathrm{CH} 40} \times\left(\mathrm{C}_{\mathrm{CH} 4}-\mathrm{C}_{\mathrm{CH} 4 \mathrm{E}}\right)}
$$

An Arrhenius Plot of the $\mathrm{k} I$ values resulted in the following rate constant equation.

$$
k 1=5.4 \times 10^{3} \exp (-31.3 \mathrm{kcal} / \mathrm{RT}) \quad 1 / \mathrm{sec}
$$

The activation energy appears to indicate a diffusion controlled process most likely influenced by the high surface area of the submicron carbon particles deposited in the reaction zone.

(2) Although a definitive influence of the total pressure on the rate constant of the methane decomposition could not be clearly determined, at $900 \mathrm{C}$, within experimental error, the rate constant appears to be constant and independent of pressure in the range of 28.1 to 56.1 atm. Taking into account the rate equation modelled in this paper, the rate of decomposition is influenced by the methane partial pressure to the first-order. Taking into account these results together with literature data, the conclusion is reached that although the thermochemical equilibrium decomposition of methane is favored by lower pressure, the rate of methane decomposition is favored by higher pressure. 


\section{REFERENCES}

II-1. M. Steinberg, "Biomass and Hydrocarb Technology for Removal of Atomospheric CO2," BNL 44410, Brookhaven National of Atomospheric $\mathrm{CO}_{2}$," BNL 44410 , Brookhaven National Laboratory, Upton, NY (March 1990)

II-2. E. F. Aref eva, et al., Khimiya Tverdogo Topliviva 11, No. 1, 1129-35 (1977)

II-3. P. A. Tenser, et al., Khimiya Tverdogo Topliviva 11, No. 5 113-16 (1977)

II-4. Kurt Hedden et al., Fourth Carbon Conference, August 22, 1961

II-5. K.I. Makarov and V.K. Pechic; " Kinetics of Methane Thermal Decomposition on the Carbon Surface in Transient Regime," vol 7 pp. 278-285 (1969), Pergamon Press.

II-6. Margaret H. Back and Robert A. Back; "Thermal Decomposition and Reaction of Methane," Industrial Pyrolysis (1983)

II-7. N. Z. Muradov "How to Produce Hydrogen from Fossil Fuels without $\mathrm{CO}_{2}$ Emissions," Informal Report, Insitute of Petrochemical Processes, Azerbaijan, SSR, Baku, U.S.S.R.

II-8. Jack B. Pohlenz, et al., " Method for Hydrugen Production by Catalytic Decomposition of a Gaseous Hydrocarb Stream"; United States Patent 3,284,161, Nov. 8, 1966 and "Process Hydrogen from Hydrocarbons," Chem. Eng. 69, pp 90-91, 1962 


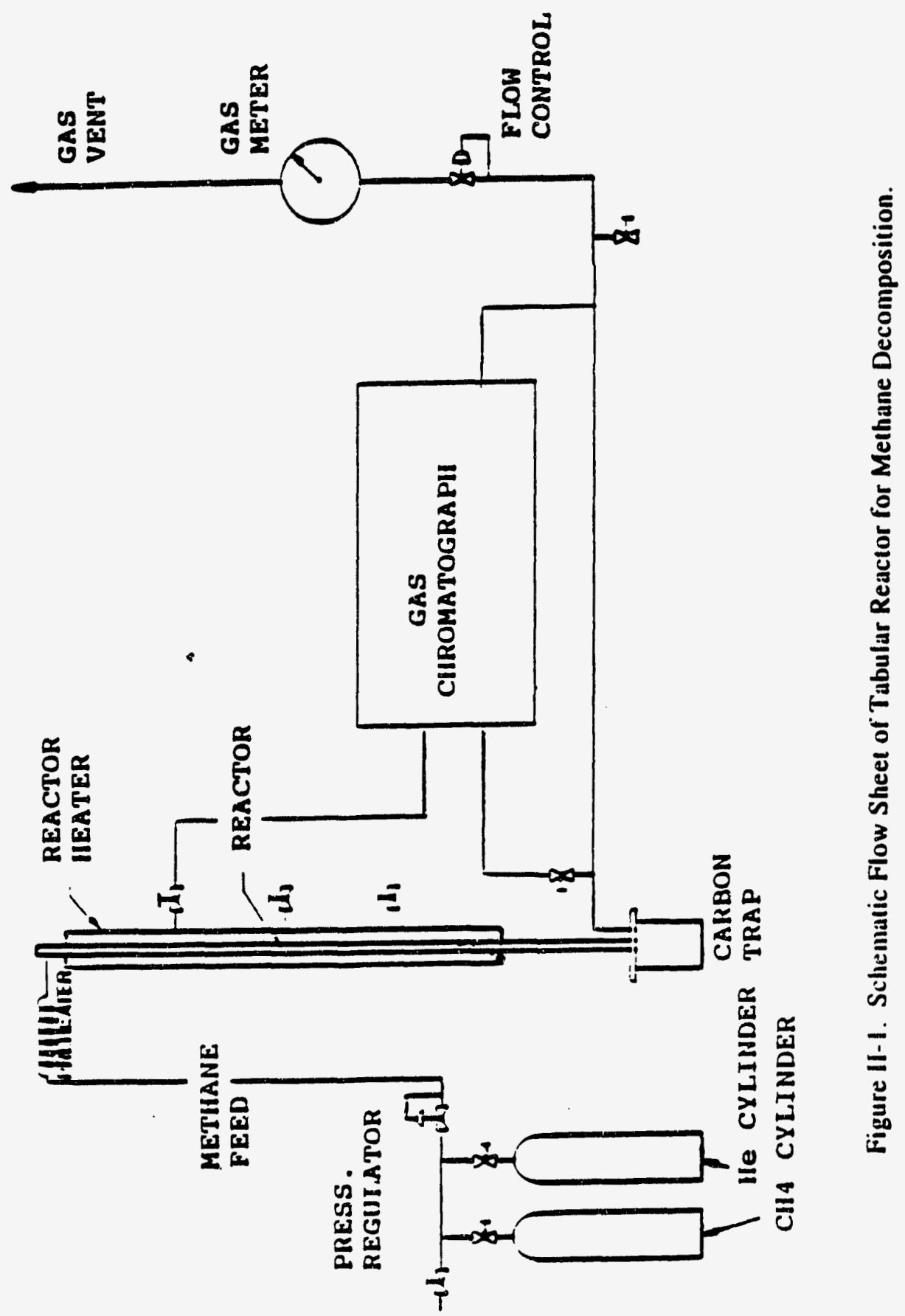

$11-12$ 


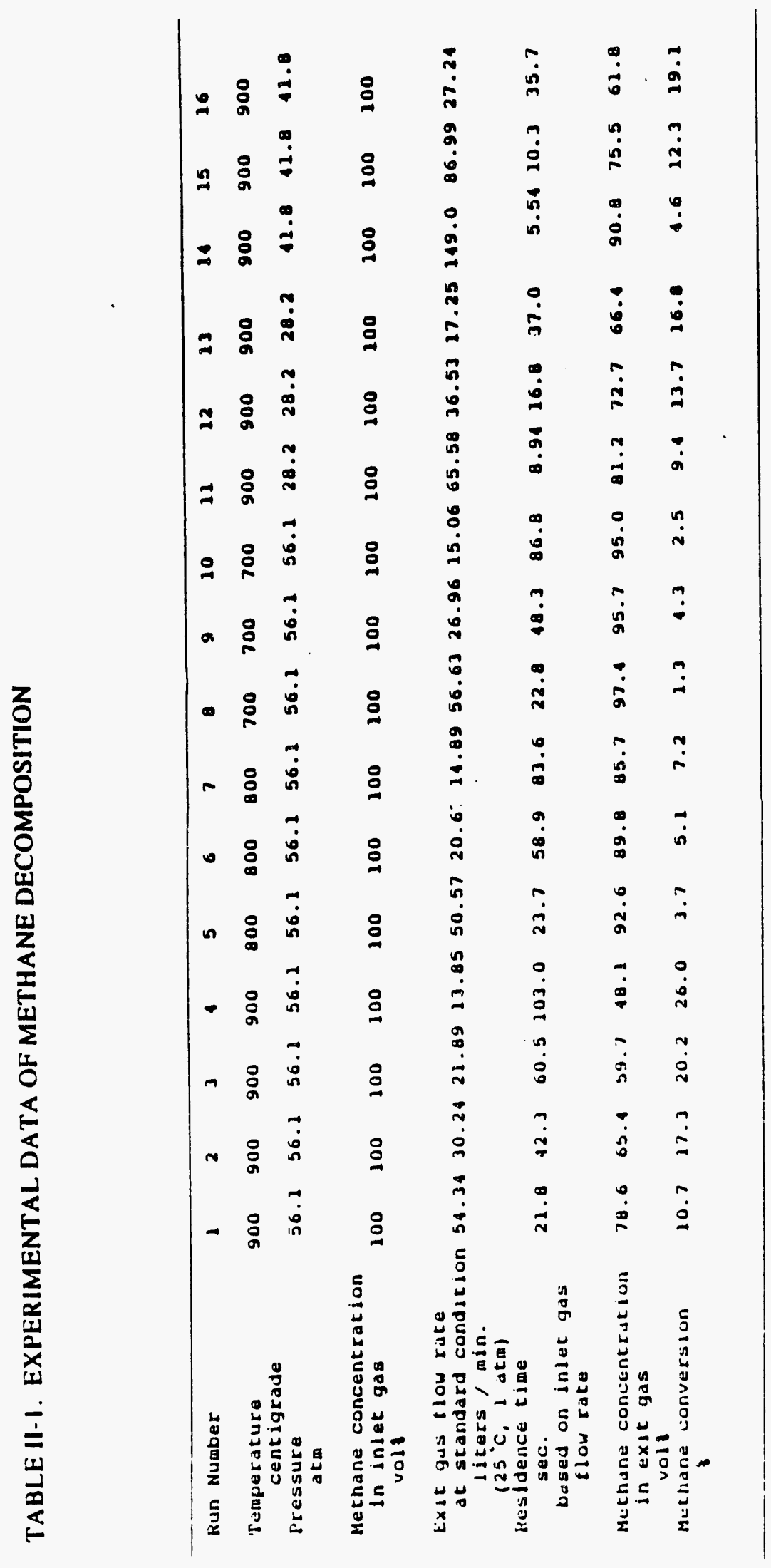

II -13 


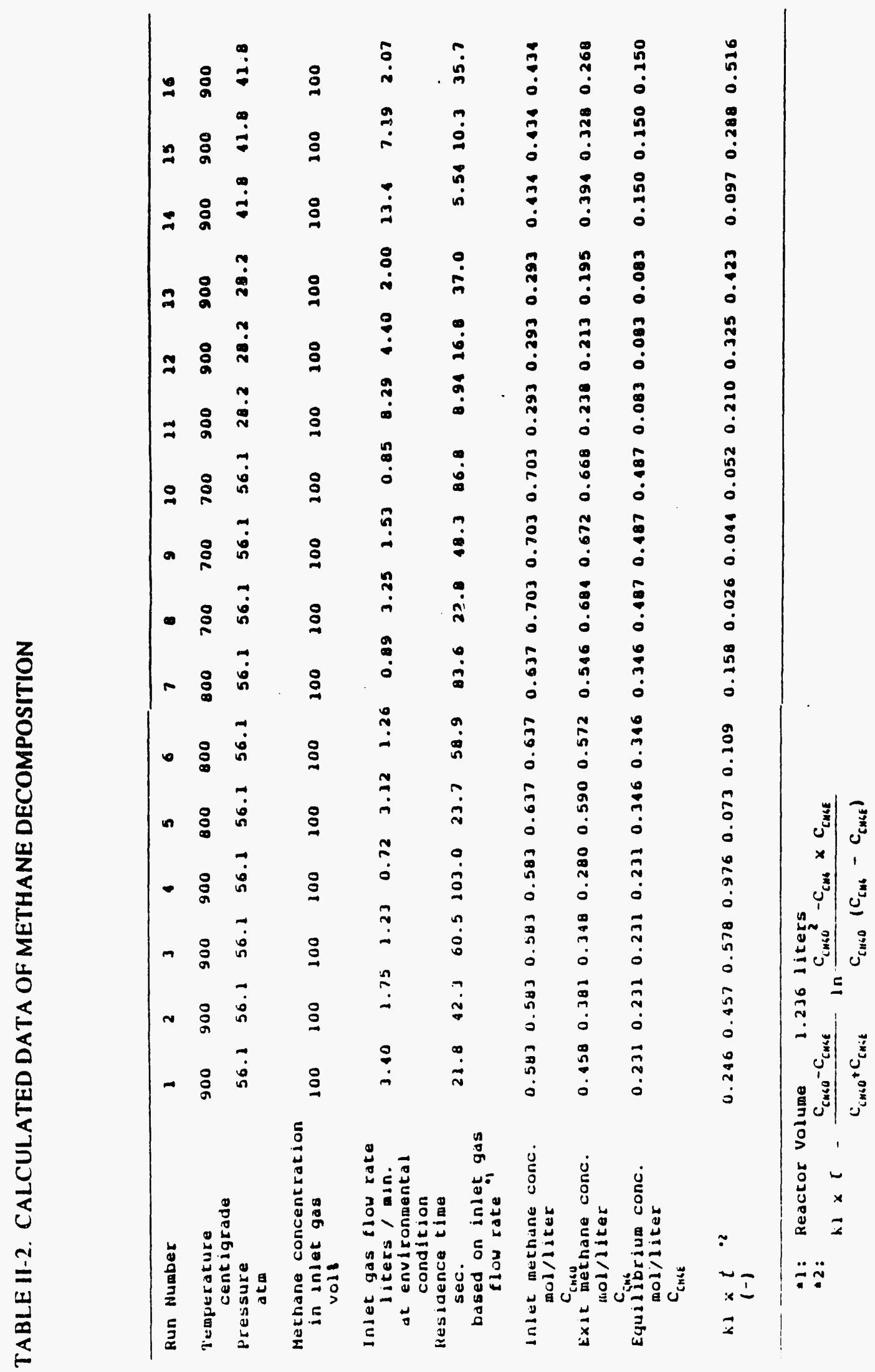

II-14 


\section{Equilibrium Data of Methane}

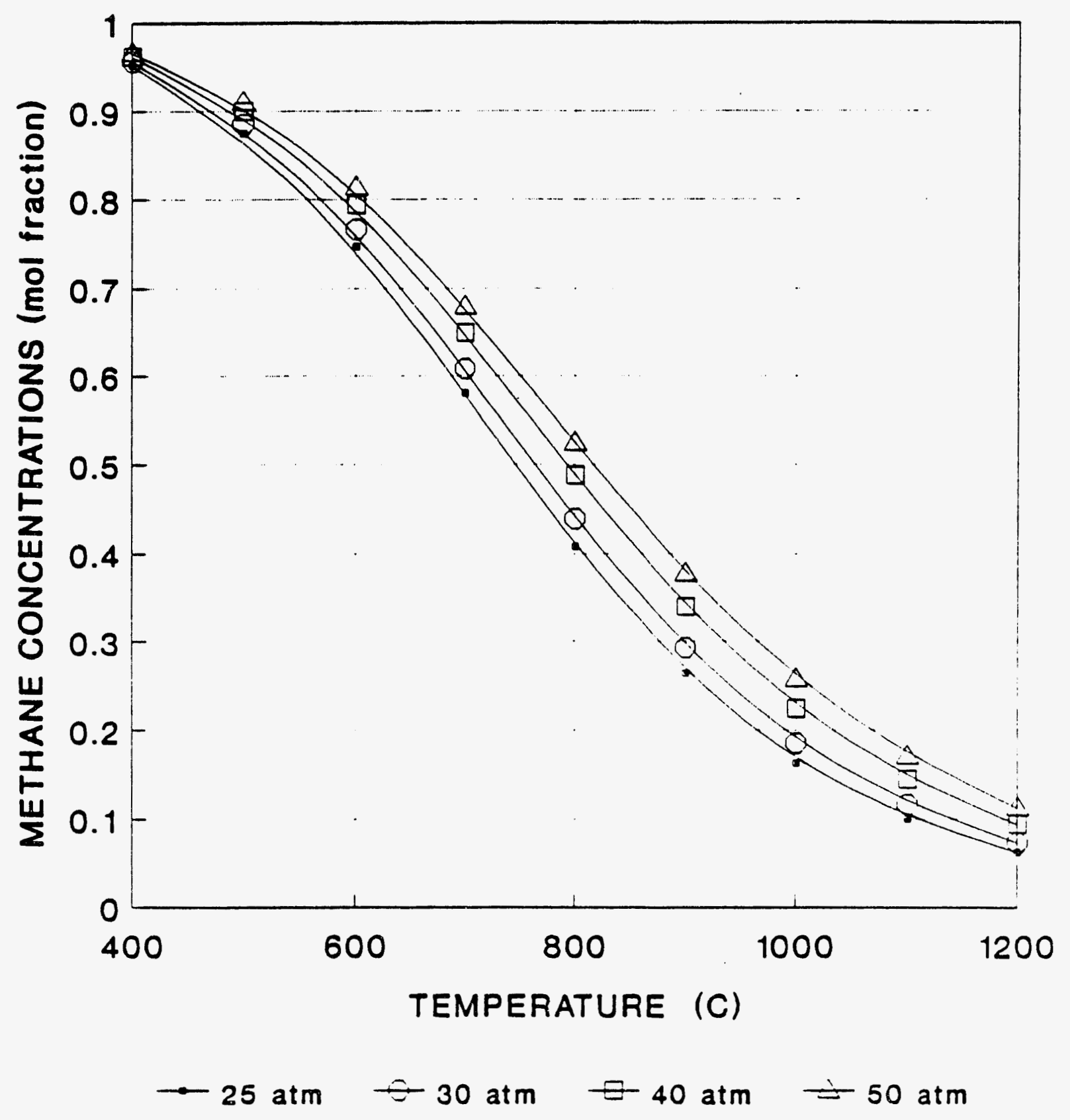

Figure II-2. Equilibrium Data of Methane. 


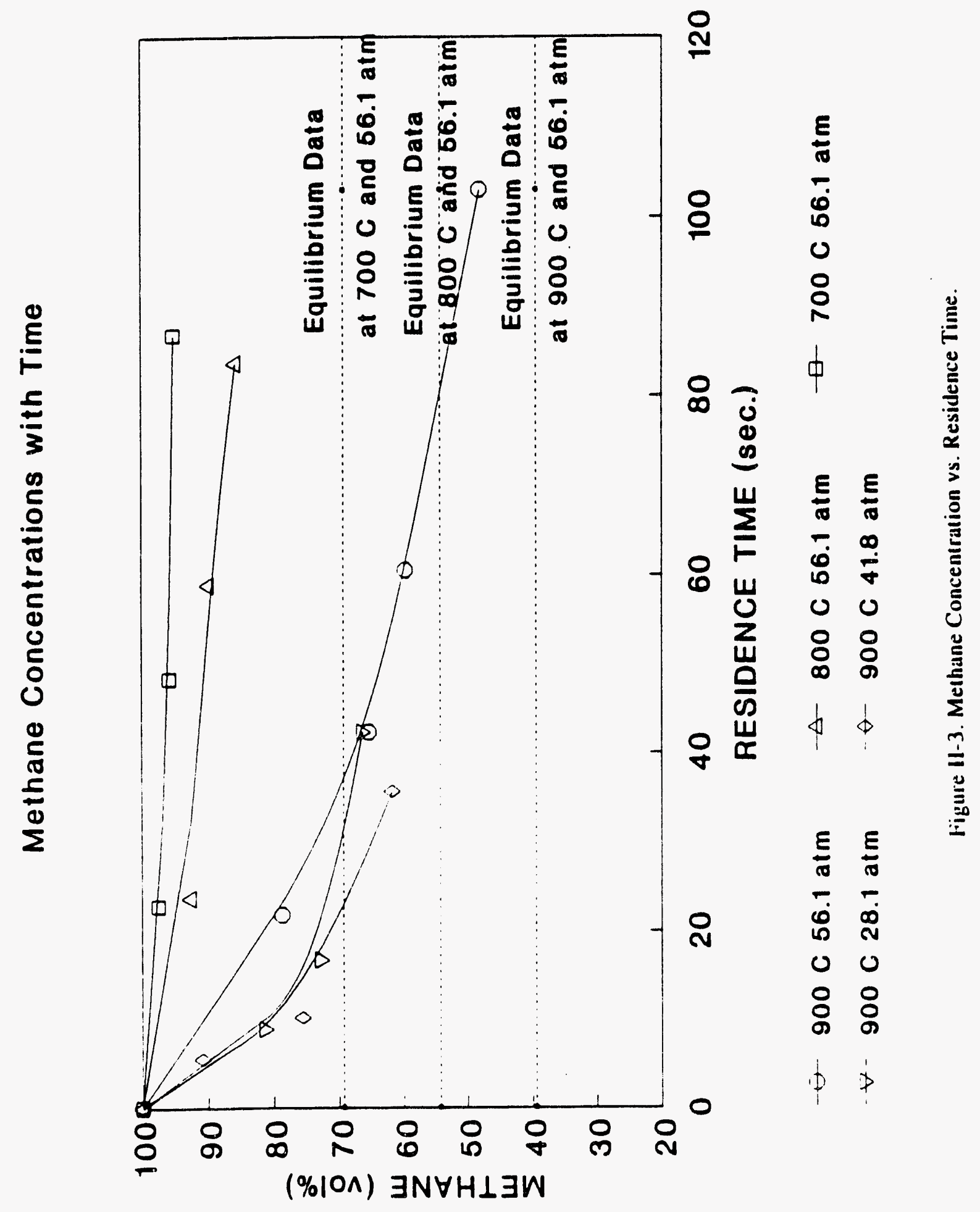

II- 16 


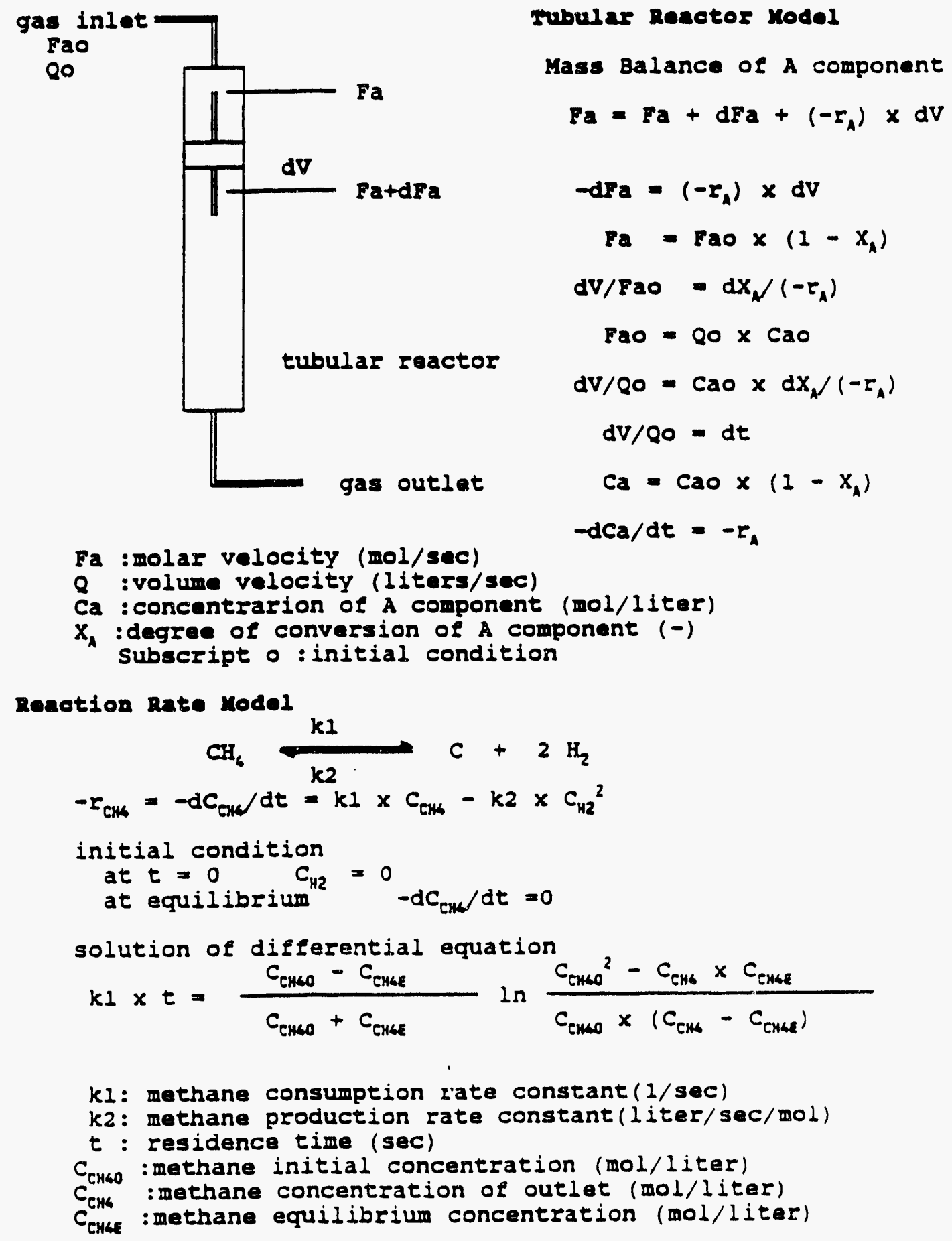

Figure II-4. Tubular Reactor Model and Derivation of Rate Equation. 


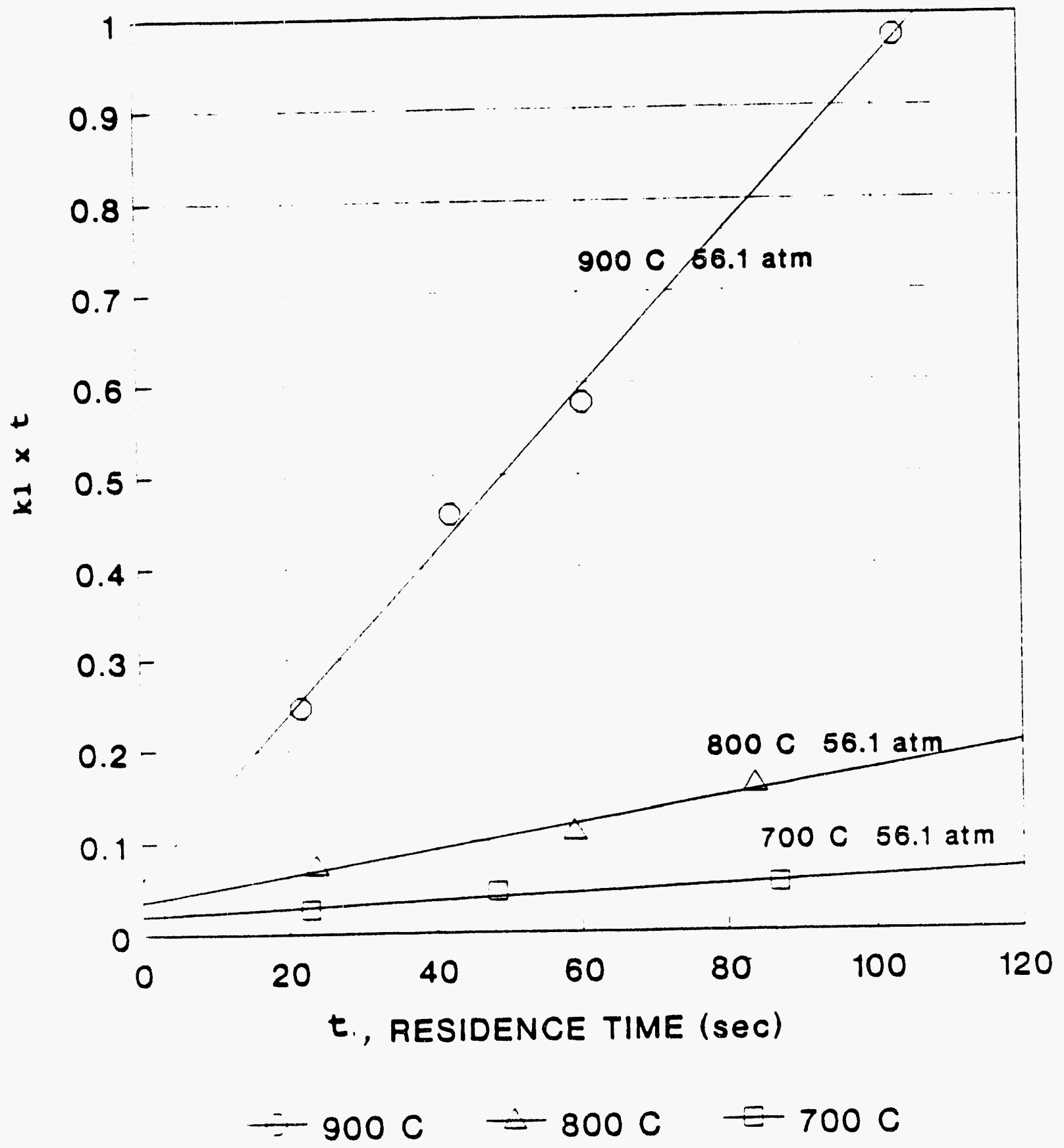

Figure $\mid 1-5 . \mathrm{kI} \times \mathrm{T}$ vs. Residence Time at 700 to $900^{\circ} \mathrm{C}$ and $56.1 \mathrm{~atm}$.

II- 18 


\section{Arrhenius Plot}

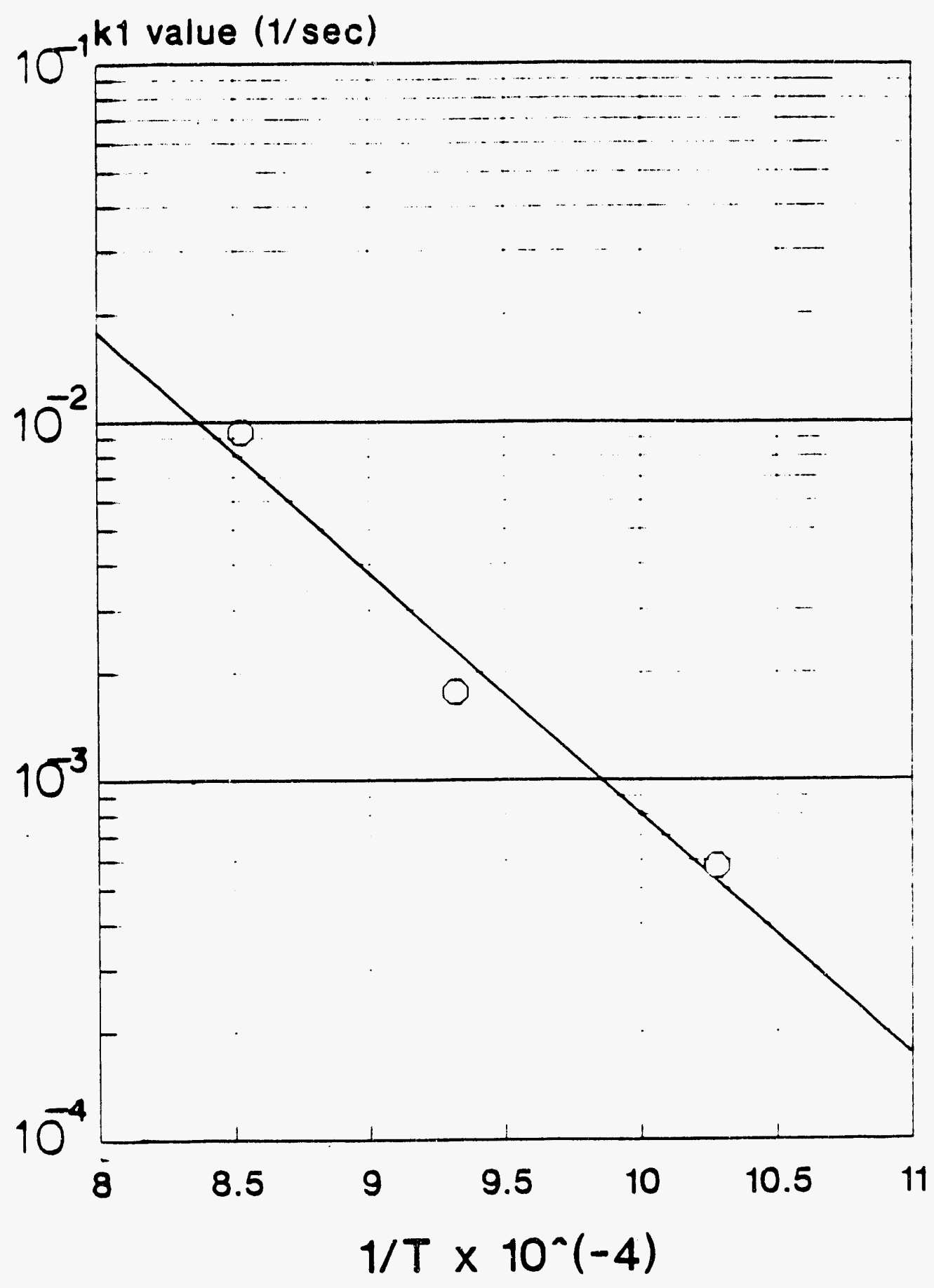

Figure II-6. Rate Constant of Methane Decomposition vs. Recipical Temperature. 


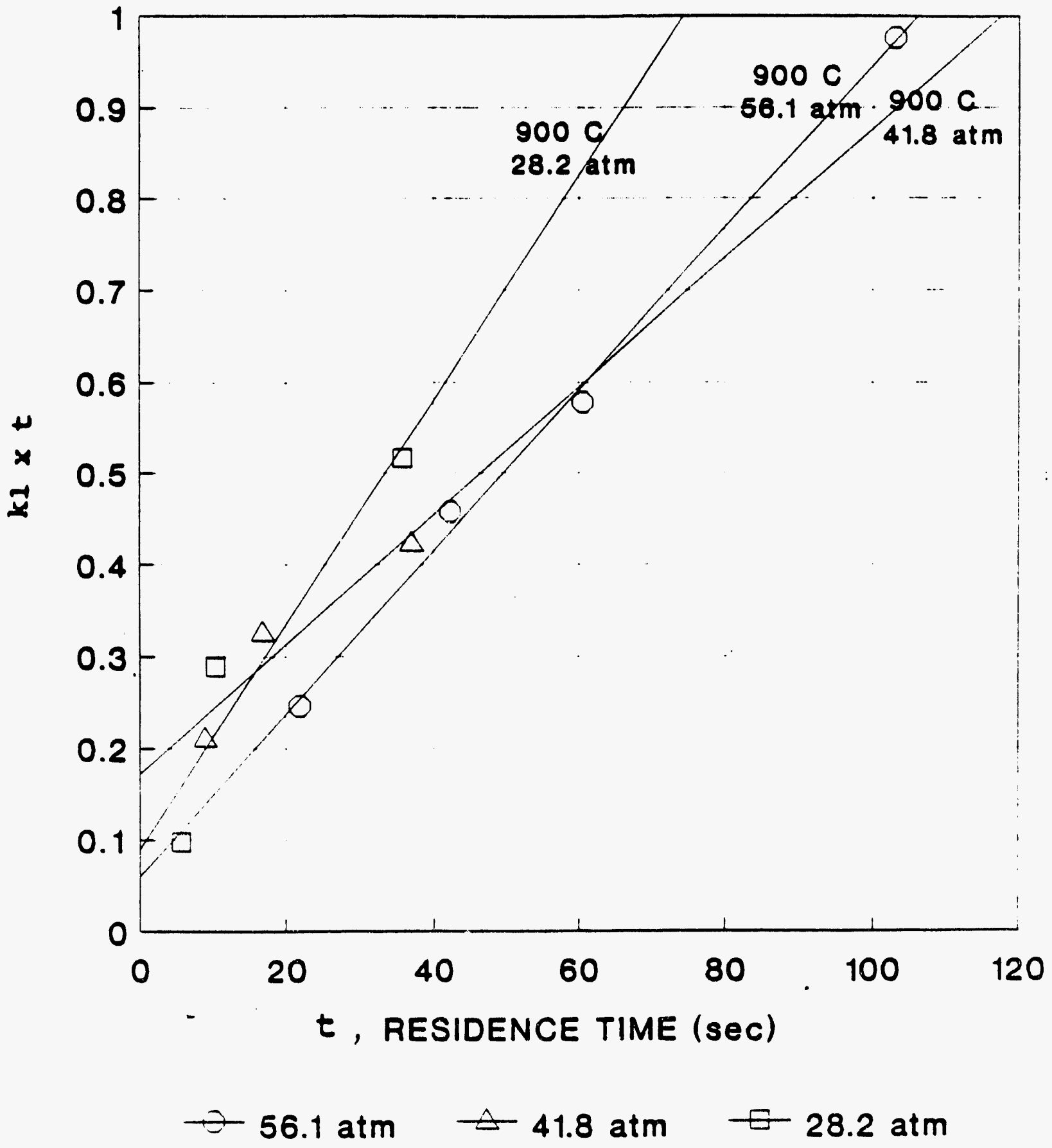

Figure II-7. $\mathrm{kl} \times \mathrm{t}$ vs. Residence Time at $900^{\circ} \mathrm{C}$ and 28.2 to $56.1 \mathrm{~atm}$. 
Part III

\section{DESIGN ANAL YSIS OF THE HYDROCARB PROCESS \\ WITH ALTERNATTVE AND MULTTPLE FEEDSTOCKS}

by

YUANKI TUNG AND MEYER STEINBERG

HYDROCARB CORPORATION

232 West 40th Street

New York, NY 10018

SUBCONTRACTOR TO

BROOKHA VEN NATIONAL LABORATORY

Upton, NY 11973

INTERAGENCY AGREEMENT NO. EPA/IAGDW89934598-0 I-2

U.S.ENVIRONMENTAL PROTECTION AGENCY AIR AND ENERGY RESEARCH LABORATORY

RESEARCH TRIANGLE PARK, NC, 27711

III-I 


\title{
Design Analysis of the Hydrocarb Process \\ With Alternative and Multiple Feedstocks
}

by

Yuanki Tung and Meyer Steinberg

Hydrocarb orporation

232 West 40th Street

New York, NY 10018

\begin{abstract}
The designed performance of the Hydrocarb process with alternative and multiple feedstocks was investigated. The alternative feedstocks studied for the Hydrocarb process included biomass (wood), Alaska Beluga (sub-bituminous) coal, Kentucky (Bituminous) coal, North Dakota (lignite) coal and Wyodak (sub-bituminous) coal. A Process Simulation Computer Model was used to design the process, and obtain complete energy and mass balances. Boundary conditions of pressure, temperature and mass balances for the cyclical process were determined. The study also included using sludge and digester gas from sewage plants as additional feedstocks. It was found that these feedstocks have to be coprocessed with either biomass or coal to obtain a workable mass balance. The maximum allowable feed ratios of sludge to biomass or sludge to coal were determined. The effect of pressure and temperature for the biomass and sludge feedstock cases were also developed.
\end{abstract}

III-2 


\section{INTRODUCTION}

In our previous report, ${ }^{(111-1)}$ an analysis was performed for the Hydrocarb Process to produce methanol and carbon black from biomass (wood) with methane (natural gas) as co-feedstock. The effects of different types of reactors, different process configurations (flowsheet arrangements), as well as operating conditions on process efficiency and product distribution were studied by using the Hydrocarb Process Simulation Program (HCSP) based on the thermodynamic equilibrium in the ternary system $\mathrm{C}-\mathrm{H}-\mathrm{O}$. The following conclusions were reached in the previous study:

(1) In order to process wood feedstock, methane should be added into the system as required by the stoichiometry. The minimum required methane depends upon the cycle (process configuration) and reactor type used.

(2) A fluidized bed reactor can simplify the procedure for mixing and separation of different kinds of solids, and, therefore, is recommended for use in the Hydrocarb Process.

(3) Cycle 1 is defined as the process configuration in which the hydropyrolyzer (HPR) output is led to the methane pyrolyzer (MPR), and then to the methanol Synthesis reactor (MSR). Cycle 1 usually provides a higher methanol yield than Cycle 2 in which the configurationn is HPR to MSR to MPR. Also Cycle 2 requires two heat exchangers whereas Cycle 1 needs only one.

(4) The reaction temperature in the HPR may be controlled by adjusting the temperature of the process gas into the reactor.

Although the previous report has gained some insight into the main features of the Hydrocarb Process, particularly for the case where wood is used as a feedstock. more work was needed to explore the feasibility of using alternative feedstocks and multiple feedstocks.

Furthermore. Steinberg ${ }^{(111-2.111-3)}$ indicated that the use of biomass through photosynthesis in combination with Hydrocarb Process can offer a solution to the global greenhouse problem, utilizing biomass as a co-feedstock with fossil fuel to produce methanol while 
sequestering the carbon can significantly reduce and even eliminate $\mathrm{CO}_{2}$ greenhouse gas emissions to the atmosphere.

A pilot plant project, treating $22.7 \mathrm{~kg} / \mathrm{hr}$ of sludge and municipal solid waste (MSW) together with methane to produce methanol and carbon black, has been proposed and is being conducted in California. ${ }^{(4)}$ Our preliminary calculation showed that the sludge can not be utilized alone to make up heat balance in the HPR due to its very low heating value. Thus, multiple feedstocks have to be considered. This requires an investigation of multi-feedstock utilization in the Hydrocarb Process.

According to a proposal ${ }^{(111-4)}$ by Acurex Corporation to the South Coast Air Quality Management District (SCAQMD), a typical water quality control plant, where a Hydrocarb may be built, treats about $113 ; 562 \mathrm{~m}^{3}$ per day of wastewater. It provides 28 tons/day of dried sludge ( $90 \%$ solids content) and, at the same time, produces 13.3 tons/day of digester gas. The latter contains $61.2 \mathrm{~mol} \% \mathrm{CH}_{4}$ and $37.5 \mathrm{~mol} \% \mathrm{CO}_{2}$. The question consequently raised here is whether this digester gas can be fed into the process instead of pure pipeline methane.

To meet the above challenge, our program has been extended to treat the case where we can co-feed as many different feedstocks as we wish including digester gas.

In the present study, the following topics are investigated:

(1) Feasibility of using alternative feedstocks:

Kentucky Coal, Alaska Beluga Coal, North Dakota Coal, and Wyodak Coal have been chosen for this study, because they range over a wide variety of ranks and from different locations:

(2) Co-feeding Biomass with Kentucky Coal;

(3) Utilization of sludge and digester gas;

(4) Effects of heat sources for operating the MPR on the process efficiency: and

(5) Pressure and temperature effects on process efficiency. 


\section{BASIC DATA AND DEFINITION}

Table III- 1 lists the basic data of different feedstocks used in this analysis. It should be noted that the heating value here is provided in both English and Metric Units on a dry basis, while the heat of formation is expressed on a moisture and ash free basis.

For each set of feedstocks, both Cycle 1 and Cycle 2 were calculated and compared to each other. Brief flowsheets cf Cycle 1 and Cycle 2 are illustrated in Figure III-1. Our previous report ${ }^{(I I I-1)}$ gives a detailed description of these cycles. In Cycle 1 , the process gas at $1000 \mathrm{C}$ from the MPR is cooled down by a gas heat exchanger to around the reaction temperature of the methanol convertor, and this recovered energy is used in the heat exchanger to heat the process gas from the condensers at $50 \mathrm{C}$ up to about the HPR's temperature. When an energy balance is performed, the temperature of process gas into the HPR. $T_{7}$, is so determined that the reaction heat generated in the HPR is just balanced by the enthalpy difference of inlet and outlet streams. The temperature of process gas into the MSR, $T_{s}$, is then calculated by the heat balance around the gas heat exchanger. In Cycle 2, two gas exchangers are used as shown in Figure III-1. One exchanger is to cool the gas stream from the temperature of the HPR to the temperature of the MSR by heating up the gas stream coming from the condensers. Before entering the MPR, the process gas is further heated in the second gas heat exchanger by the hot gas stream from the MPR. In this case, the calculation is made to first determine $T$, by balancing the heat load of the HPR to be zero. Then, $T_{6}$ and $T_{3}$, the temperatures of gas leaving the two heat exchangers can be calculated respectively from the heat balances of the two heat exchangers.

All calculations were made based on the use of fluidized beds for the HPR and the MPR.

The heat source for the MPR could be any of the following fuels: (1) the residual char discharged from the HPR, (2) purge gas discharged from the recycle stream after the condensers, and (3) additional natural gas or solid fuel including any type of coal and biomass. In this study, two cases were investigated: one for burning char, off gas and biomass or digester gas 
or fossil fuel; and another for burning off gas and natural gas only without using solid fuel in the combustor.

The carbon conversion of any solid feedstock in the HPR was assumed to be $90 \%$. This may lead to a conservative estimate for wood conversion because of its higher reactivity in the hydrogasifier.

Except for those runs made for investigating the effects of operating conditions, the system pressure was chosen to be $50 \mathrm{~atm}$ and the temperatures for the HPR and MPR were 900 and $1000 \mathrm{C}$ respectively. The choice of temperature of $900 \mathrm{C}$ for operation of the HPR is to ensure the effectiveness of sulfur removal with the use of limestone and dolomite. The MPR temperature was chosen by consideration of the state of the art for limitation of the materials of construction. The temperature of the methanol convertor is assumed to be $260 \mathrm{C}$ and the condenser is operated at $50 \mathrm{C}$. Preliminary calculation showed that these conditions resulted in a satisfactorily high process efficiency $(70-80 \%)$.

All calculations were made on a capacity basis of 100 tons per calendar day of the major solid feedstock. The actual feed rate into the HPR is equal to the above capacity divided by the operating factor which is assumed to be $90 \%$. Therefore, for a 100 tons per calendar day plant of an as-received coal, for instance, the feed rate of this feedstock into the HPR is $100 / 0.9=$ 111.1 tons/day or $4629.6 \mathrm{~kg} / \mathrm{h}$ if no drying is needed before feeding into the HPR.

When a single solid feedstock was tested, the strategy of calculation is shown in Figure III-2. First of all, an as-received (AR) undried feedstock is tried to see whether a material and energy balance can be achieved. If the answer is positive, then feeding additional water into the HPR may be tried until a maximum allowable value of additional water is found. If the balance can not be made for the AR feedstock, two approaches may be tried depending on whether the material balance or the energy balance is in question. If the material balance fails, co-feeding some methane into the HPR may be the way to make up the balance. A minimum $\mathrm{CH}_{4}$ requirement is then calculated. However, $\mathrm{CH}_{4}$ has little effect on the heat load of the 
HPR. Thus, if the HPR is endothermic in spite of adjusting the temperature of the inlet gas, drying the feedstock may be necessary and the calculation then is aimed at obtaining the maximum allowable moisture of feedstock. In some cases, both adding methane and drying feedstock may be needed to obtain a workable cycle.

When multiple feedstocks are investigated, and sludge is used as one of the feedstocks, the digester gas is always assumed as a co-feedstock. Considering its availability in the Riverside Water Quality Sewage Plant in California, the weight ratio of digester gas to sludge was set as 0.5 . The calculations were aimed at obtaining a maximum allowable sludge feed rate.

In the calculation, limestone feed rate is determined by assuming a molar ratio of $\mathrm{Ca}$ to $\mathrm{S}$ of 2. The composition of $\mathrm{CaCO}_{3}$ in limestone is assumed to be $70 \%$, and the rest being ash. 


\section{RESULTS AND DISCUSSION}

\section{SINGLE SOLID FEEDSTOCK}

\section{Alaska Beluga (Sub-Bituminous) Coal:}

Tak!. III-2 shows that, for Cycle 1, as-received (AR) Beluga coal has to be dried from $21.70 \%$ of moisture to $11 \%$ before it can be fed into the HPR in order to obtain material and energy balances. If the coal is directly used without drying, there would be a minimum requirement for methane co-feedstock at a ratio of 5 wt.\% to the as-received Beluga coal. Since the water may react with carbon to form $\mathrm{CO}$, the use of the as-received Beluga coal greatly increases the methanol production and improves the methanol ratio in the product streams. The latter case also showed about a $2 \%$ higher thermal efficiency compared to the drying case. It is also found in most of the calculations that, if the residual char discharged from the HPR is used together with other heat sources for the MPR, it reduces the consumption of other fuels for combustion and provides an increase of about $5 \%$ in thermal efficiency. A comparison of the results of Cycle 1 with Cycle 2 for Beluga coal shows that Cycle 2 can directly use as-received Beluga coal without the need to dry the coal. Furthermore, additional water is allowable for feeding into the HPR with as-received coal. The gas circulation for Cycle 2 is relatively less than that for Cycle 1 . However, Cycle 2 usually produces more carbon and less methanol in comparison with Cycle 1, and its thermal efficiency is lower.

\section{Kentucky (Bituminous) Coal:}

It was found from Table III-2 that, when as-received Kentucky coal is used alone as a single solid feedstock, the material and energy balances can be established for both Cycle 1 and Cycle 2. For Cycle 1, an additional amount of water can be co-fed into the HPR at a maxi- 
mum allowable content of 29 wt.\% of the as-received Kentucky coal according to the material and energy balance. For Cycle 2, the allowable additional water is as high as 67 wt.\% of the coal. The addition of the water for Cycle 1 improves the thermal efficiency (the ratio of the total heating value of carbon and methanol to the total heating value of feedstocks and methane), however, its effect in Cycle 2 is the reverse. The gas circulation rate appears higher than when Beluga coal is used. The thermal efficiency for Cycle 2 is better than for Cycle 1 if as-received Kentucky coal is used alone.

\section{North Dakota (Lignite) Coal:}

Table III-2 shows that neither Cycle 1 and Cycle 2 can use North Dakota lignite alone without drying. For Cycle 1, in addition to drying the coal from 30.1 wt\% moisture to 5 wt\%, a minimum methane feed rate of 2 wt.\% of the coal has to be co-fed into the HPR; for Cycle 2, the coal is required to be dried down to only $15 \%$. Cycle 2 gives a $5 \%$ lower thermal efficiency than Cycle 1 .

\section{Wyodak (Sub-Bituminous) Coal:}

The results in Table III-2 indicate that Wyodak coal also needs drying when it is fed alone into the HPR for Cycle 1 . The maximum allowable moisture in this case is 13 wt.\%. For Cycle 2, however, as-received Wyodak coal can be used. The results also show that the maximum additional water rate is 7 wt.\% of the coal for Cycle 2. Residual char burning may raise the thermal efficiency by an additional $4-5 \%$, which is essentially similar to the results obtained for other feedstocks.

\section{Biomass (Wood):}

The calculated results for wood feedstock, as listed in Table III-2, show the necessity of co-feeding methane for both Cycles when as-received wood is directly fed into the HPR. 
The required minimum methane feed rate is $15 \mathrm{wt. \%}$ of the as-received wood for Cycle 1; while Cycle 2 needs a methane rate of only 6 wt.\%. It can be seen that, in general, the product ratio (methanol/pure carbon) for wood as feedstock is relatively higher, and more methanol and less carbon black are produced in comparison with other feedstocks. It also shows that Cycle 1 has a higher thermal efficiency than Cycle 2.

The computer printout for Cycle 1 under 100 tons per calendar day of wood and 15 tons per calendar day of methane feed rate conditions is shown in Appendix III-1. Figure III-3 summarizes the flow rates, compositions and temperatures of the major streams in the system. After purging a small amount of off-gas $(3 \mathrm{kgmol} / \mathrm{hr})$ for use with other fuels (char, biomass and methane) to heat up the MPR, the temperature of the remaining process gas of 2170 $\mathrm{kgmol} / \mathrm{hr}$ from the condenser is raised up to $927 \mathrm{C}$ by the gas heat exchanger to meet the requirement of a neutral energy balance around the HPR. In the gas heat exchanger, the heat is provided by recovering the energy from the process gas at $1000 \mathrm{C}$ leaving the MPR. The calculated temperature of the hot gas stream leaving the heat exchanger is $257 \mathrm{C}$ which then enters the methanol converter. The residual char of $212 \mathrm{~kg} / \mathrm{hr}$ is discharged from the HPR and is then burned in the combustor together with the $3 \mathrm{kmol} / \mathrm{hr}$ of off-gas and $1546 \mathrm{~kg} / \mathrm{hr}$ of wood to provide the heat required by the endothermic reactions in the MPR. Thus, the total wood consumption for producing $3192 \mathrm{~kg} / \mathrm{hr}$ of methanol and $1222 \mathrm{~kg} / \mathrm{hr}$ of carbon black is $6176 \mathrm{~kg} / \mathrm{hr}$, of which about one fourth is used for combustion. The use of wood as fuel is desirable because it is produced by photosynthesis and its net $\mathrm{CO} 2$ emission is zero.

\section{MULTIPLE-FEEDSTOCKS WITH SEWAGE SLUDGE AND DIGESTER GAS}

Since sludge has quite a low heating value, in order to maintain a desired temperature in the HPR, the utilization of sludge has to be accompanied by biomass and/or other fossil fuel. In this study, wood, Kentucky coal and Wyodak coal are used as co-feedstock with sludge respectively to calculate the possible maximum capacity of sludge. The feed rate of digester 
gas is always kept at $50 \mathrm{wt} . \%$ of the sludge rate, according to the gas availability in a water quality control plant. The calculated results are summarized in Table III-3.

\section{Sludge with Wood:}

When sludge is treated together with wood, methane must be used as a co-feedstock at a rate of $15 \mathrm{wt} \%$ of wood. It was found that, for Cycle 1 , both wood and sludge have to be dried before being used. The sludge was assumed to be dried to contain 5 wt\% moisture, and its feed ratio is dependent upon the moisture content of the dried wood. Figure III-4 plots the product ratio of methanol to carbon and the thermal efficiency as functions of sludge feed rate. It shows that both methanol production and thermal efficiency increase with the ratio of sludge feed rate to the wood feed rate. There is a maximum allowable sludge feed ratio in order to maintain a desired reaction temperature in the HPR. When wood is dried to 5 wt $\%$ moisture and fed with $15 \mathrm{wt} \%$ of methane, the allowable maximum feed ratio of sludge to wood is 70 wt\%. If wood is further dried to 1 wt\% moisture, the feed ratio of sludge increases to 80 wt\%. For Cycle 2, as-received wood and as-received sludge can be used with a maximum sludge feed rate of $50 \mathrm{wt} \%$. If a dried wood of $5 \mathrm{wt} \%$ moisture is used, the sludge feed ratio reaches 90 wt\%. However, comparing the two cycles, Cycle 2 has a lower thermal efficiency, and it produces more carbon and less methanol, though its gas circulation requirement is slightly smaller. It is interesting to note in Appendix III-2, that with feeding digester gas into the HPR. the $\mathrm{CO}_{2}$ component reacts in the HPR to form $\mathrm{CO}$ and $\mathrm{CH}_{4}$, thus increasing the $\mathrm{CO}$ mole fraction in the process gas from $2.4 \%$ to $6.2 \%$. These constituents are then converted to methanol and carbon black in the following steps. This ability for the HYDROCARB Process to convert $\mathrm{CO}_{2}$ in the clean fuels should be significant for greenhouse gas mitigation. Figure III-5 summarizes the calculation results for this case. 
Sludge with Kentucky Coal:

When Kentucky coal is used as co-feedstock with sludge, it was found that a methane cofeedstock is unnecessary. The coal and sludge can be used without drying. In Table III-3, the allowable maximum feed ratio of sludge to the as-received coal is $4: 1$ for Cycle 1 and 1.7 for Cycle 2. It shows that Cycle I has a much higher treatment ability for sludge.

Sludge with Wrodak Coal:

Wyodak coal can also be used as a co-feedstock with sludge. The results in Table III-3 show that as-received Wyodak coal can not make up the heat balance in the HPR and it has to be dried down to 5 wt\% moisture. However, as-received sludge can be used in both cycles. For Cycle 1, the maximum allowable co-feeding rate of sludge is $120 \mathrm{wt} \%$. In Cycle 2, only 90 wt\% sludge can be fed together with Wyodak coal of 5 wt\% moisture content.

\section{PRESSURE AND TEMPERATURE EFFECTS}

The effects of pressure and temperature on process efficiency and product distribution were investigated for the Alaska Beluga coal. Table III-4 summarizes the calculated results. The following trends can be found from the Table:

(i) The minimum required methane feed per unit of biomass increases with a decrease in system pressure.

(ii) The maximum allowable moisture in the coal decreases with a decrease in system pressure.

(iii) The product distribution of methanol vs. carbon decreases with a decrease in system pressure.

(iv) Higher temperatures in the HPR and MPR promoce higher methanol production and higher thermal efficiency. 
These trends, of course, are limited by the thermal and structural properties of the materials of construction used. Taking these factors into account leads to recommending the operating conditions of $50 \mathrm{~atm}$ and $900 \mathrm{C}$ for the HPR and $1000 \mathrm{C}$ for the MPR. 


\section{CONCLUSION}

(1) Cycle 1 usually provides a higher process efficiency and more methanol production than Cycle 2. Thus, Cycle 1 is recommended for most cases.

(2) Burning residual char for heating up the MPR increases the thermal efficiency of the process by about 4 to $5 \%$ compared to that of the process without buming residual char.

(3) Beluga coal can be fed with natural gas without drying. However it has to be dried when used alone, and the maximum allowable moisture content is $11 \mathrm{wt} \%$.

(4) Kentucky coal ( $8.6 \%$ moisture) can be processed without drying, in which case additional water may be co-fed to improve thermal efficiency and methanol and carbon product distribution.

(5) North Dakota coal and Wyodak coal, which have over $26 \%$ moisture, have to be dried before being used as a single solid feedstock.

(6) As-received (AR) biomass (wood) together with 15 wt\% of methane produces a 2.6:1 weight ratio of product methanol to carbon black. The thermal efficiency is about $75 \%$.

(7) Sludge can be processed together with woody biomass or coal. The maximum feed ratio of sludge to wood is 0.7 if both sludge and wood are dried to 5 wt\% moisture, and the feed ratios of methane and digester gas are 0.15 and 0.35 , respectively. The thermal effeciency in this case is $76 \%$. The methanol product ratio to carbon black is 2.19 .

(8) $\mathrm{CO}_{2}$ in the digester gas can be converted to $\mathrm{CO}$ in the hydrogasifier (HPR), which is turther converted to carbon and methanol in the methane pyrolyzer (MPR) and the methanol converter. The ability of converting $\mathrm{CO}_{2}$, which causes global greenhouse problems, to the useful clean fuels, methanol and carbon black, is an attractive feature of the Hydrocarb Process, especially if biomass is used as co-feedstock.

(9) Reference ${ }^{(I I I-5)}$ discussed the feedstock's effects on the material balance of the Hydrocarb Process. This study showed that there is a need to systematically investigate the effects of feedstock composition based on both material and energy balances to determine the allowable operational zone in the thermodynamic equilibrium ternary system, C-H-O.

III-14 


\section{REFERENCES}

III-1. Steinberg, M., Grohse, E. W. and Tung, Y.: "An Analysis of the Hydrocarb Process for Co-Processing Fossil Fuel (Natural Gas) with Biomass (Wood)," EPA Contract No.DW-89934598-0, EPA-600/7-91-007 November 1991

III-2. Steinberg, M.: "Biomass and Hydrocarb Technology for Removal of Atmospheric CO," BNL 44410, Brookhaven National Laboratory, Upton, NY, February 1991

III-3. Borgwardt, R.H., Steinberg, M., Grohse, E.W. and Tung, Y.: "Biomass and Fossil Fuel to Methanol and Carbon via the Hydrocarb Process," presented at the Conference on Energy from Biomass and Wastes, Washington, DC, March 27, 1991

III-4. "Demonstration of Methanol Production Using the Hydrocarb Process with Biomass Feedstock," Acurex proposal to EPA and SCAQMD, January 1990

III-5. Tung. Y.: "Effects of Feedstock Composition on Material Baiance of the HYDROCARB Process," Internal Progress Report, Hydrocarb Corporation, June 1991 
TABLE III-I. BASIC DATA FOR THE FEEDSTOCKS USED IN THE.STUDY

\begin{tabular}{|c|c|c|c|c|c|c|}
\hline Feedstock & $\begin{array}{l}\text { Biomass } \\
\text { Wood }\end{array}$ & $\begin{array}{c}\text { Kentucky } \\
\text { Coal }\end{array}$ & $\begin{array}{l}\text { N. Dakota } \\
\text { Coal }\end{array}$ & $\begin{array}{l}\text { Wyodak } \\
\text { Coal }\end{array}$ & $\begin{array}{l}\text { Beluga } \\
\text { Coal }\end{array}$ & $\begin{array}{l}\text { Sewag } \\
\text { sludg }\end{array}$ \\
\hline \multicolumn{7}{|c|}{$\begin{array}{c}\text { Composition } \\
\text { (wt } f \text { ) }\end{array}$} \\
\hline $\begin{array}{r}\mathrm{C} \\
\mathrm{H} \\
\mathrm{O} \\
\mathrm{H}_{2} \mathrm{O} \\
\mathrm{Ash} \\
\mathbf{S} \\
\mathrm{N}\end{array}$ & $\begin{array}{r}45.86 \\
5.27 \\
36.07 \\
11.67 \\
0.66 \\
0.04 \\
0.43\end{array}$ & $\begin{array}{c}67.02 \\
4.54 \\
7.22 \\
8.60 \\
8.34 \\
2.85 \\
1.43\end{array}$ & $\begin{array}{r}43.37 \\
2.78 \\
13.97 \\
30.10 \\
8.30 \\
0.81 \\
0.67\end{array}$ & $\begin{array}{c}49.95 \\
3.51 \\
12.58 \\
26.40 \\
6.03 \\
0.60 \\
0.93\end{array}$ & $\begin{array}{c}49.33 \\
4.00 \\
15.56 \\
21.78 \\
8.67 \\
0.12 \\
0.54\end{array}$ & $\begin{array}{r}28.55 \\
4.09 \\
16.03 \\
9.82 \\
36.53 \\
1.36 \\
3.62\end{array}$ \\
\hline
\end{tabular}

Heating Value

(Higher)

(BTU/ 1 b-MF)

(kcal/ kg-MF)

$-8800.0-13650$

$\begin{array}{llll}-10254 & -11730 & -11082 & -5510\end{array}$

$\begin{array}{lllll}-7583.3 & -5696.7 & -6516.7 & -6156.7 & -3061.1\end{array}$

Heat of

Formation

$\begin{array}{lllllll}(\mathrm{kcal} / \mathrm{kg}-\mathrm{MAF}) & -1214.4 & 183.0 & -593.0 & -461.7 & -584.9 & -1769.7\end{array}$

Heat Capacity

(kcal/kgMF/C)
0.570
0.315

0.315

0.315

0.315

0.250

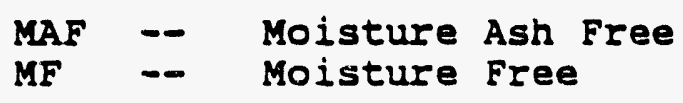

Coal Rank: Kentucky coal - bituminous

N. Dakota coal - lignite

Wyodak coal - sub-bituminous

Beiuga coal - sub-bituminous 
TABLE III-2 RESULTS WITH SINGLE SOLID FEEDSTOCK.

( $p=50 \mathrm{~atm} / \mathrm{HPR}=900 \mathrm{C} / \mathrm{MPR}=1000 \mathrm{C}$ )

\begin{tabular}{|c|c|c|c|c|c|c|c|c|}
\hline CYC & $\begin{array}{c}\text { Feedstocks } \\
t / d\end{array}$ & comb. & $\begin{array}{r}\text { Carb } \\
t / d\end{array}$ & $\begin{array}{r}\text { MeOH } \\
t / d\end{array}$ & PR & $\underset{t}{C e f f}$ & $\underset{t}{\text { Teft }}$ & $\begin{array}{c}\text { GCR } \\
\mathrm{kmol} / \mathrm{h}\end{array}$ \\
\hline $\begin{array}{l}1 \\
1 \\
1 \\
1 \\
2 \\
2 \\
2 \\
2 \\
1 \\
1 \\
1 \\
1 \\
2 \\
2 \\
2 \\
2 \\
1 \\
1 \\
2 \\
2 \\
1 \\
1 \\
2 \\
2 \\
2 \\
2 \\
1 \\
1 \\
2 \\
2\end{array}$ & $\begin{array}{l}11 B 100 * \\
11 B 100 \\
\text { AB100+G5 } \\
\text { AB100+G5 } \\
\text { AB100 } \\
\text { AB100 } \\
\text { AB100+H11 } \\
\text { AB100+H11 } \\
\text { AK100 } \\
\text { AK1100 } \\
\text { AK100+H29 } \\
\text { AR100+H29 } \\
\text { AK100 } \\
\text { AK100 } \\
\text { AK100+H67 } \\
\text { AK100+H67 } \\
5 N 100+G 2 \\
5 N 100+G 2 \\
15 N 100 \\
15 N 100 \\
13 Y 100 \\
13 Y 100 \\
\text { AY100 } \\
\text { AY100 } \\
\text { AY100+H7 } \\
\text { AY100+H7 } \\
\text { AW100+G15 } \\
\text { AW100+G15 } \\
\text { AW100+G6 } \\
\text { AW100+G6 }\end{array}$ & $\begin{array}{l}\text { TG11 } \\
\text { CTG8 } \\
\text { TG12 } \\
\text { CTG9 } \\
\text { TG11 } \\
\text { CTG8 } \\
\text { TG15 } \\
\text { CTG12 } \\
\text { CTK2 } \\
\text { TG5 } \\
\text { CTK22 } \\
\text { TG15 } \\
\text { CT } \\
\text { TG1 } \\
\text { CTK37 } \\
\text { TG23 } \\
\text { CTN23 } \\
\text { TG9 } \\
\text { CTN28 } \\
\text { TG11 } \\
\text { CTY22 } \\
\text { TG11 } \\
\text { CTY26 } \\
\text { TG12 } \\
\text { CTY33 } \\
\text { TG15 } \\
\text { CTH33 } \\
\text { TG14 } \\
\text { CTW39 } \\
\text { TG15 }\end{array}$ & $\begin{array}{l}32.3 \\
32.3 \\
29.3 \\
29.3 \\
34.5 \\
34.5 \\
32.3 \\
32.3 \\
50.7 \\
50.7 \\
38.9 \\
38.9 \\
52.1 \\
52.1 \\
38.8 \\
38.8 \\
32.1 \\
32.1 \\
33.0 \\
33.0 \\
33.8 \\
33.8 \\
35.0 \\
35.0 \\
33.6 \\
33.6 \\
26.4 \\
26.4 \\
32.9 \\
32.9\end{array}$ & $\begin{array}{l}32.4 \\
32.4 \\
49.6 \\
49.6 \\
23.5 \\
23.5 \\
32.4 \\
32.4 \\
16.8 \\
16.8 \\
56.9 \\
56.9 \\
7.7 \\
7.7 \\
57.3 \\
57.3 \\
22.0 \\
22.0 \\
16.2 \\
16.2 \\
29.4 \\
29.4 \\
24.4 \\
24.4 \\
30.0 \\
30.0 \\
69.0 \\
69.0 \\
33.6 \\
33.6\end{array}$ & $\begin{array}{l}1.0 \\
1.0 \\
1.7 \\
1.7 \\
.68 \\
.68 \\
1.0 \\
1.0 \\
.33 \\
.33 \\
1.5 \\
1.5 \\
.15 \\
.15 \\
1.5 \\
1.5 \\
.68 \\
.68 \\
.49 \\
.49 \\
.87 \\
.87 \\
.70 \\
.70 \\
.89 \\
.89 \\
2.6 \\
2.6 \\
1.0 \\
1.0\end{array}$ & $\begin{array}{l}77.1 \\
80.2 \\
77.3 \\
80.2 \\
74.9 \\
77.8 \\
73.0 \\
75.7 \\
83.1 \\
80.3 \\
74.0 \\
76.8 \\
83.9 \\
80.8 \\
65.7 \\
71.4 \\
73.9 \\
77.8 \\
70.3 \\
75.6 \\
73.8 \\
77.3 \\
70.2 \\
74.6 \\
67.5 \\
73.4 \\
72.2 \\
77.7 \\
66.7 \\
73.5\end{array}$ & $\begin{array}{l}68.2 \\
72.7 \\
70.7 \\
74.8 \\
62.9 \\
67.0 \\
62.4 \\
66.2 \\
68.8 \\
64.0 \\
72.8 \\
68.5 \\
73.4 \\
63.2 \\
64.7 \\
61.3 \\
72.1 \\
67.6 \\
67.8 \\
63.6 \\
72.8 \\
68.2 \\
67.3 \\
63.2 \\
66.8 \\
62.9 \\
74.9 \\
71.6 \\
64.7 \\
61.4\end{array}$ & $\begin{array}{l}1897 \\
1897 \\
2007 \\
2007 \\
1769 \\
1769 \\
1941 \\
1941 \\
2477 \\
2477 \\
2541 \\
2541 \\
2145 \\
2145 \\
2872 \\
2872 \\
1745 \\
1745 \\
1546 \\
1546 \\
1925 \\
1925 \\
1813 \\
1813 \\
1919 \\
1919 \\
2167 \\
2167 \\
1997 \\
1997\end{array}$ \\
\hline
\end{tabular}

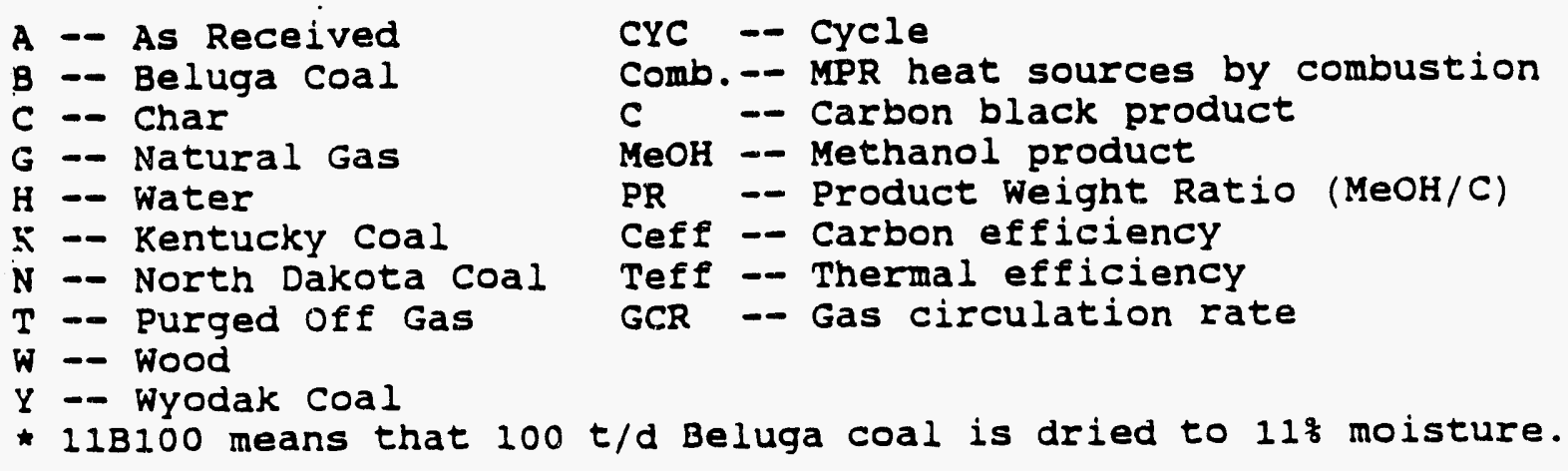


TABLE III-3 RESULTS OF HYDROCARB PROCESS WITH MULTIPLE FEEDSTOCKS. $(p=50 \mathrm{~atm} / \mathrm{HPR}=900 \mathrm{C} / \mathrm{MPR}=1000 \mathrm{C})$

\begin{tabular}{ll} 
CYC & \multicolumn{1}{c}{$\begin{array}{c}\text { Feedstocks } \\
\text { tons/daY }\end{array}$} \\
\hline 1 & $5 W 100+5 S 70+G 15+D 35 *$ \\
1 & $5 W 100+5 S 70+G 15+D 35$ \\
1 & $1 W 100+5 S 80+G 15+D 40$ \\
1 & $1 W 100+5 S 80+G 15+D 40$ \\
2 & AW100+AS50+G15+D25 \\
2 & AW100+AS50+G15+D25 \\
2 & $5 W 100+A S 90+G 15+D 45$ \\
2 & $5 W 100+A S 90+G 15+D 45$ \\
1 & AK100+AS400+D200 \\
1 & AR100+AS400+D200 \\
2 & AK100+AS170+D85 \\
2 & AR100+AS170+D85 \\
1 & $5 Y 100+A S 120+D 60$ \\
1 & $5 Y 100+A S 120+D 60$ \\
2 & $5 Y 100+A S 90+D 45$ \\
2 & $5 Y 100+A S 90+D 45$
\end{tabular}

Comb. C MeOH PR Ceff Teff GCR

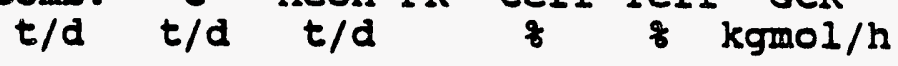

$\begin{array}{lllllll}\text { TG20 } & 46.6 & 102 & 2.2 & 78.9 & 72.9 & 3520 \\ \text { CTW49 } & 46.6 & 102 & 2.2 & 73.7 & 76.0 & 3520 \\ \text { TG20 } & 50.7 & 102 & 2.0 & 79.3 & 72.8 & 3697 \\ \text { CTW47 } & 50.7 & 102 & 2.0 & 74.5 & 76.0 & 3697 \\ \text { TG10 } & 51.2 & 47.3 & .92 & 76.6 & 64.2 & 2936 \\ \text { CTW20 } & 51.2 & 47.3 & .92 & 75.3 & 67.3 & 2936 \\ \text { TG11 } & 65.4 & 55.0 & .84 & 77.4 & 65.0 & 3605 \\ \text { CTW21 } & 65.4 & 55.0 & .84 & 76.4 & 68.0 & 3605 \\ \text { TG65 } & 140 & 297 & 2.1 & 78.8 & 74.4 & 10488 \\ \text { CTD149 } & 140 & 297 & 2.1 & 80.8 & 77.4 & 10488 \\ \text { TG15 } & 107 & 60.3 & .57 & 78.7 & 65.6 & 5154 \\ \text { CTG21 } & 107 & 60.3 & .57 & 81.2 & 69.2 & 5154 \\ \text { TG26 } & 63.7 & 103 & 1.6 & 78.5 & 72.9 & 4304 \\ \text { CTD58 } & 63.7 & 103 & 1.6 & 80.8 & 76.4 & 4304 \\ \text { TG13 } & 68.2 & 37.3 & .55 & 78.1 & 65.9 & 3271 \\ \text { CTD23 } & 68.2 & 37.3 & .55 & 80.7 & 69.6 & 3271\end{array}$

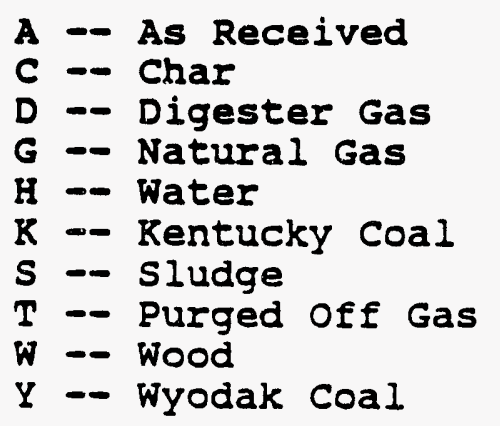

CYC -- Cycle

Comb. -- MPR heat sources by combustion

C -- Carbon black product

MeOH -- Methanol product

PR -- Product Ratio ( $\mathrm{MeOH} / \mathrm{C}$ )

Ceff -- Carbon efficiency

Teff -- Thermal efficiency

GCR -- Gas circulation rate

* 5W100+5S70+G15+D35 means that the feedstocks consist of $100 \mathrm{t} / \mathrm{d}$ wood which is dried to $5 \%$ moisture, $70 \mathrm{t} / \mathrm{d}$ sludge which is also dried to $5 \%$ moisture, $15 \mathrm{t} / \mathrm{d}$ methane and $35 \mathrm{t} / \mathrm{d}$ digester gas. 
TABLE III-4 EFFECTS OF PRESSURE AND TEMPERATURE ON PROCESS EFFICIENCY AND PRODUCT DISTRIBUTION.

(100 $\mathrm{t} /$ day of Beluga coal)

\begin{tabular}{|c|c|c|c|c|c|c|c|}
\hline CYC & $\begin{array}{l}P \\
\text { atm }\end{array}$ & $\begin{array}{c}T(H P R / M P R) \\
C\end{array}$ & $\underset{8}{\text { Moist }}$ & $\mathrm{CH} 4 / \mathrm{Coal}$ & MeOH/C & $\operatorname{Ceff}_{t}$ & $\underset{q}{\text { Teff }}$ \\
\hline $\begin{array}{l}1 \\
1 \\
1 \\
2 \\
2\end{array}$ & $\begin{array}{l}50 \\
50 \\
50 \\
50 \\
50\end{array}$ & $\begin{array}{l}900 / 1000 \\
900 / 1000 \\
800 / 900 \\
900 / 1000 \\
800 / 900\end{array}$ & $\begin{array}{l}21.78 \\
11 \\
21.78 \\
21.78 \\
21.78\end{array}$ & $\begin{array}{l}.05 \\
0 \\
.05 \\
0 \\
0\end{array}$ & $\begin{array}{l}1.67 \\
1 \\
0.59 \\
0.67 \\
0.09\end{array}$ & $\begin{array}{l}77.3 \\
77.1 \\
78.7 \\
74.9 \\
77.5\end{array}$ & $\begin{array}{l}70.7 \\
68.2 \\
66.0 \\
62.8 \\
61.2\end{array}$ \\
\hline $\begin{array}{l}1 \\
1 \\
1 \\
2 \\
2 \\
2\end{array}$ & $\begin{array}{l}35 \\
35 \\
35 \\
35 \\
35 \\
35\end{array}$ & $\begin{array}{l}800 / 900 \\
800 / 900 \\
800 / 900 \\
800 / 900 \\
800 / 900 \\
800 / 900\end{array}$ & $\begin{array}{c}21.78 \\
5 \\
5 \\
5 \\
21.78 \\
5\end{array}$ & $\begin{array}{l}.05 \\
.05 \\
.1 \\
.05 \\
.05 \\
.1\end{array}$ & $\begin{array}{l}0.71 \\
0.29 \\
0.26 \\
0.04 \\
0.06 \\
0.04\end{array}$ & $\begin{array}{l}70.8 \\
76.8 \\
78.9 \\
78.9 \\
75.4 \\
80.2\end{array}$ & $\begin{array}{l}56.8 \\
60.1 \\
60.9 \\
61.2 \\
56.8 \\
72.3\end{array}$ \\
\hline $\begin{array}{l}1 \\
2 \\
2 \\
2\end{array}$ & $\begin{array}{l}30 \\
30 \\
30 \\
30\end{array}$ & $\begin{array}{l}800 / 900 \\
800 / 900 \\
800 / 900 \\
800 / 900\end{array}$ & $\begin{array}{c}5 \\
5 \\
5 \\
21.78\end{array}$ & $\begin{array}{l}.15 \\
.1 \\
.15 \\
.15\end{array}$ & $\begin{array}{l}0.24 \\
0.03 \\
0.03 \\
0.05\end{array}$ & $\begin{array}{l}80.3 \\
80.2 \\
81.3 \\
78.2\end{array}$ & $\begin{array}{l}68.4 \\
71.4 \\
81.9 \\
71.0\end{array}$ \\
\hline
\end{tabular}

III- 19 
CYCLE 1

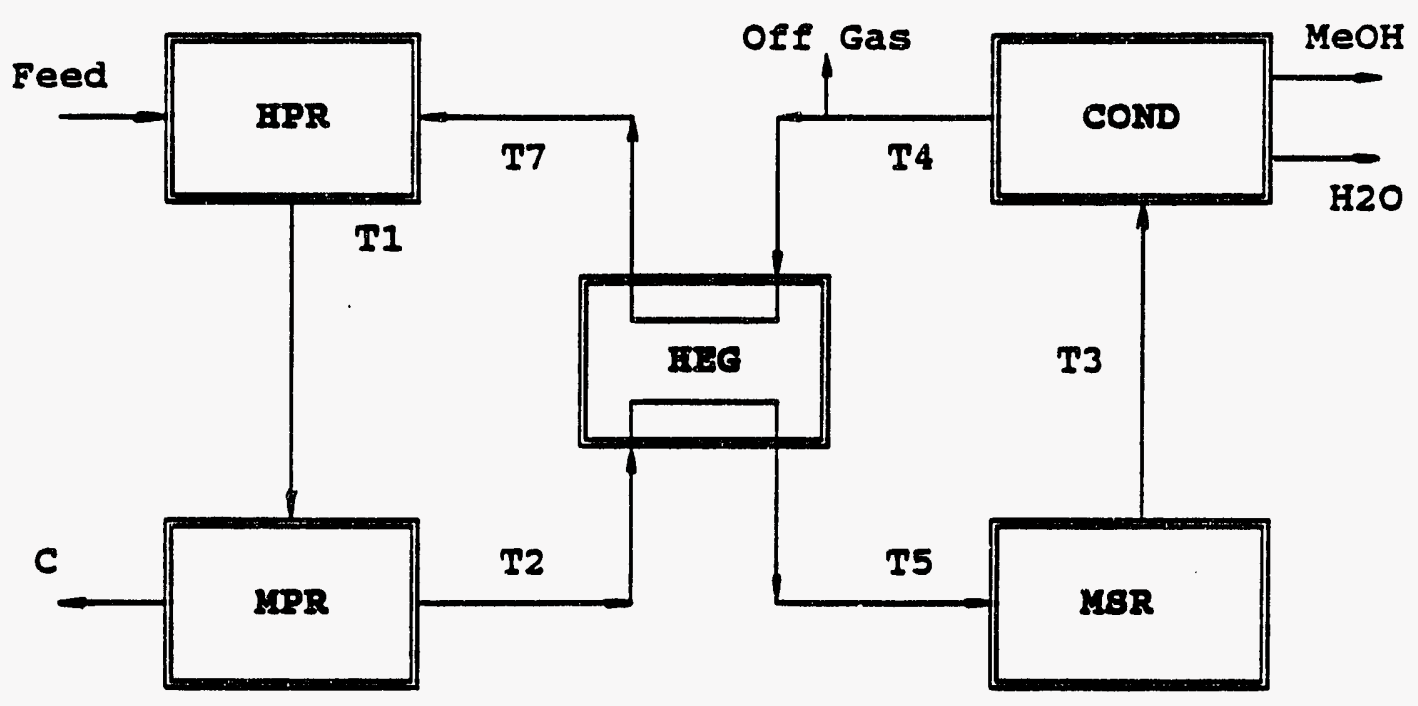

CYCLE 2

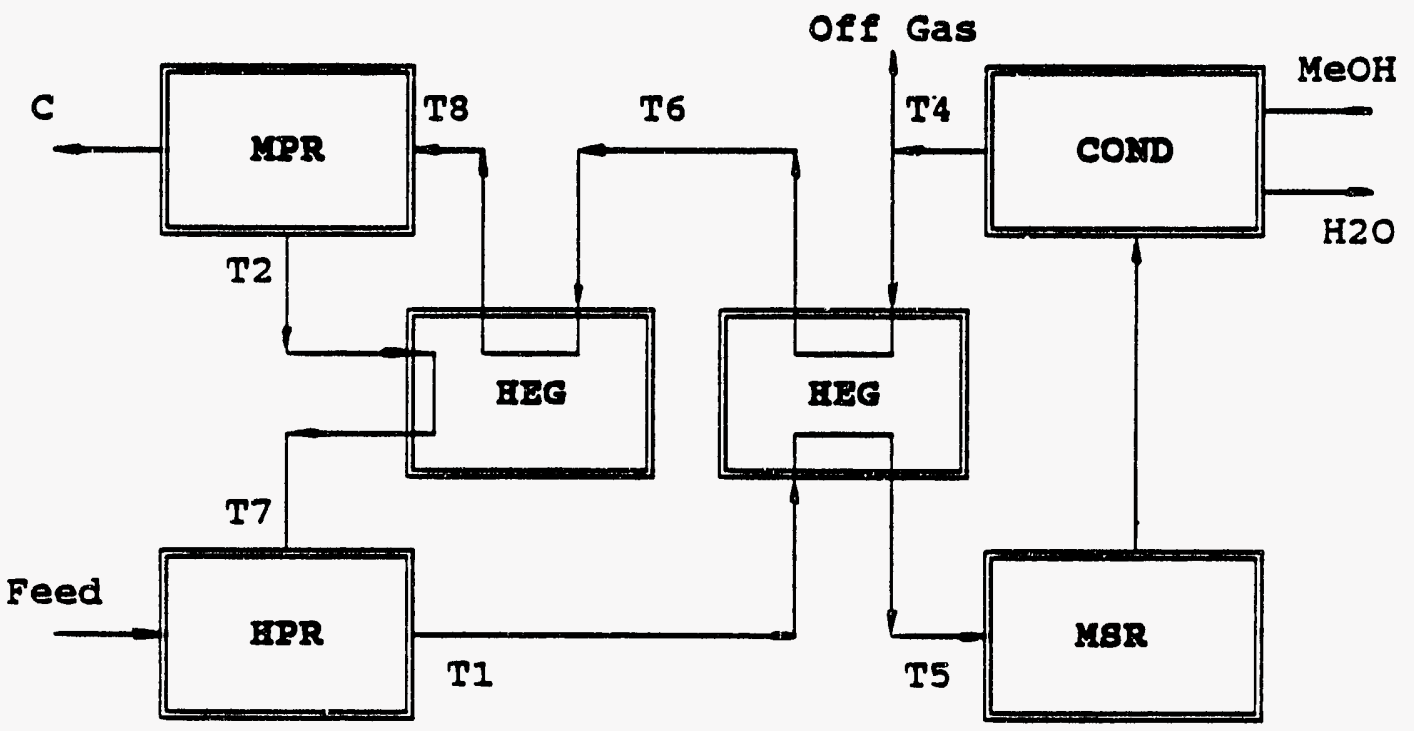

Figure III-1. Brief illustration of Cycle 1 and Cycle 2.

III-20 


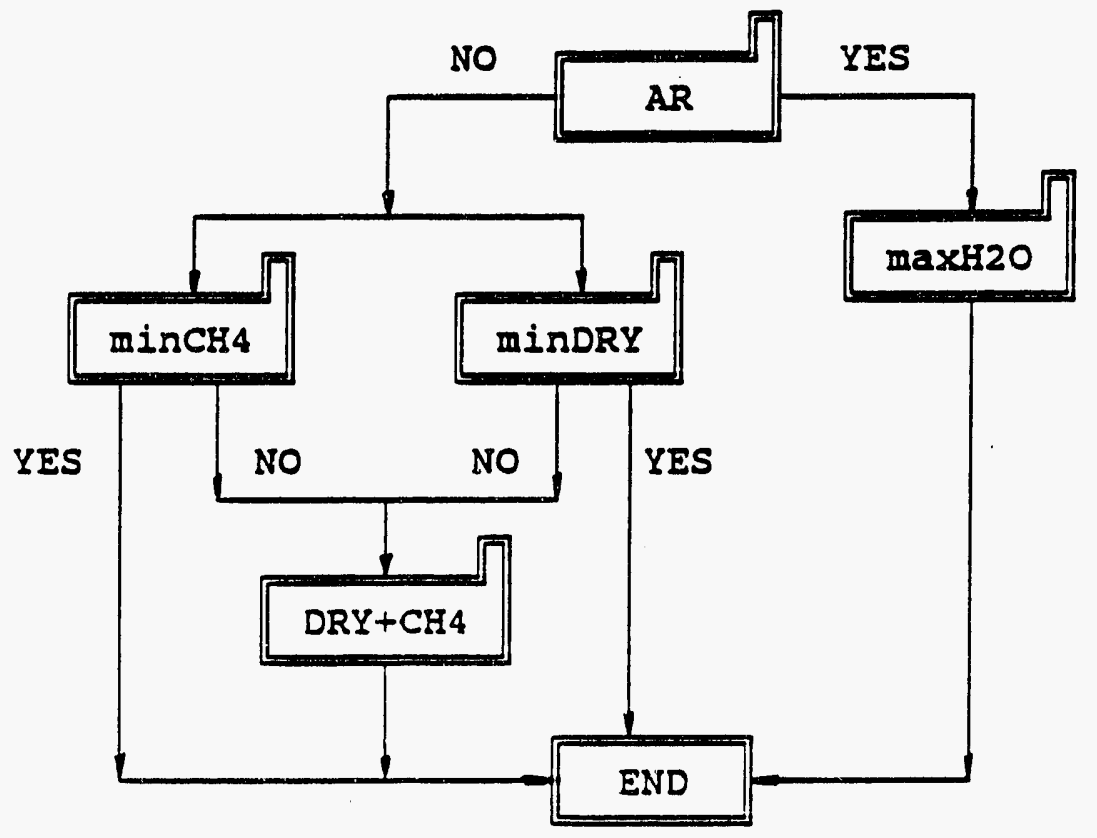

Figure III-2. Strategy of computer calculation for a single solid feestock. 
HYDROCARB PROCESB (CYCLE 1)

(BIOmass + NG)

$(P=50 \mathrm{~atm})$

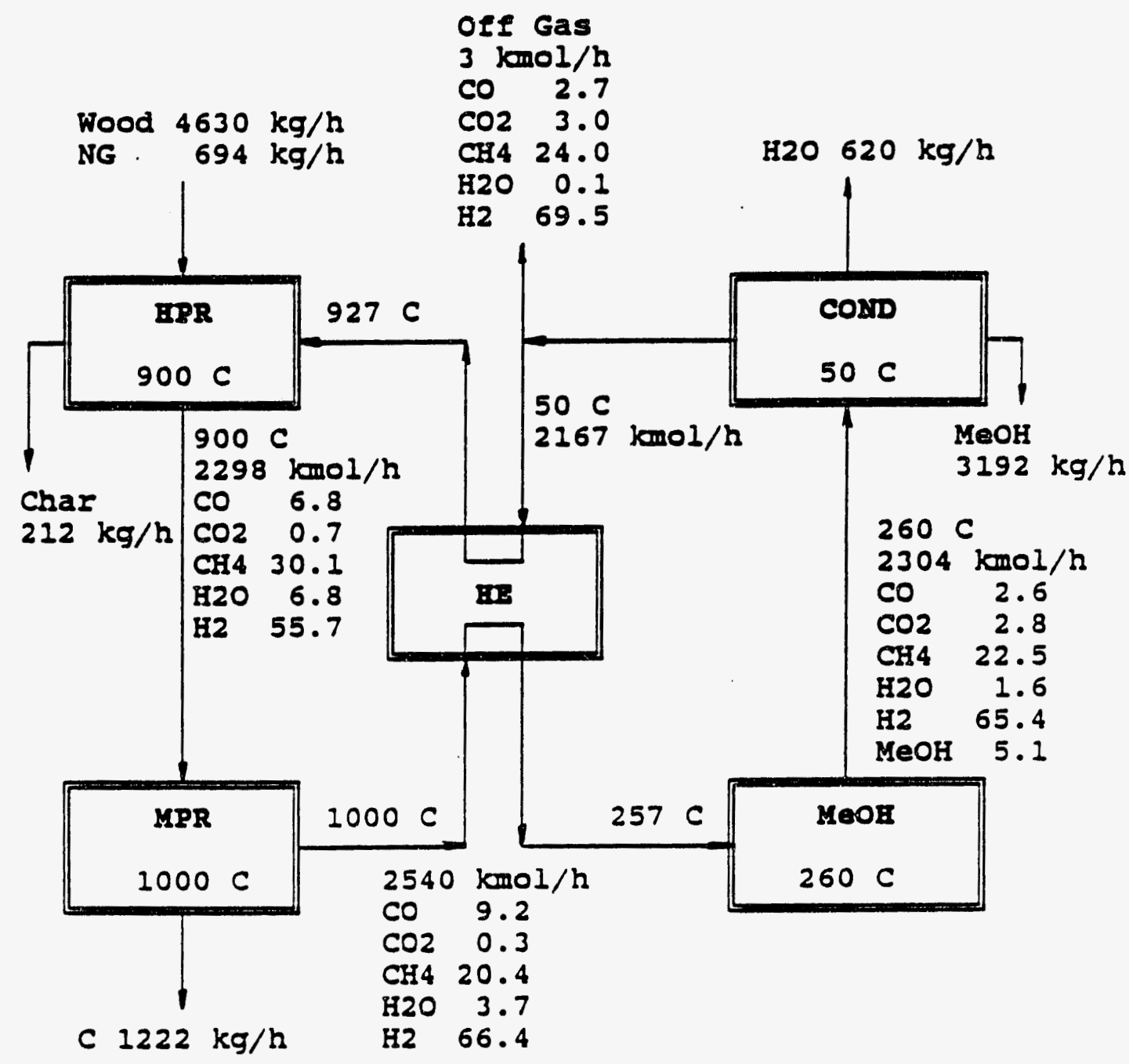

Carbon Conversion of Feedstock in HPR: $90 \%$

Carbon Efficiency: $72.2 \%$

Thermal Efficiency: $74.9 \%$

Figure III-3. Data summary with wood and $\mathrm{CH}_{4}$ as feedstocks.

III-22 

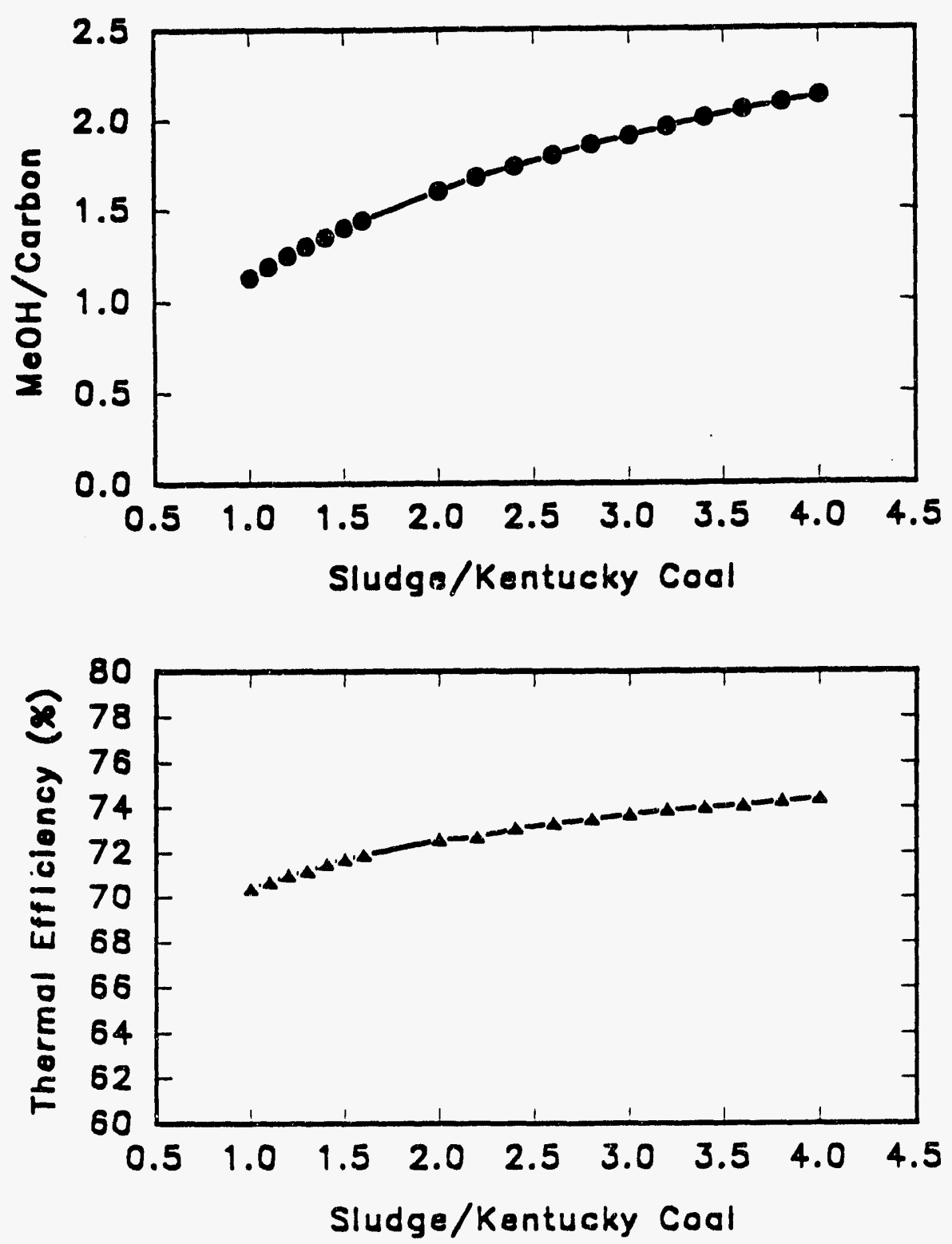

Figure IIl-4. Plot of Methanol Production and Thermal Efficiency vs. Sludge Feed Rate. 


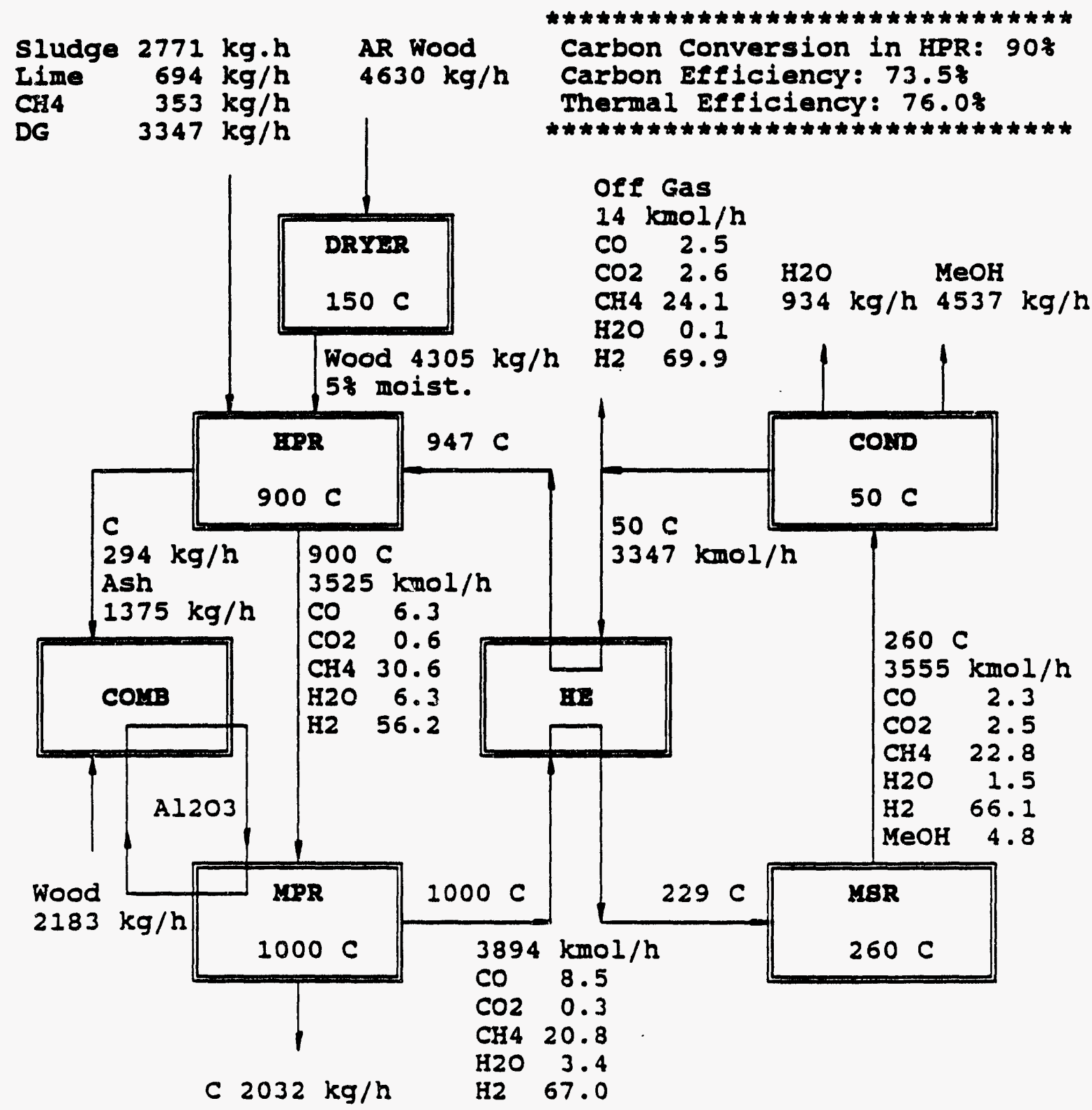

Figure III-5. Data summary with wood, sludge, $\mathrm{CH}_{\downarrow}$, and digester gas as feedstocks. 
Appendix III-1 Computer Printout with Wood and $\mathrm{CH}_{4}$ as Feedstocks.

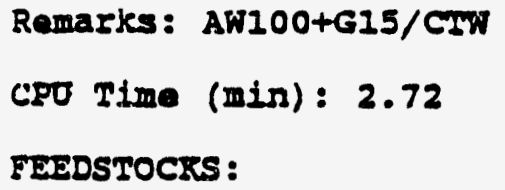

No. 1 Name: Hood PROCESS CAPACITY (AR tons/Cd): 100 AR COLPOSIIION (wtt):

C: 45.86

H: 5.27

$0: 36.07$

H20: 11.67

ASE: .66

S: 04

OTHINR: .43

HEATING VALUE ( $\mathrm{kCal} / \mathrm{kg}-\mathrm{MF}):-4888.9$

HTAT OF FORMATION ( $\mathrm{kCal} / \mathrm{kg}-\mathrm{MAF}$ ): -1214.4

HEAT CAPACITY (kCal/'C*MAFkg): .57

MOISTURE AFIIER DRYING (Wt : 11.67

OTHER INPOT: CA4 into HPR (tons/Cd): 15

$(\mathrm{kg} / \mathrm{kg}-\mathrm{ARfead} \# 1): .15$

Digester Gas into HPR (tons/Cd): 0

H2O is to HPR (tors/cd): 0 $(\mathrm{kg} / \mathrm{kg}-A R E$ eed $\# 1): 0$

LIMESTONE (tons/Cd): .3565728

FOR COMBUSTION (tons/cd) :

Wood: 33.38297

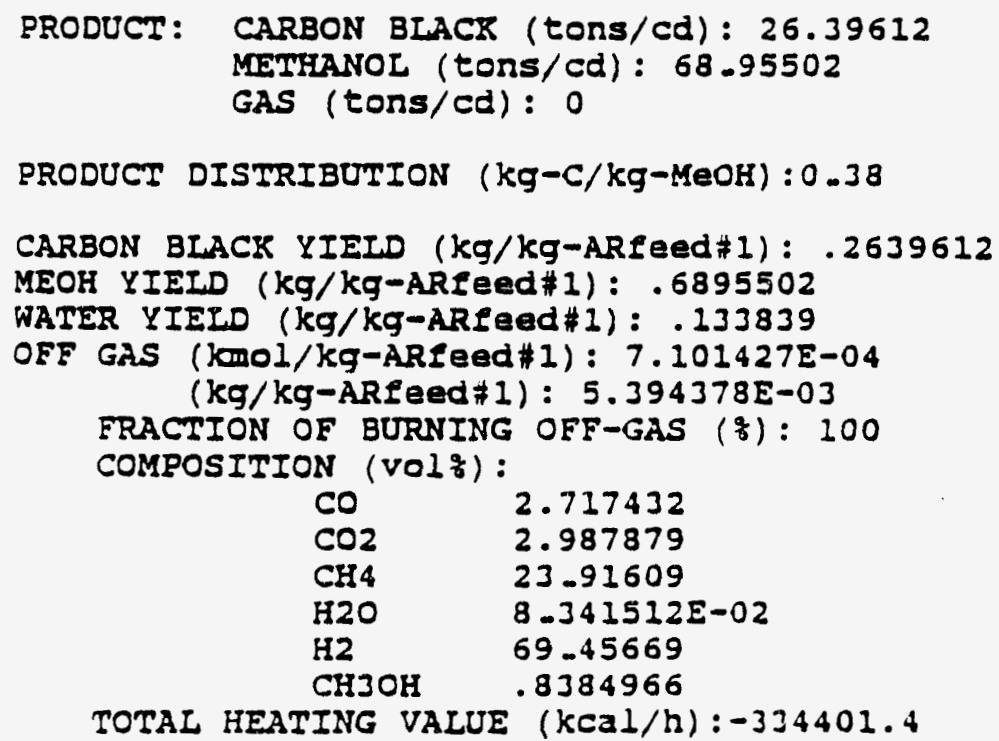


Appendix III-1 Computer Printout with Wood and $\mathrm{CH}_{4}$ as Feedstocks. (cont'd)

CONVERSION OF CARBON IN FEEDSTOCX FOR HPR ( $(3): 90$

CARBON EFFICIENCY (7): 72.16

THORLAL EFFICIENCY $(7): 74.89$

BALANCE CRECK:

C IN 202.3981

B IN 475.2008

O IN 134.358

C OOT 202.3903
B OOT 475.1611
0 OOT 134.3459

ONIT I\# HYDROGASIFIER (BPR)

(I) OPERATING CONDITIONS, Pressura (atm): 50

Temperature $\left({ }^{\prime} \mathrm{C}\right): 900$

(II) INPOT:

(1) Feadstocks:

(1) Name: Wood

Rate $(\mathrm{kg} / \mathrm{h}): 4629.63$

Somposition C? we: 45.86

H* wt: 5.27

Of wt: 36.07

H20\% wt: 11.67

Asht wt: .66

St wt: .04

Enthalpy (kcal/h): -6977758

remperature ('C): 25

(2) CH4 Feed Rate $(\mathrm{kg} / \mathrm{h}): 694.4445$

Enthalpy (kcal/h): -774179.9

remperature ('C): 25

(3) Digestar Gas

Feed Rate $(\mathrm{kg} / \mathrm{h}): 0$

Enthalpy (kcal/h): 0

Temperature ('C): 25

(4) Additional Water

Fead Rate $(\mathrm{kg} / \mathrm{h}): 0$

Enthalpy $(\mathrm{kcal} / \mathrm{h}): 0$

Temperature ('C): 100

(5) Limestone

Feed Rata $(\mathrm{kg} / \mathrm{h}): 16.508$

Content: CaCO3t wt: 70

Enthalpy $(\mathrm{kcal} / \mathrm{h}):-33302.16$

Temperature ('C): 25

(6) Gas Stream $\langle F\rangle$

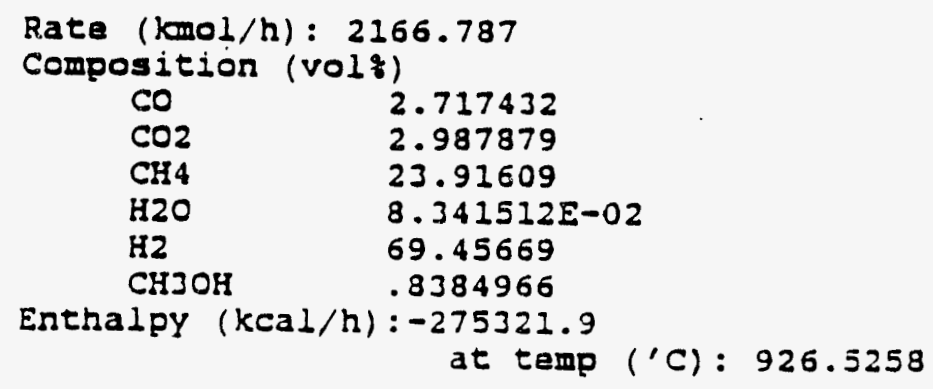

$\mathrm{CO} 2$

$\mathrm{CH} 4$

H2O

H2

$\mathrm{CH} 3 \mathrm{OH}$

2.717432

2.987879

23.91609

$8.341512 E-02$

.8384966

Enthalpy $(\mathrm{kcal} / \mathrm{h}):-275321.9$

at temp $(' C): 926.5258$

(III) OUTPUT: 
Appendix III-1 Computer Printout with Wood and $\mathrm{CH}_{4}$ as Feedstocks. (cont'd)

(1)Ash Discharge Rate (kg/h): 44.046702

Entbalpy (kcal/h): -7573.43

at tamp ('C): 900

(2).Gas Stream <G>

Flow Rata (kmol/h): 2297.939

Composition (vols)

Co $\quad 6.810789$

$\mathrm{CO2} \quad .6568884$

C84 30.06123

H2O 6.788135

H2 $\quad 55.68296$

CH3OH 0

Enthalpy (kcal/h): -8119087

at temp ('C): 900

(3) Residue Carbon Rate $(\mathrm{kg} / \mathrm{h}): 212.3149$

Entbalpy (keal/h): 66082.81

Heating value (kCal/h): -1662664

(IV) HEAT LOAD (kcal/h): -16.22302

(V) VALUE OF $(\mathrm{H} / \mathrm{O}): 16.44135$

(VI) BALANCE CEICX:

IN C: 862.399

IN H: 5634.289

OOT C: 862.3912

OUT H: 5634.249

IN $0: 342.6967$ OUT $0: 342.6847$

UNIT 2\# METHANE PYROLYZER (MPR)

(I) OPERATING CONDITION, Pressure (atm): 50

Temperature ('C): 1000

(II) INPUT:

(1) Gas Stream <G>

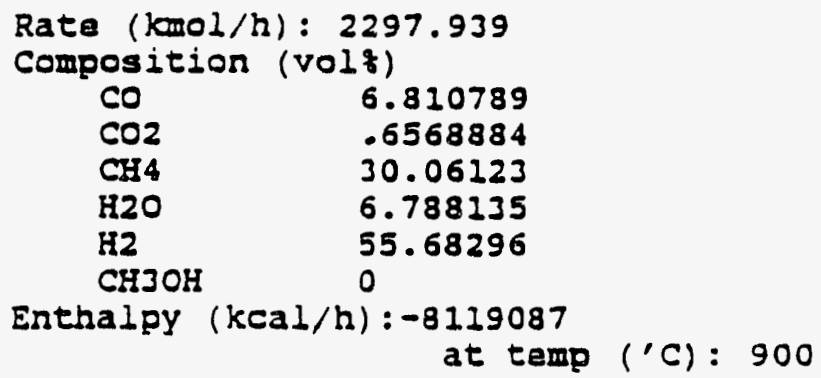

(2)Alumina Rate $(\mathrm{kg} / \mathrm{h}): 63042.24$

Temperature ('C): 1400

(III) OUTPUT

(1) Gas Stream <H> Rate (kmol/h): 2539.77

Composition (vol\%)

$\begin{array}{ll}\mathrm{CO} & 9.204524 \\ \mathrm{CO} 2 & .3098129 \\ \mathrm{CH} 4 & 20.4348 \\ \mathrm{H} 2 \mathrm{O} & 3.668596 \\ \mathrm{H} 2 & 66.38226 \\ \mathrm{CH} 3 \mathrm{OH} & 0\end{array}$

III-27 
Appendix III-1 Computer Printout with Wood and $\mathrm{CH}_{4}$ as Feedstocks. (cont'd)

Enthalpy (kcal/h) : 116196.7

ta temp ('C): 1000

(2) Carbon Black <M> Discharge Rate (kg/h): 1222.042

$(\mathrm{kmol} / \mathrm{h}) ; 101.7521$

Enthalpy $(\mathrm{kcal} / \mathrm{h}): 435849.1$

at tamp ('C): 1000

(3)Alumina Rate $(\mathrm{kg} / \mathrm{h}): 63042.24$

Temperature ('C): 1000

(IV) HEAT LOAD (kcal/h): .2649658

(V) VALUE OF $(\mathrm{H} / \mathrm{O}): 16.44135$

(VI) BALANCE CEECR:

IN C: 862.3912

IN H: 5634.249

IN $0: 342.6847$

OOT C: 862.3912

OOT B: 5634.249

OOT $0: 342.6847$

UNIT 3\# METHANOL CONVERTER

(I) OPERATING CONDITION,

Pressure (atm): 50

Temperature ('C): 260

(II) INPUT:

(1) Gas Stream <H>

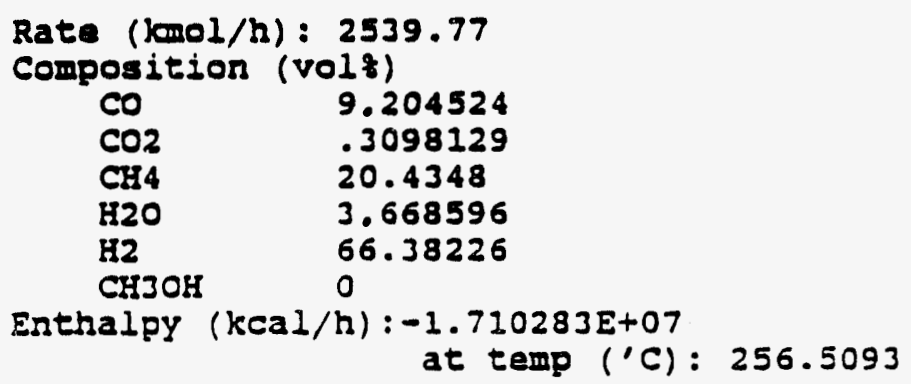

co

$\mathrm{CO} 2$

CH4

H2O

$\mathrm{H2}$

Cस3OH

Enthalpy $(\mathrm{kcal} / \mathrm{h}):-1.710283 E+07$

9.204524

.3098129

20.4348

3.668596

66.38226

at temp ('C): 256.5093

(III) OUTPUT:

(1) Gas stream <S>

$\begin{array}{cc}\text { Rata }(\mathrm{kmol} / \mathrm{h}): & 2304.104 \\ \text { Composition } & (\mathrm{vOl}) \mathrm{l}) \\ \text { CO } & 2.559359 \\ \mathrm{CO} 2 & 2.814074 \\ \mathrm{CH4} & 22.52489 \\ \mathrm{H} 2 \mathrm{O} & 1.57125 \\ \mathrm{H} 2 & 65.41639 \\ \text { CH3OH } & 5.114038\end{array}$

Enthalpy $(\mathrm{kcal} / \mathrm{h}):-2.033917 \mathrm{E}+07$

at temp $\left({ }^{\prime} C\right): 260$

(IV) HEAT LOAD $(\mathrm{kcal} / \mathrm{h}):-3236343$

(V) VALUE OF $(\mathrm{H} / \mathrm{O}): 16.4415$

(VI) BALANCE CHECK:

IN C: 760.6392

IN $\mathrm{H}: 5634.249$

OUT C: 760.6391

OUT H: 5634.248

III -28 
Appendix III-1 Computer Printout with Wood and $\mathrm{CH}_{4}$ as Feedstocks. (cont'd)

IN $0: 342.6847$ OUT $0: 342.6846$

UNIT 4" CONDENSER

(I) OPERATING CONDIFION, Prassure (atm): 50

Temperature $(' C): 50$

(II) INPOT:

(1) Gas Stream <S>

$\begin{array}{cc}\text { Rate (mol/h) : } & 2304.104 \\ \text { Composition (yolt) } \\ \mathrm{CO} & 2.559359 \\ \mathrm{CO} 2 & 2.814074 \\ \mathrm{CH4} & 22.52489 \\ \mathrm{H2O} & 1.57125 \\ \mathrm{H2} & 65.41639 \\ \mathrm{CH} 3 \mathrm{OH} & 5.114038\end{array}$

Enthalpy (kcal/h): $-2.033917 \mathrm{E}+07$

at temp ("C): 260

(III) OUTPOT:

(1) Gas Stream <U> Rate (lomol/h): 2170.074

Composition (volt)

$\begin{array}{lc}\mathrm{CO} & 2.717432 \\ \mathrm{CO} & 2.987879 \\ \mathrm{CH} & 23.91609 \\ \mathrm{H2O} & 8.341512 \mathrm{E}-02 \\ \mathrm{H2} & 69.45669 \\ \mathrm{CH} 3 \mathrm{OH} & .8384966 \\ \text { thalpy } & (\mathrm{kcal} / \mathrm{h}):-1.75192 \mathrm{E}+07\end{array}$

Enthalpy (kcal/h): $-1.75192 \mathrm{E}+07$

at temp $\left({ }^{\prime} C\right): 50$

(2) MeOH Rate $(\mathrm{kmol} / \mathrm{h}): 99.63677$

$(\mathrm{kg} / \mathrm{h}): 3192.362$

(3) H2O Rate $(\mathrm{kmol} / \mathrm{h}): 34.39304$

$(\mathrm{kg} / \mathrm{h}): 619.625$

(IV) HEAT LOAD ( $\mathrm{kcal} / \mathrm{h}):-4668477$

(V) VALUE OF $(\mathrm{H} / \mathrm{O}): 24.76298$

(VI) BALANCE CHECX:

IN C: 760.6391 OUT C: 760.6391

IN H: 5634.248 OUT H: 5634.249

IN $0: 342.6846$ OUT $0: 342.6846$

UNIT 5* GAS HEAT EXCHANGER

(I) ORERATING CONDITION, Pressure (atII): 50

(II) INSIDE

(1) Gas In <H> Rate $(\mathrm{kmol} / \mathrm{h}): 2539.77$

Temp ('C) : 1000

Enthalpy $(\mathrm{kcal} / \mathrm{h}): 116196.7$ 
Appendix III-1 Computer Printout with Wood and $\mathrm{CH}_{4}$ as Feedstocks. (cont'd)

(2) Gas Out <H> Rate ( $\mathrm{kmol} / \mathrm{h})$ : 2539.77

Temp ('C) : 256.5093

Enthalpy $(\mathrm{kcal} / \mathrm{h}):-1.710283 \mathrm{E}+07$

(III) OOTSIDE

(1) Gas In <F> Rate ( $\mathrm{kmol} / \mathrm{h}): 2166.787$

Temp ('C): 50

Enthalpy (kcal/b): $-1.749266 \mathrm{E}+07$

(2) Gas Out <F> Rate (lomol/h): 2166.787

Temp ('C): 926.5258

Enthalpy (kcal/h): -275321.9

(IV) BEEAT IOAD (kcal/h) : -1689.224

ONIT 6* CORBUSTOR

(I) INPOT:

(1) Residual Char (kg/h): 212.3149

(2) OEf Gas (kmol/h): 3.287698

(3) Ais $(\mathrm{xmol} / \mathrm{h}): 16.00207$

(4) Alumina (kg/h): 63042.24

(5) $\operatorname{WoOd}(\mathrm{kg} / \mathrm{h}): 1545.508$

(II) OUTPUT:

(1) Flue Gas (kmol/h): 19.28977 (approx.)

(2)Alumina $(\mathrm{kg} / \mathrm{h}): 63042.24$

(III) HEAT LOAD ( $\mathrm{kcal} / \mathrm{h}):-8671133$

III-30 
Appendix III-2 Computer Printout with Wood, Sludge, $\mathrm{CH}_{4}$ and Digester Gas as Feedstocks.

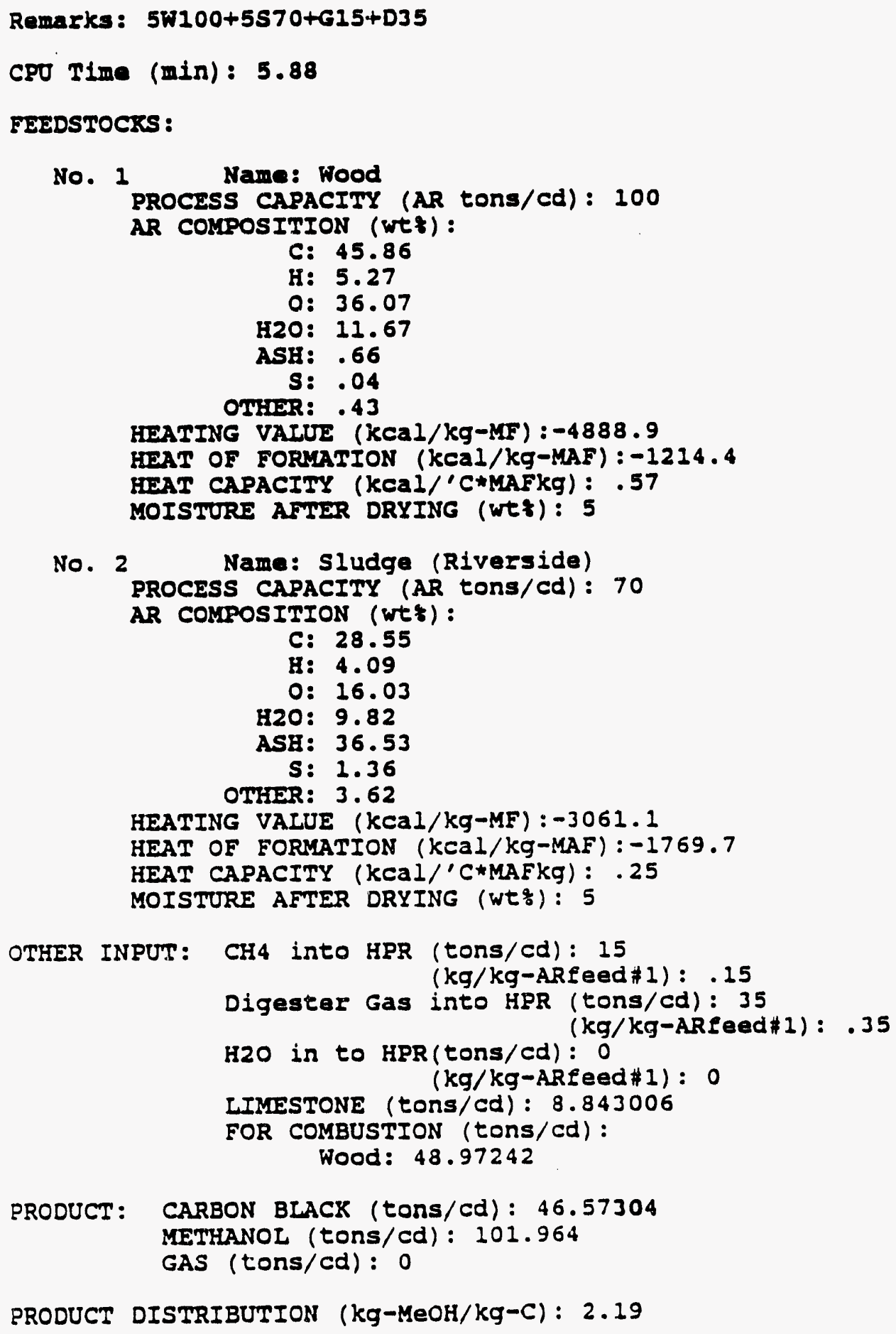


Appendix III-2 Computer Printout with Wood, Sludge, $\mathrm{CH}_{4}$ and Digester Gas as Feedstocks. (cont'd)

CARBON BLACK YIEID (kg/kg-ARFeed\#1): .4657304

MEOH YIEID $(\mathrm{kg} / \mathrm{kg}$-ARfeed\# 1$): 1.01964$

WATER YIEID (kg/kg-ARfeed 1 ) : .2113636

OFF GAS (Kol/kg-ARfeed 1 I): $3.458929 \mathrm{E}-03$

(kg/kg-ARfeed\$1): 2.555812E-02

$(\mathrm{kmol} / \mathrm{b}): 16.01356$

PURGE FRACTION $(z): .452814$

FRACIION OF BURNING OFF-GAS $(t): 100$

COMLOSITION (VOLt):

CO 2.444442

$\mathrm{CO} 2 \quad 2.597323$

CH4 24.13597

$1208.682551 \mathrm{E}-02$

H2 69.90885

CH3OH $\quad .8265951$

TOTAI HEATING VALUE (kcal/h):-1637921

CONVERSION OF CARBON IN FEEDSTOCX FOR HPR ( $(z): 90$

CARBON EFFICIENCY ( $(7): 73.68$

THERMAL EFFICIENCY $(z): 76.03$

BALANCE CHECK:
C IN 331.6794
H IN 736.4289
C OJT 331.6683
O IN 203.0361
H OOT 736.3698
O OUT 203.0176

UNIT 1* HYDROGASIEIER (HPR)

(I) OPERATING CONDITIONS, Pressure (atm): 50

Temperature $(' \mathrm{C}): 900$

(II) INPUT:

(1) Feedstocks:

( 1 ) liame: Wood

Rate $(\mathrm{kg} / \mathrm{h}): 4304.581$

Composivion C\& wt: 49.32 .299

H* wt: 5.66795

Of wt: 38.79373

H2O\& wt: 5

Ashr wt: .7098382

S\% wt: $4.302049 E-02$

Enthalpy $(\mathrm{kcal} / \mathrm{h}): \mathbf{- 5 2 5 7 7 4 3}$

Temperature $\left({ }^{\prime} \mathrm{C}\right): 150$

( 2 ) Name: Sludge (Riverside)

Rate $(\mathrm{kg} / \mathrm{h}): 3076.316$

Composition C\& wt: 30.07596

HE Wt: 4.308605

of wt: 16.88678

H2O\% wt: 5

Ash? Wt: 38.48248

S? wt: 1.43269

Enthalpy ( $\mathrm{kcal} / \mathrm{h}):-3452120$

Temperature $\left({ }^{\prime} \mathrm{C}\right)$ : 150

(2) CH4 Feed Rate $(\mathrm{kg} / \mathrm{h}): 694.4445$

Enthalpy $(\mathrm{kcal} / \mathrm{h}):-774179.9$

[II-32 
Appendix III-2 Computer Printout with Wood, Sludge, $\mathrm{CH}_{4}$ and Digester Gas as Feedstocks. (cont'd)

Temperature ('C): 25

(3) Digestar Gas Feed Rate (kg/h): 1620.37

Enthalpy (kcal/h): -2845242

Temperature $\left({ }^{\circ} \mathrm{C}\right): 25$

(4) Additional Water

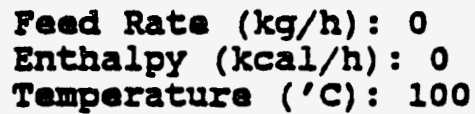

(5) Limestone

Feed Rate $(\mathrm{kg} / \mathrm{h}): 409.3984$

Content: Caco3s wt: 70

Enthalpy (kcal/h): -825893.6

Temperature ('C): 25

(6) Gas Stream $\langle F\rangle$

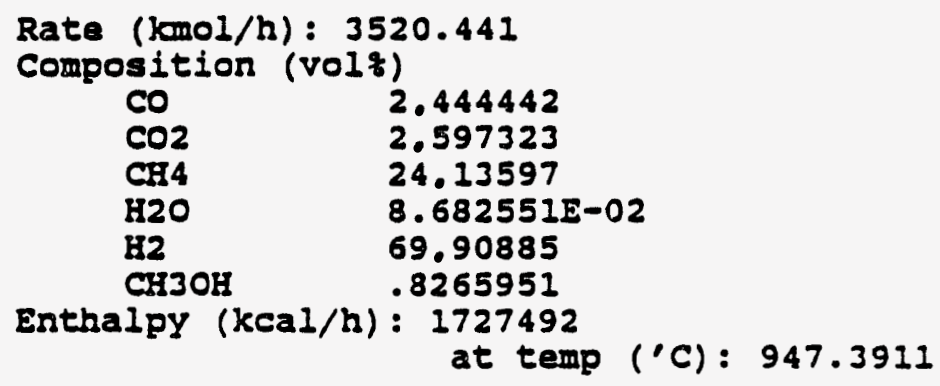

(III) OUTPUT:

(3.) Ast.

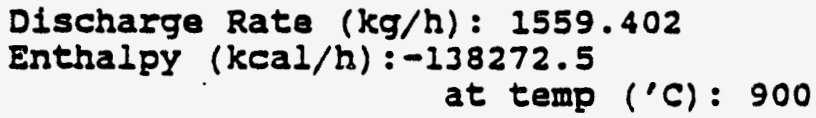

(2) Gas stream <G>

$\begin{array}{cc}\text { Flow Rate (kmol/h) : } 3704.471 \\ \text { Composition (volr) } \\ \text { CO } & 6.23228 \\ \text { CO2 } & .5500355 \\ \text { CH4 } & 30.68466 \\ \text { H2O } & 6.275629 \\ \text { H2 } & 56.2574 \\ \text { CH3OH } & 0\end{array}$

Enthalpy (kcal/h) : $-1.138444 \mathrm{E}+07$

at temp ('C): 900

(3) Residue Carbon Rate (kg/h): 304.838

Enthalpy $(\mathrm{kcal} / \mathrm{h}): 94880.56$

Heating value $(\mathrm{kcal} / \mathrm{h}):-2387225$

(IV) HEAT IOAD (kcal/h) : -147.7762

(V) VALUE OF $(\mathrm{H} / \mathrm{O}): 18.21008$

(VI) BALANCE CHECK:
IN C: 1387.964
IN $H: 9179.912$
OUT C: 1387.953
IN O: 504.1222
OUT H: 9179.854
our 0: 504.1037

INIT 2\# METHINE PYROLYZER (MPR)

(I) OPERATING CONDITION, Pressure (atm): 50 
Appendix III-2 Computer Printout with Wood, Sludge, $\mathrm{CH}_{4}$ and Digester Gas as Feedstocks. (cont'd)

$$
\text { Temperature ('C): } 1000
$$

(II) INPUT:

(1) Gas Stream 〈G>

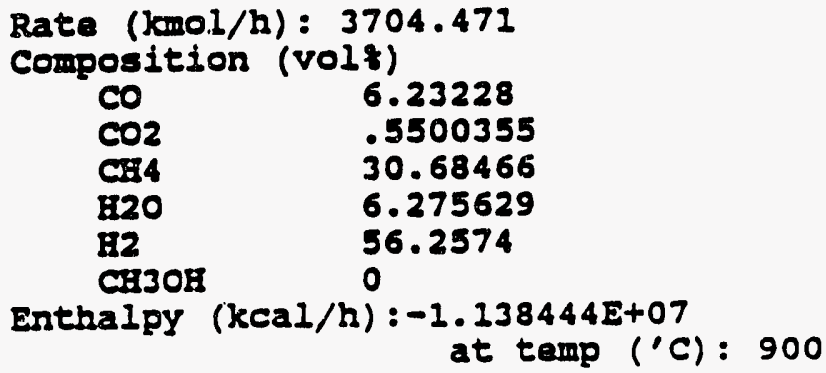

(2) Alumina

Rate $(\mathrm{kg} / \mathrm{h}): 100446.7$

Temperature ('C): 1400

(III) OUTPOTI

(1) Gas Stream <H>

Rate $(\mathrm{kmol} / \mathrm{h}): 4091.234$

Composition (Vols)

$\begin{array}{ll}\mathrm{CO} & 8.414859 \\ \mathrm{CO} 2 & .2589349 \\ \mathrm{CH} 4 & 20.86308\end{array}$

CH4

H2O

3.388828

$\mathrm{H2}$ 67.0743

CH3OH

0

Enthalpy (keal/h) : 1662475

ta temp ('C): 1000

(2) Carbon Black $\langle\mathrm{M}\rangle$

Discharge Rate $(\mathrm{kg} / \mathrm{h}): 2156.159$

$(\mathrm{kmol} / \mathrm{h}): 179.5303$

Enthalpy $(\mathrm{kcal} / \mathrm{h}): 769007.8$

at temp $\left({ }^{\prime} C\right): 1000$

(3) Alumina Rate $(\mathrm{kg} / \mathrm{h}): 100446.7$

Temperature ('C): 1000

(IV) HEAT LOAD ( $\mathrm{kcal} / \mathrm{h}): 7.686876 \mathrm{E}-02$

(V) VALUE OF $(\mathrm{H} / \mathrm{O}): 18.21008$

(VI) BALANCE CHECK:

IN C: 1387.953

IN H: 9179.854

IN $0: 504.1037$

OUT C: 1387.953

OUT H: 9179.854

OUT 0: 504.1037

\section{UNIT 3\# METHANOL CONVERTER}

(I) OPERATING CONDITION,

Pressure (atm): 50

Temperature ('C): 260

(II) INPUT :

(1) Gas Stream $\langle\mathrm{H}\rangle$

Rate $(k m o l / h): 4091.234$

Composition (vol\%)

$\mathrm{CO}$

8.414859

.2589349 
Appendix III-2 Computer Printout with Wood, Sludge, $\mathrm{CH}_{4}$ and Digester Gas as Feedstocks. (cont'd)

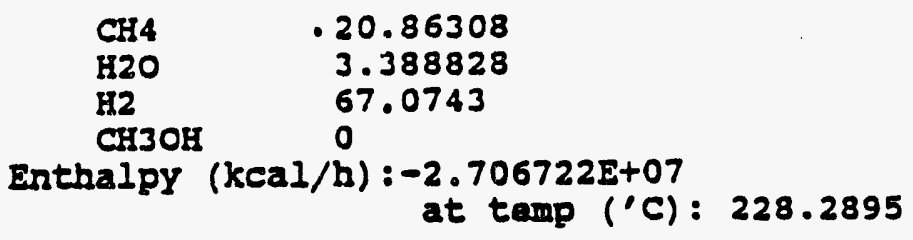

(III) OUTPUT:

(1) Gas Stream <S>

$\begin{array}{cc}\text { Rate (lomol/h) : } & 3738.103 \\ \text { Composition (volf) } \\ \text { CO } & 2.312579 \\ \text { CO2 } & 2.457213 \\ \mathrm{CH} 4 & 22.83398 \\ \mathrm{H2O} & 1.535146 \\ \mathrm{H2} & 66.13769 \\ \mathrm{CH} 3 \mathrm{OH} & 4.723396\end{array}$

Enthalpy (kcal/h) : $-3.094903 E+07$ at temp ('C): 260

(IV) HEAT LOAD ( $\mathrm{kCaI} / \mathrm{h}):-3881819$

(V) VALUE OF $(H / 0): 18.21025$

(VI) BALANCE CHECK:

IN C: 1208.423

IN H: 9179.854

OUT C: 1208.423

IN 0: 504.1037

OUT H: 9179.854

OUT O: 504.1037

UNIT 4\# CONDENSER

(I) OPERATING CONDITION,

Pressure (atm): 50

Temperature $\left({ }^{\prime} \mathrm{C}\right): 50$

(II) INPUT :

(1) Gas Stream <S>

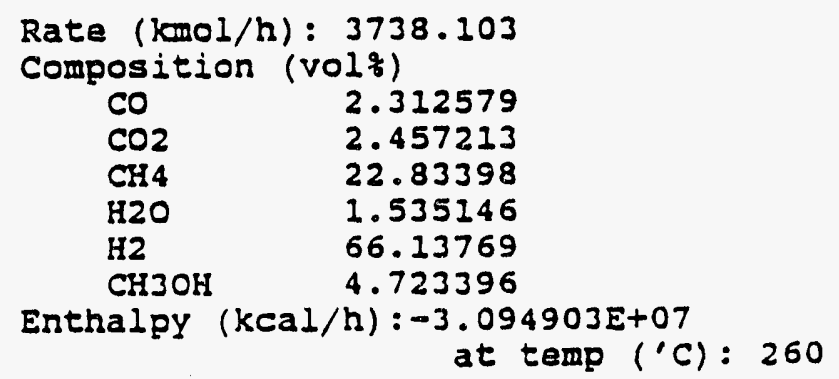

(III) OUTPUT:

(1) Gas Stream $\langle U\rangle$

$\begin{array}{ll}\text { Rate }(\mathrm{kmol} / \mathrm{h}) & 3536.455 \\ \text { Composition (vol\%) } \\ \mathrm{CO} & 2.444442 \\ \mathrm{CO} 2 & 2.597323 \\ \mathrm{CH} 4 & 24.13597 \\ \mathrm{H} 2 \mathrm{O} & 8.682551 \mathrm{E}-02 \\ \mathrm{H} 2 & 69.90885 \\ \mathrm{CH} 3 \mathrm{OH} & .8265951\end{array}$


Appendix III-2 Computer Printout with Wood, Sludge, $\mathrm{CH}_{4}$ and Digester Gas as Feedstocks. (cont'd)

$$
\begin{gathered}
\text { Enthalpy }(\mathrm{kcal} / \mathrm{h}):-2.712234 \mathrm{E}+07 \\
\text { at temp }\left({ }^{\prime} \mathrm{C}\right): 50
\end{gathered}
$$

(2) MeOH Rate (kmol/h): 147.3333

$(\mathrm{kg} / \mathrm{h}): 4720.558$

(3) H2O Rate $(\mathrm{kmol} / \mathrm{h}): 54.3148$

$(\mathrm{kg} / \mathrm{h}): 978.5354$

(IV) HEAT LOAD $(\mathrm{kcal} / \mathrm{h}):-7473811$

(V) VALUE OF $(B / O): 28.04342$

(VI) BALANCE CEECK:

IN C: 1208.423

IN H: 9179.854

IN $0: 504.1037$

OUT C: 1208.423
OUT H: 9179.854
OUT O: 504.1037

UNIT 5\# GAS HEAT EXCHANGER

(I) OPERATING CONDITION, Pressure (atm): 50

(II) INSIDE

(1) Gas In <H> Rate (kmol/h): 4091.234

Temp ('C) : 1000

Enthalpy (kcal/h): 1662475

(2) Gas Out <H> Rate (lomol/h): 4091.234

Temp ("C) : 228.2895

Enthalpy (kcal/h): $-2.706722 E+07$

(III) OUTSIDE

(1) Gas In <F> Rate $(\mathrm{kmol} / \mathrm{h}): 3520.441$

Temp ('c): 50

Enthalpy $(\mathrm{kcal} / \mathrm{h}):-2.699952 E+07$

(2) Gas out <F> Rate $(\mathrm{kmol} / \mathrm{h}): 3520.441$

Temp ('C): 947.3911

Enthalpy (kcal/h): 1727492

(IV) HEAT LOAD (kCal/h): -2674.644

UNIT 6\# COMBUSTOR

(I) INPUT:

(1) Residual Char $(\mathrm{kg} / \mathrm{h}): 304.838$

(2) Off Gas $(\mathrm{kmol} / \mathrm{h}): 16.01356$

(3) Air $(\mathrm{kmol} / \mathrm{h}): 78.41016$

(4) Alumina (kg/h): 100446.7

(5) Wood $(\mathrm{kg} / \mathrm{h}): 2267.242$

(II) OUTPUT : 
Appendix III-2 Computer Printout with Wood, Sludge, $\mathrm{CH}_{4}$ and Digester Gas as Feedstocks. (cont'd)

(1)Flue Gas (lomol/h): 94.42373 (approx.)

(2) Alumina $(\mathrm{kg} / \mathrm{h}): 100446.7$

(III) HEAT LOAD (kCal/h): $-1.381593 \mathrm{E}+07$ 


\section{APPENDIX A \\ Quality Control Evaluation Report}

The experimental measurements reported in this document were obtained with the use of the Brookhaven Tubular Reactor Facility. The design, construction operation and a description of the measurement equipment and instrumentation was initially reported in Brookhaven National Laboratory Report No. 50698, "Design, Construction, Operation and Initial Results of a Flash Hydropyrolysis Experimental Unit," by Peter Fallon and Meyer Steinberg (January 1977). The construction procedures and instrumentation used were in accordance with best practices available for this type of experiment. A Safety Analysis Report on the Brookhaven Hydropyrolysis Experimental Equipment was written in November 1991 to requalify and obtain approval from the Brookhaven National Laboratory Safety Committee for operation. Since initial construction and operation, the equipment has been requalified twice, the latest being November 1991, just before performing the experiments reported herein.

The facility contains the following measuring equipment: thermocouple temperature monitoring and control, pressure indicating and control, volumetric flow meter, and on-line gas chromatograph for determining the gaseous component concentration.

The temperature and pressure instrumentation were checked against secondary standards which were in turn calibrated against primary standards. The precision of temperature measurements was $\pm 5^{\circ} \mathrm{C}$. The precision of pressure measurement was within \pm 5 psi. The on-line gas chromatograph was calibrated before each run using standard gas calibrating gases obtained from vendors with certification. The gases monitored included $\mathrm{H}_{4}, \mathrm{C}_{2} \mathrm{H}_{6}, \mathrm{CO}$ and $\mathrm{CO}_{2}$. The precision of the chromatograph calibration is estimated to be $\pm 5 \%$ of the gas component concentration.

The feedstock composition of samples of biomass were analyzed in duplicate by Commercial Testing and Engineering Co., Lombard, Illinois, in accordance with well-established analytical procedures. 
The mass balances after the flow runs with this tubular reactor facility could be made with an accuracy of within $\pm 5 \%$.

A-2 

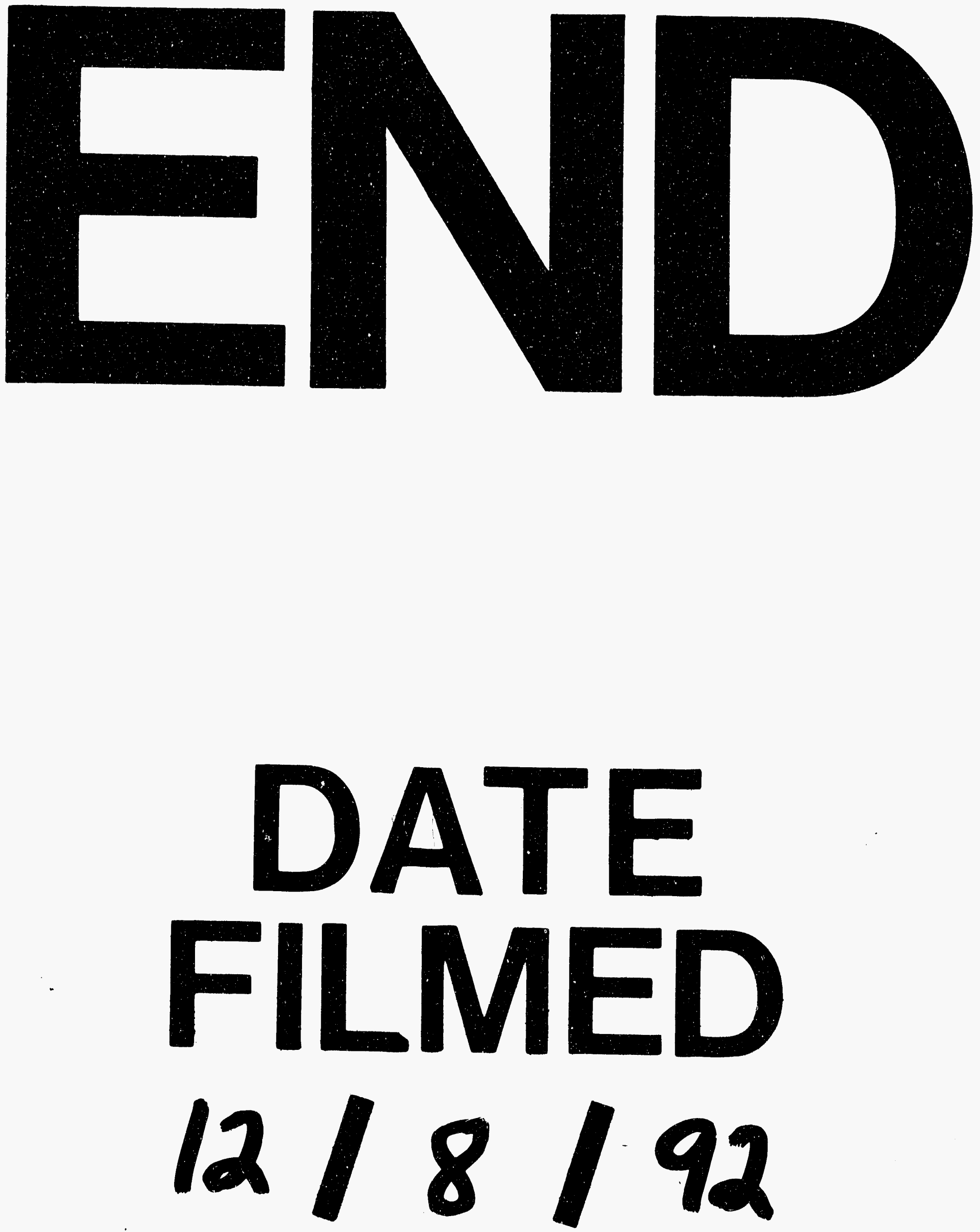
